\title{
External Quality-Assurance Results for the National Atmospheric Deposition Program/National Trends Network, 2002-03
}

Scientific Investigations Report 2005-5061 


\section{External Quality-Assurance Results for the National Atmospheric Deposition Program/ National Trends Network, 2002-03}

By Gregory A. Wetherbee, Natalie E. Latysh, and Kevin P. Burke

Scientific Investigations Report 2005-5061 


\title{
U.S. Department of the Interior Gale A. Norton, Secretary
}

\author{
U.S. Geological Survey \\ Charles G. Groat, Director
}

\section{U.S. Geological Survey, Reston, Virginia: 2005}

\author{
For sale by U.S. Geological Survey, Information Services \\ Box 25286, Denver Federal Center \\ Denver, CO 80225 \\ For more information about the USGS and its products: \\ Telephone: 1-888-ASK-USGS \\ World Wide Web: http://www.usgs.gov/
}

Any use of trade, product, or firm names in this publication is for descriptive purposes only and does not imply endorsement by the U.S. Government.

Although this report is in the public domain, permission must be secured from the individual copyright owners to reproduce any copyrighted materials contained within this report.

Suggested citation:

Wetherbee, G.A., Latysh, N.E., and Burke, K.P., 2005, External quality-assurance results for the National Atmospheric Deposition Program/National Trends Network, 2002-03: U.S. Geological Survey Scientific Investigations Report 2005$5061,59 \mathrm{p}$. 


\section{Contents}

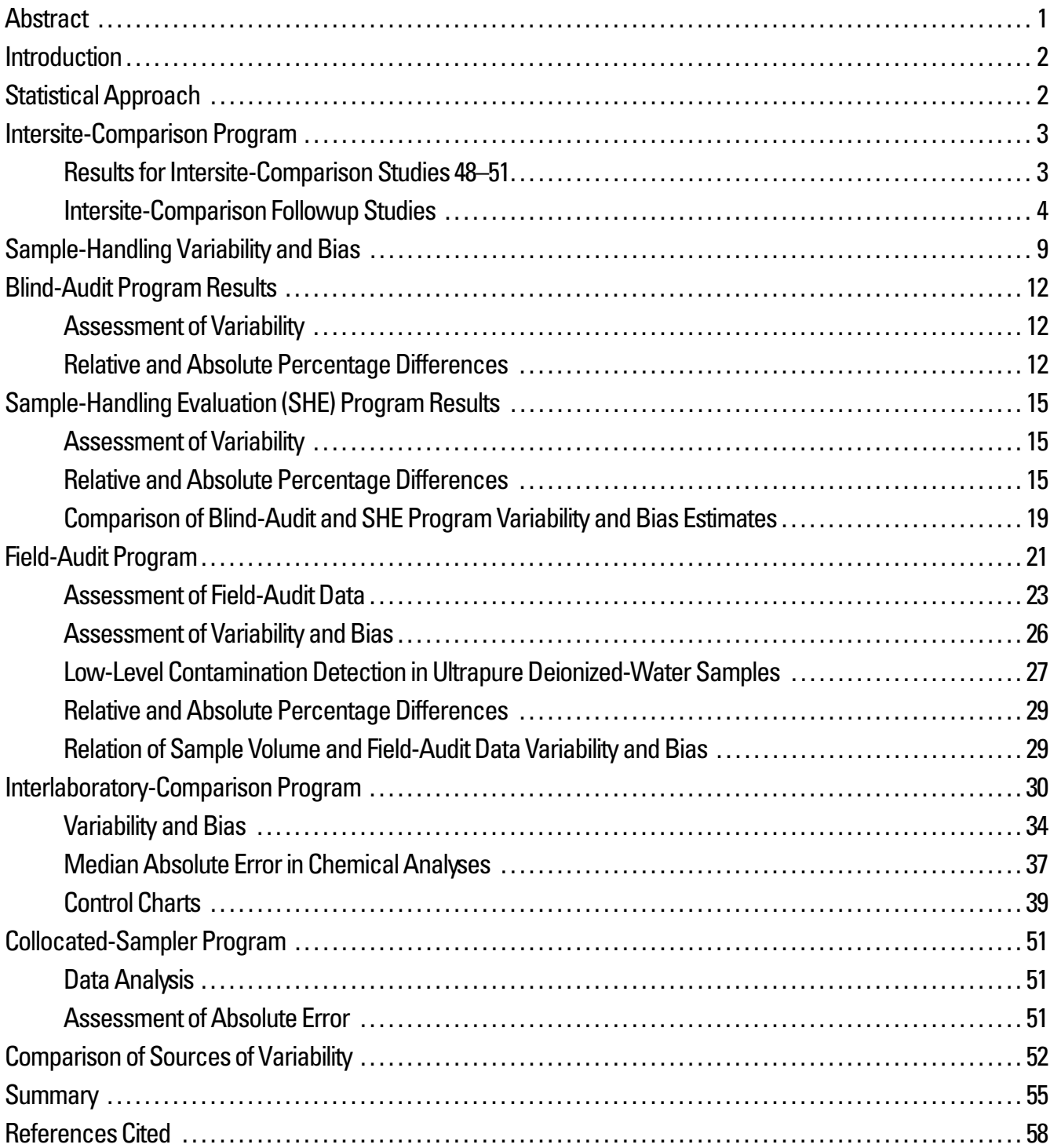

\section{Figures}

1. Flowchart showing intersite-comparison program of U.S. Geological Survey External Quality-

Assurance Project

2-6. Graphs showing:

2. Distribution of $\mathrm{pH}$ and specific conductance values for intersite-comparison studies 48 and 49 .

3. Distribution of $\mathrm{pH}$ and specific conductance values for intersite-comparison studies 50 and 51 .

4. Summary of followup study results obtained during 2002 for intersite-comparison program ...9

5. Summary of followup study results obtained during 2003 for intersite-comparison program. 10 
6. Percentage of successful $\mathrm{pH}$ and specific conductance measurements in intersite-

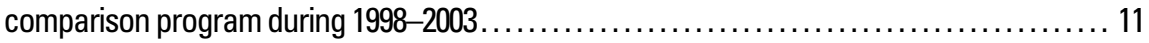

7. Flowchart showing blind-audit program of U.S. Geological Survey ...................... 13

8. Flowchart showing sample-handling evaluation program of U.S. Geological Survey ........... 14

9-13. Boxplots showing:

9. Paired bucket-sample minus bottle-sample measurement differences for blind-audit

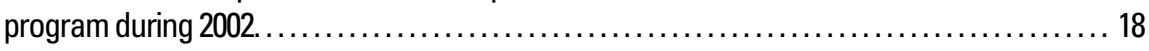

10. Comparison of distributions of bucket-minus-bottle concentration differences for 2002 blind-audit program and 2003 sample-handling evaluation program.................. 22

11. Comparison of distribution of bucket-minus-bottle differences for hydrogen-ion concentration and specific conductance for 2002 blind-audit program and 2003 sample-

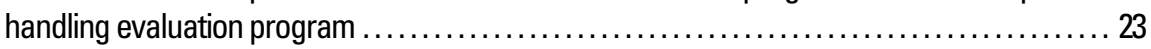

12. Relation of bucket-minus-bottle hydrogen-ion concentration differences and sample volume for 2002 blind-audit data and 2003 sample-handling evaluation data............. 24

13. Relation of paired bucket-minus-bottle specific conductance differences and sample volume for 2002 blind-audit data and 2003 sample-handling evaluation data............. 25

14. Flowchart showing field-audit program of U.S. Geological Survey........................ 26

15-19. Boxplots showing:

15. Bucket-minus-bottle concentration differences for 2002-03 field-audit major ions . ........28 28

16. Bucket-minus-bottle differences for hydrogen-ion concentration and specific conductance for 2002-03 field-audit data

17. Relation of paired bucket-minus-bottle major cation concentration differences and sample volume for 2002-03 field-audit data

18. Relation of paired bucket-minus-bottle ammonium and major anion concentration differences and sample volume for 2002-03 field-audit data. ...

19. Relation of paired bucket-minus-bottle differences for hydrogen-ion concentration and specific conductance to sample volume for $2002-03$ field-audit data .................... 34

20. Flowchart showing interlaboratory-comparison program of U.S. Geological Survey ..............35

21-32. Graphs showing:

21. Difference between measured calcium concentration values and median calcium concentration value calculated by solution for all participating laboratories in interlaboratory-comparison program during 2002-03.

22. Difference between measured magnesium concentration values and median magnesium concentration value calculated by solution for all participating laboratories in interlaboratory-comparison program during 2002-03....

23. Difference between measured sodium concentration values and median sodium concentration value calculated by solution for all participating laboratories in interlaboratory-comparison program during 2002-03.

24. Difference between measured potassium concentration values and median potassium concentration value calculated by solution for all participating laboratories in interlaboratory comparison program during 2002-03...

25. Difference between measured ammonium concentration values and median ammonium concentration value calculated by solution for all participating laboratories in interlaboratory-comparison program during 2002-03.

26. Difference between measured chloride concentration values and median chloride concentration value calculated by solution for all participating laboratories in interlaboratory-comparison program during 2002-03.

27. Difference between measured nitrate concentration values and median nitrate concentration value calculated by solution for all participating laboratories in interlaboratory-comparison program during 2002-03. . 
28. Difference between measured sulfate concentration values and median sulfate concentration value calculated by solution for all participating laboratories in interlaboratory-comparison

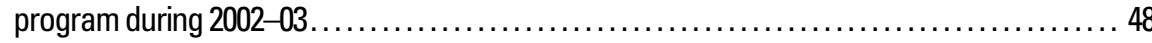

29. Difference between measured $\mathrm{pH}$ values and median $\mathrm{pH}$ value calculated by solution for all participating laboratories in interlaboratory-comparison program during $2002-03 . .$.

30. Difference between measured specific conductance values and median specific conductance value calculated by solution for all participating laboratories in interlaboratorycomparison program during 2002-03.

31. Median absolute error for analyte concentration and deposition for weekly samples from collocated precipitation collectors during 2002-03 for selected analytes 53

32. Median absolute error for hydrogen-ion concentration and deposition, specific conductance, and sample volume for weekly samples from collocated precipitation collectors and precipitation depth from collocated rain gages during 2002-03. 54

33. Pie chart showing proportions of selected components of overall variability in National Atmospheric Deposition Program/National Trends Network measurements as estimated by U.S. Geological Survey external quality-assurance programs during 2002-03.

\section{Tables}

1. Site-operator responses and summary statistics for 2002 intersite-comparison program studies 48 and $49 . .$.

2. Site-operator responses and summary statistics for 2003 intersite-comparison program studies 50 and 51

3. Solutions used in 2002-03 blind-audit, sample-handling evaluation, field-audit, and interlaboratory-comparison programs

4. Target values for solutions used in 2002-03 U.S. Geological Survey blind-audit, samplehandling evaluation, field-audit, and interlaboratory-comparison programs 16

5. Selected statistics for paired bucket-sample minus bottle-sample concentration differences in blind-audit program during 2002. 17

6. Relative and absolute bucket-minus-bottle differences calculated as a percentage of target concentration or value for each analyte during 2002 for blind-audit program ....

7. Selected statistics for paired bucket-sample minus bottle-sample concentration differences for sample-handling evaluation program during 2003

8. Relative and absolute bucket-minus-bottle differences calculated as a percentage of target concentration or value for each analyte during 2003 for sample-handling evaluation program. ... 21

9. Selected statistics for paired bucket-sample minus bottle-sample concentration differences for field-audit program during 2002-03 for wet- and dry-coded samples.

10. Number of determinations exceeding minimum detection limit for 24 ultrapure deionized-water samples submitted in 2002 and for 18 ultrapure deionized-water samples submitted in 2003 as part of field-audit program.

11. Relative and absolute bucket-minus-bottle differences calculated as a percentage of target concentration or value for each analyte in field-audit program during 2002-03

12. Most probable values for solutions used in 2002-03 U.S. Geological Survey interlaboratorycomparison program.

13. Comparison of differences between reported concentrations and most probable values for synthetic precipitation samples in interlaboratory-comparison program during 2002-03...

14. Number of analyte determinations greater than minimum detection limits for each participating laboratory and each ion for ultrapure deionized-water samples during 2002-03 ..... 39 
15. Summary of absolute differences for analysis of replicate, synthetic-precipitation solution samples determined by eight laboratories participating in 2002-03 interlaboratory-comparison

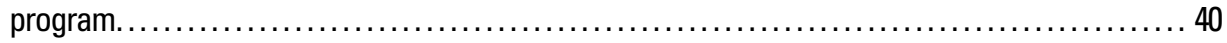

16. Comparison of median absolute differences determined for collocated-sampler sites OR02/020R and WI98/98WI during water year 2002 to median values obtained during 2002 for all National Atmospheric Deposition Program/National Trends Network sites and to median absolute differences for 41 collocated-sampler sites during 1989-2001 . ...

17. Comparison of median absolute differences determined for collocated-sampler sites 0K00/000K and WI98/98WI during water year 2003 to median values obtained during 2002 for all National Atmospheric Deposition Program/National Trends Network sites and to median absolute differences for 41 collocated-sampler sites during 1989-2001 ...

18. Comparison of components of overall variability in National Atmospheric Deposition Program/ National Trends Network data as determined by U.S. Geological Survey external qualityassurance programs during 2002-03 for major ion concentrations and specific conductance.... 57 


\section{Conversion Factors, Abbreviated Units, and Acronyms}

\begin{tabular}{lcl}
\hline \multicolumn{1}{c}{ Multiply } & By & \multicolumn{1}{c}{ To obtain } \\
\hline & Length & \\
centimeter (cm) & 0.3937 & inch (in.) \\
liter (L) & 1.057 & quart (qt) \\
milliliter (mL) & 0.0338 & ounce (oz), fluid \\
kilogram per hectare (kg/ha) & 0.8924 & pound per acre (lb/acre) \\
\hline
\end{tabular}

Temperature can be converted from degree Celsius $\left({ }^{\circ} \mathrm{C}\right)$ to degree Fahrenheit $\left({ }^{\circ} \mathrm{F}\right)$ by using the following equation:

${ }^{\circ} \mathrm{F}=9 / 5\left({ }^{\circ} \mathrm{C}\right)+32$.

Water year is the 12-month period October 1 through September 30 and is designated by the year in which it ends.

The following terms and abbreviations also are used in this report:

\begin{tabular}{|c|c|}
\hline Abbreviation & Full name \\
\hline absolute value of $\mathrm{x}=|\mathrm{x}|$ & $\begin{array}{l}\text { where } \mathrm{x} \text { takes the form of numerical values or algebraic } \\
\text { expressions }\end{array}$ \\
\hline$\alpha$ & $\begin{array}{l}\text { alpha, maximum probability of rejecting the null hypothesis when } \\
\text { it is true }\end{array}$ \\
\hline ADORC & Acid Deposition and Oxidant Research Center, Niigata-shi, Japan \\
\hline AIRMoN & Atmospheric Integrated Research Monitoring Network \\
\hline APD & absolute percentage difference \\
\hline CAL & $\begin{array}{l}\text { Illinois State Water Survey, Central Analytical Laboratory, } \\
\text { Champaign, Illinois }\end{array}$ \\
\hline CALNAT & $\begin{array}{l}\text { randomly collected natural wet-deposition samples collected at } \\
\text { NADP/NTN sites for use in interlaboratory-comparison } \\
\text { program }\end{array}$ \\
\hline HPS & High Purity Standards, Charleston, South Carolina \\
\hline IQR & interquartile range \\
\hline MAD & median absolute difference, in units of concentration or $\mu \mathrm{S} / \mathrm{cm}$ \\
\hline MAE & median absolute error, in percent \\
\hline MATEC & MATEC, Inc., Gainesville, Florida \\
\hline $\mathrm{M} \Omega$ & megohm \\
\hline MDN & Mercury Deposition Network \\
\hline$\mu e q / L$ & microequivalents per liter \\
\hline$\mu \mathrm{S} / \mathrm{cm}$ & microsiemens per centimeter at 25 degrees Celsius \\
\hline $\mathrm{mg} / \mathrm{L}$ & milligrams per liter \\
\hline MDL & minimum detection limit \\
\hline MOEE & $\begin{array}{l}\text { Ontario Ministry of Environmental and Energy, Dorset Research } \\
\text { Facility, Dorset, Ontario, Canada }\end{array}$ \\
\hline MPV & most probable value \\
\hline MSC & Meteorological Service of Canada, Downsview, Ontario, Canada \\
\hline NADP/NTN & $\begin{array}{l}\text { National Atmospheric Deposition Program/National Trends } \\
\text { Network }\end{array}$ \\
\hline NILU & Norwegian Institute for Air Research, Kjeller, Norway \\
\hline NIST & National Institute of Standards and Technology \\
\hline
\end{tabular}




\begin{tabular}{ll}
\hline \multicolumn{1}{c}{ Abbreviation } & \multicolumn{1}{c}{ Full name } \\
\hline NYSDEC & $\begin{array}{l}\text { New York State Department of Environmental Conservation, } \\
\text { Albany, New York } \\
\text { QA }\end{array}$ \\
QC & quality assurance \\
RPD & relative percentage difference \\
SA & Shepard Analytical, Simi Valley, California \\
SHE & sample-handling evaluation program \\
SOP & standard operating procedure \\
\hline
\end{tabular}




\title{
External Quality-Assurance Results for the National Atmospheric Deposition Program/National Trends Network, 2002-03
}

\author{
By Gregory A. Wetherbee, Natalie E. Latysh, and Kevin P. Burke
}

\section{Abstract}

Six external quality-assurance programs were operated by the U.S. Geological Survey (USGS) External Quality-

Assurance (QA) Project for the National Atmospheric Deposition Program/National Trends Network (NADP/NTN) from

2002 through 2003. Each program measured specific components of the overall error inherent in NADP/NTN wetdeposition measurements.

The intersite-comparison program assessed the variability and bias of $\mathrm{pH}$ and specific conductance determinations made by NADP/NTN site operators twice per year with respect to accuracy goals. The percentage of site operators that met the $\mathrm{pH}$ accuracy goals decreased from 92.0 percent in spring 2002 to 86.3 percent in spring 2003 . In these same four intersitecomparison studies, the percentage of site operators that met the accuracy goals for specific conductance ranged from 94.4 to 97.5 percent.

The blind-audit program and the sample-handling evaluation (SHE) program evaluated the effects of routine sample handling, processing, and shipping on the chemistry of weekly NADP/NTN samples. The blind-audit program data indicated that the variability introduced by sample handling might be environmentally significant to data users for sodium, potassium, chloride, and hydrogen ion concentrations during 2002. In 2003, the blind-audit program was modified and replaced by the SHE program. The SHE program was designed to control the effects of laboratory-analysis variability. The 2003 SHE data had less overall variability than the 2002 blind-audit data. The SHE data indicated that sample handling buffers the $\mathrm{pH}$ of the precipitation samples and, in turn, results in slightly lower conductivity. Otherwise, the SHE data provided error estimates that were not environmentally significant to data users.

The field-audit program was designed to evaluate the effects of onsite exposure, sample handling, and shipping on the chemistry of NADP/NTN precipitation samples. Field-audit results indicated that exposure of NADP/NTN wet-deposition samples to onsite conditions tended to neutralize the acidity of the samples by less than 1.0 microequivalent per liter. Onsite exposure of the sampling bucket appeared to slightly increase the concentration of most of the analytes but not to an extent that was environmentally significant to NADP data users.

An interlaboratory-comparison program was used to estimate the analytical variability and bias of the NADP Central Analytical Laboratory (CAL) during 2002-03. Bias was identified in the CAL data for calcium, magnesium, sodium, potassium, ammonium, chloride, nitrate, sulfate, hydrogen ion, and specific conductance, but the absolute value of the bias was less than analytical minimum detection limits for all constituents except magnesium, nitrate, sulfate, and specific conductance. Control charts showed that CAL results were within statistical control approximately 90 percent of the time. Data for the analysis of ultrapure deionized-water samples indicated that CAL did not have problems with laboratory contamination.

During 2002-03, the overall variability of data from the NADP/NTN precipitation-monitoring system was estimated using data from three collocated monitoring sites. Measurement differences of constituent concentration and deposition for paired samples from the collocated samplers were evaluated to compute error terms. The medians of the absolute percentage errors (MAEs) for the paired samples generally were larger for cations (approximately 8 to 50 percent) than for anions (approximately 3 to 33 percent). MAEs were approximately 16 to 30 percent for hydrogen-ion concentration, less than 10 percent for specific conductance, less than 5 percent for sample volume, and less than 8 percent for precipitation depth.

The variability attributed to each component of the sample-collection and analysis processes, as estimated by USGS quality-assurance programs, varied among analytes. Laboratory analysis variability accounted for approximately 2 percent of the overall variability in NADP/NTN measurements. Sample onsite exposure accounted for approximately 8 percent of the overall variability. Sample handling accounted for approximately 26 percent of the overall variability. The remaining variability, not accounted for by laboratory analysis, onsite exposure, and sample handling (approximately 64 percent), was attributed to the variable function of the onsite instrumentation and natural variability. 


\section{External Quality-Assurance Results for the National Atmospheric Deposition Program/National Trends Network, 2002-03}

\section{Introduction}

A fundamental objective of the National Atmospheric Deposition Program (NADP) is to provide scientific investigators worldwide with a long-term, high-quality database of atmospheric wet-deposition information (Nilles, 2001). The NADP consists of three monitoring networks that are used to collect precipitation depth data and atmospheric deposition samples for chemical analysis-(1) National Trends Network (NTN),

(2) Atmospheric Integrated Research Monitoring Network (AIRMoN), and (3) Mercury Deposition Network (MDN). NADP/NTN has monitored the effects of wet deposition across the United States since 1978 (Robertson and Wilson, 1985; Peden, 1986). Research scientists use NADP/NTN data to study the effects of atmospheric deposition on human health and the environment. All operators of NADP/NTN sites adhere to the same sample-collection and analysis procedures using identical wet-deposition collectors, described by Dossett and Bowersox (1999), and standard NADP/NTN sample-handling and shipping protocols are followed at the sites. Samples from NADP/NTN sites are sent to the Illinois State Water Survey, Central Analytical Laboratory (CAL), for analysis. A protocol report providing detailed information on the quality-assurance (QA) procedures and analytical methods is available (See and others, 1990).

This report describes the results of the external QA programs operated by the U.S. Geological Survey (USGS) External QA Project in support of NADP/NTN during 2002-03 (study period). These programs are designed to: (1) assess the variability and bias of onsite determinations of $\mathrm{pH}$ and specific conductance (intersite-comparison program); (2) evaluate effects of potential contamination due to handling, processing, and shipping of samples collected by NADP/NTN (blind-audit and sample-handling evaluation programs); (3) evaluate potential contamination introduced from onsite exposure of the samples, sample handling, and shipping (field-audit program); (4) estimate the variability and bias of analytical results determined by separate laboratories routinely measuring wet deposition (interlaboratory-comparison program); (5) estimate the overall variability of NADP/NTN data from the point of sample collection through laboratory data-quality control (collocatedsampler program); and (6) facilitate integration of data from various monitoring networks.

The term "major ions" in this text refers to calcium, magnesium, sodium, potassium, ammonium, chloride, nitrate, and sulfate. Throughout this report, concentration results are presented for cations first (calcium, magnesium, sodium, potassium, and ammonium), followed by anions (chloride, nitrate, and sulfate), followed, where appropriate, by hydrogen-ion concentration, specific conductance, sample volume, and precipitation depth. Hydrogen-ion concentrations are calculated from reported $\mathrm{pH}$ values. Conversion of the $\mathrm{pH}$ measurements to hydrogen-ion concentration allows for resolution of differences that would be masked by the nonlinear $\mathrm{pH}$ scale.

\section{Statistical Approach}

Nonparametric rank-based alternatives to traditional hypothesis testing constitute the statistical analysis framework in this report. Nonparametric statistical tests were used because the datasets do not adhere to the normal distribution requirements of traditional parametric statistics. Hypothesis tests included the Wilcoxon signed-rank test, the Kruskal-Wallis test, and the Sign test (Kanji, 1993). The Wilcoxon signed-rank test (Hollander and Wolfe, 1999) was used to determine if there were shifts in data distributions due to the exclusion of samples identified as contaminated. The Kruskal-Wallis test (Iman and Conover, 1983) was used to compare two or more independent samples (SAS Institute Inc., 1989). The Sign test was used to identify bias in chemical analysis data from analytical laboratories.

All null hypotheses were tested at the 95-percent confidence level ( $\alpha=0.05$ statistical significance level), which implies that a 5-percent chance of rejecting the null hypothesis when it is true, is acceptable. For each test, the probability of rejecting the null hypothesis when it is true ( $p$-value) is calculated. A $p$-value less than 0.05 indicates that there is less than a 5 -percent chance of rejecting the null hypothesis when it is true. The hypothesis tests are based on two-sided rather than onesided alternatives, whereby the total acceptable uncertainty of 5 percent $(\alpha=0.05)$ is split between the positive and negative ends of the data distribution. Huntsberger and Billingsley (1981) provide a detailed explanation of two-sided and onesided hypothesis testing.

The f-pseudosigma values are presented for many of the results in this report. The f-pseudosigma is used as a nonparametric analogue of the standard deviation of a statistical sample. The f-pseudosigma is calculated as the interquartile range (IQR, 75 th percentile value minus the 25 th percentile value) divided by 1.349 (Hoaglin and others, 1983), as shown in equation 1.

$$
\text { f-pseudosigma }=\frac{\text { 75th percentile }-25 \text { th percentile }}{1.349} \text {. }
$$

Relative and absolute percentage differences are calculated for each QA program as an estimation of the relative amount of error attributed to individual components of the datacollection process. The absolute percentage differences are used to quantify variability, whereas the relative percentage differences are used to quantify bias. The relative and absolute percentage differences are calculated for each paired difference as a percentage of the target sample concentration:

$$
\begin{gathered}
\text { Relative percentage difference }(\mathrm{RPD})=[(\mathrm{C} 1-\mathrm{C} 2) / \mathrm{C} 3] \bullet 100 \text {, } \\
\text { and }
\end{gathered}
$$

Absolute percentage difference $(\mathrm{APD})=|(\mathrm{C} 1-\mathrm{C} 2) / \mathrm{C} 3| \bullet 100$, 
where

$\mathrm{C} 1$ = sample concentration, in milligrams per liter $(\mathrm{mg} / \mathrm{L})$, for the sample exposed to the collection and processing steps of a normal weekly precipitation sample;

$\mathrm{C} 2$ = sample concentration (in milligrams per liter) for the control sample subjected to minimal handling, and processing; and

C3 = target concentration (in milligrams per liter), which is the theoretically accepted concentration on the basis of laboratory preparation of performance evaluation samples from solutions of known concentration or determined experimentally as the median concentration on the basis of many independent analyses.

Concise graphical displays, such as boxplots, were used to depict data distributions and provide visual representations of NADP/NTN data quality. Tukey's "schematic plot" version of the boxplot (Chambers and others, 1983) was used for all boxplots, whereby notches in the sides of the boxes are used to highlight the location of the median. The ends of the box are drawn at the lower and upper quartiles, which are the 25th and 75th percentiles, respectively. The ends of the box depict the interquartile range (IQR). Whiskers are drawn from the quartiles to the last value that is located within a distance of 1.5 times the IQR. Values greater than 1.5 times the IQR are graphed individually as asterisks and are called "outside values" (SAS Institute, 1989). In a normal distribution, there should be one outside value for every 100 data points (Helsel and Hirsch, 1992). Therefore, the occurrence of asterisks more frequently than expected indicates that the data are not normally distributed. The magnitude of measurement bias was quantified in several ways for the convenience of the reader, including units of concentration (for example, in $\mathrm{mg} / \mathrm{L}$ ), signed differences, and percentage differences.

\section{Intersite-Comparison Program}

Intersite-comparison studies are completed by the USGS to assess the accuracy of onsite $\mathrm{pH}$ and specific conductance measurements made by NADP/NTN site operators. Measurement accuracy is defined herein as the combined evaluation of variability and bias. If measurements are not accurate, site operators are provided troubleshooting assistance by USGS. A flowchart depicting the chronological order of the intersite-comparison program is shown in figure 1. Due to the low ionic strength of precipitation, minor changes may occur between sample collection and laboratory analysis (Bigelow and others, 1989).

Many authors have determined that onsite measurements (of $\mathrm{pH}$ in particular) are more representative of precipitation than subsequent laboratory determinations (Hem, 1985).

In the intersite-comparison studies, site operators determined the $\mathrm{pH}$ and specific conductance of synthetic precipitation-check samples prepared by USGS. Protocols identical to
NADP/NTN sample measurement methods were used (Gordon and others, 1991; Dossett and Bowersox, 1999). USGS prepared the synthetic precipitation-check samples by adding nitric acid and potassium chloride to deionized water to obtain solutions with $\mathrm{pH}$ and specific conductance similar to natural wetdeposition samples collected by NADP/NTN. The $\mathrm{pH}$ of the solution is adjusted to a target value ranging from 3.9 to 5.3 standard units by adding nitric acid. Then, the specific conductance of the solution is adjusted to a target value using the potassium chloride. The $\mathrm{pH}$ and specific conductance target values for the solutions were verified by USGS before the solutions were mailed to the sites. The same unique check solution was sent to all NADP/NTN sites for each study. Each site's ability to achieve the target $\mathrm{pH}$ and specific conductance values was evaluated. Operators also measured quality-control (QC) check standards provided by CAL (target $\mathrm{pH}: 4.19 \pm 0.15$ standard units; and target specific conductance: 14 microsiemens per centimeter $(\mu \mathrm{S} / \mathrm{cm}) \pm 2.0 \mu \mathrm{S} / \mathrm{cm})$, prior to measuring the $\mathrm{pH}$ and specific conductance of precipitation samples and intersitecomparison samples, but those measurements are not evaluated herein.

\section{Results for Intersite-Comparison Studies 48-51}

Intersite studies 48 and 49 were completed during spring and fall 2002, respectively; studies 50 and 51 were completed during spring and fall 2003, respectively. From the day the samples were mailed, operators were allowed 45 days to perform the $\mathrm{pH}$ and specific conductance measurements. Sites were not included in the study's performance evaluation if (1) they responded late, (2) the onsite equipment was completely inoperable, (3) the site was not in operation at the time of the study, or (4) the site did not perform onsite chemistry during the intersite-comparison study period.

Accuracy goals for $\mathrm{pH}$ were designed to address the increased difficulty of measuring $\mathrm{pH}$ in low-ionic-strength solutions as the hydrogen-ion concentration approaches neutrality (Gordon, 1999). Accuracy goals for $\mathrm{pH}$ measurements were based on a multiple-regression function that incorporated the solution's hydrogen-ion concentration and the results from intersite studies 1-39 (John D. Gordon, U.S. Geological Survey, written commun., 1995). The accuracy goals were symmetrical in units of hydrogen-ion concentration and, therefore, were asymmetrical in units of $\mathrm{pH}$. The specific conductance values for all of the intersite comparison solutions used during the study period were between 8 and $24 \mu \mathrm{S} / \mathrm{cm}$. For specific conductance, if the most probable specific conductance was greater than $10 \mu \mathrm{S} / \mathrm{cm}$ but less than or equal to $60 \mu \mathrm{S} / \mathrm{cm}$, the accuracy criterion was $\pm 4 \mu \mathrm{S} / \mathrm{cm}$. If the most probable specific conductance was less than $10 \mu \mathrm{S} / \mathrm{cm}$, then the accuracy criterion was $\pm 2 \mu \mathrm{S} / \mathrm{cm}$.

The median values obtained from the site operators were used as the most probable values for intersite-comparison solutions. The median values from approximately 220 site-operator measurements were considered a more accurate representation 


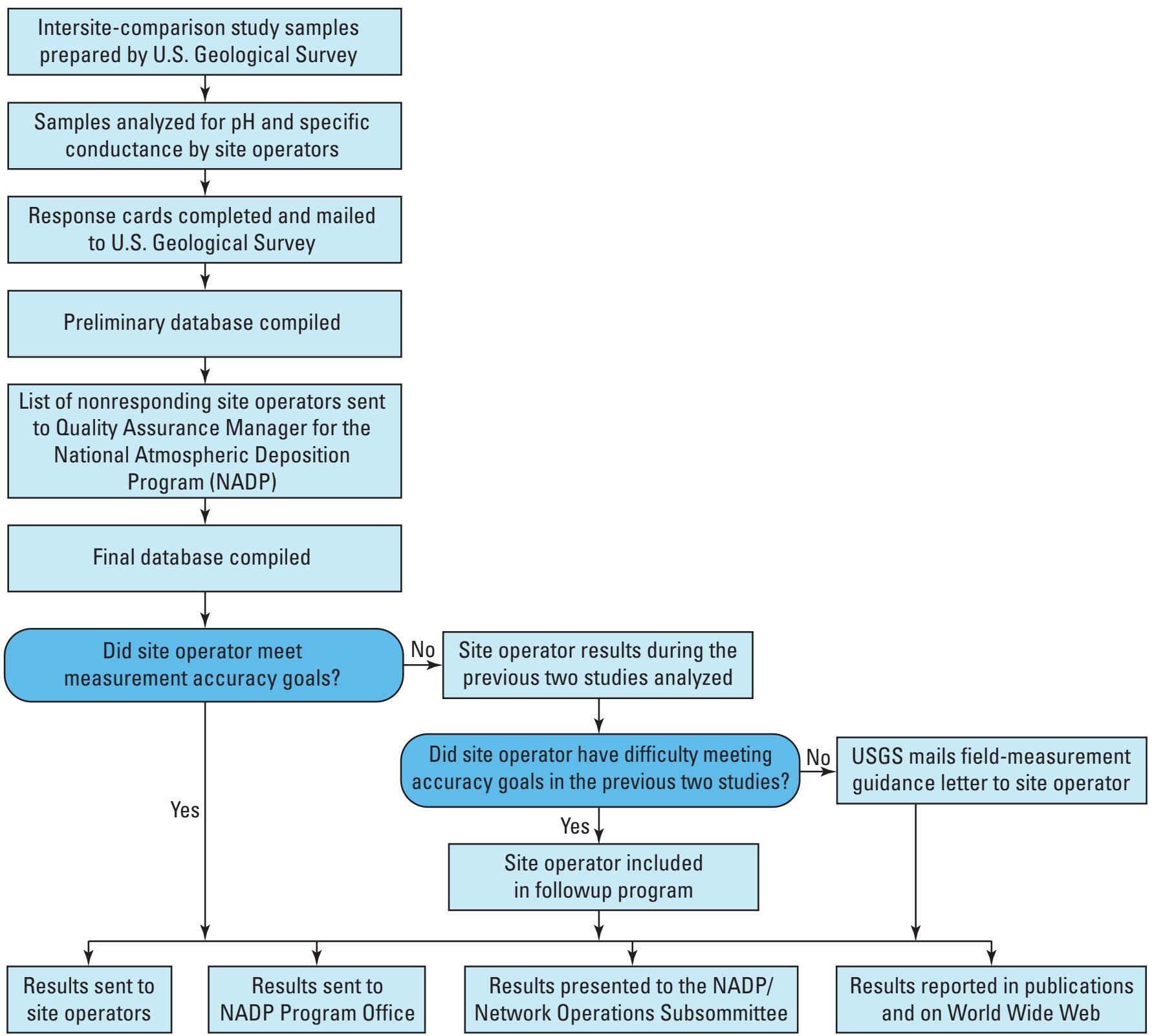

Figure 1. Intersite-comparison program of U.S. Geological Survey External Quality-Assurance Project.

of the most likely values for the intersite solutions than either a few in-house measurements or the theoretical values (Gordon, 1999; See and others, 1989). Previous studies have found no appreciable deterioration of intersite solutions over the duration of the studies, which further supports the use of the median of the values obtained from site-operator measurements as the most probable values (Gordon and others, 1995).

Table 1 contains a summary of the results for studies 48 and 49. Table 2 summarizes the results for studies 50 and 51. The accuracy goals for each study also are provided (tables 1 and 2).

The $\mathrm{pH}$ and specific conductance measurement results for intersite-comparison studies 48-51 are plotted in figures 2 and 3 . The data in figures 2 and 3 indicate that a large majority of sites met measurement goals for both $\mathrm{pH}$ and specific conductance. Moreover, there was no relation between sites that did not meet $\mathrm{pH}$ measurement goals and sites that did not meet specific conductance measurement goals during 2002-03.

\section{Intersite-Comparison Followup Studies}

After the initial intersite-comparison results were tabulated for each study, the results from site operators that did not meet the $\mathrm{pH}$ accuracy goals were evaluated further in followup studies. The purpose of the followup studies was to help site operators identify and resolve sources of measurement difficulty and to produce better weekly data for NADP/NTN. Each 
Table 1. Site-operator responses and summary statistics for 2002 intersite-comparison program studies 48 and 49.

[ $\mu \mathrm{S} / \mathrm{cm}$, microsiemens per centimeter at 25 degrees Celsius]

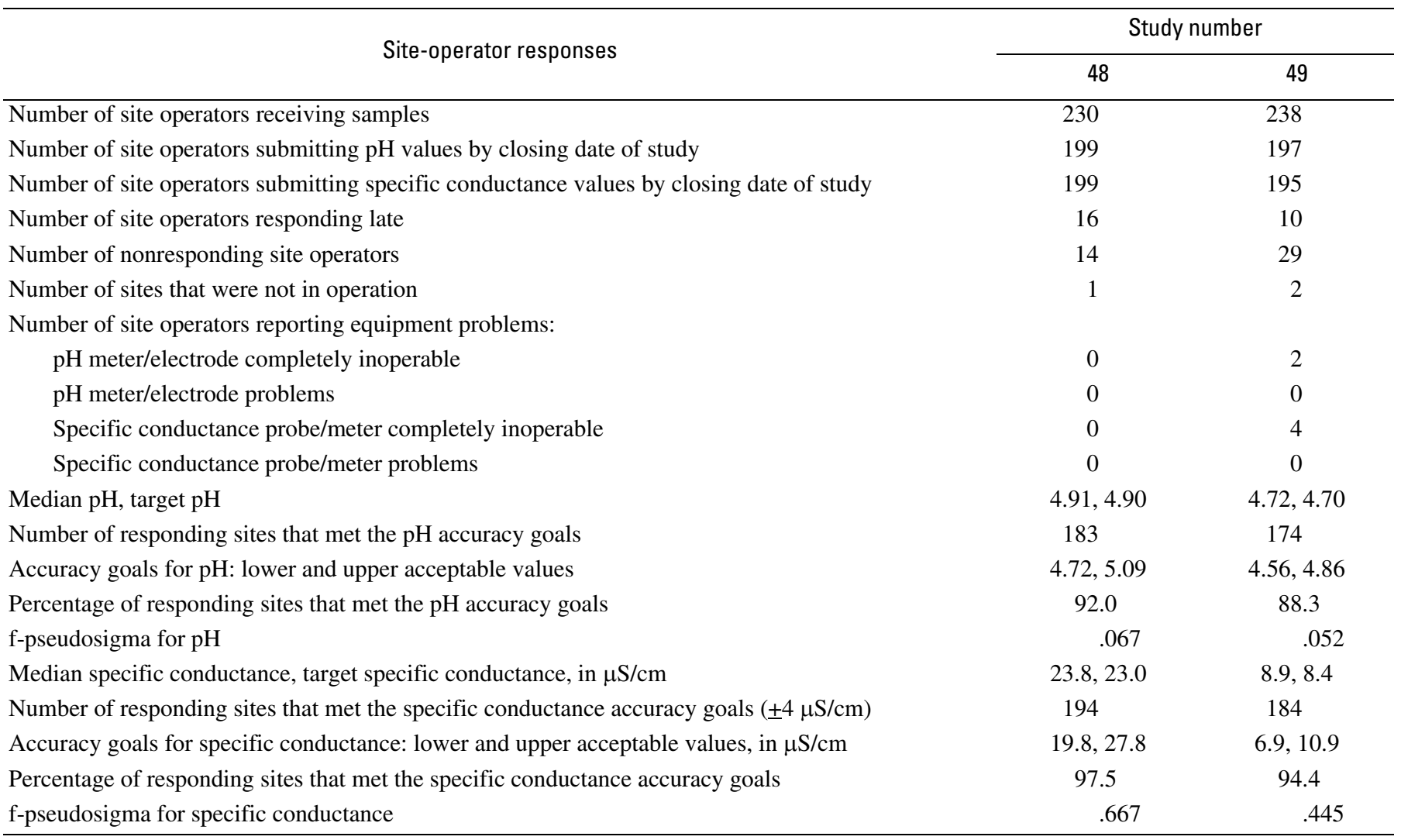

operator that failed to meet the accuracy goals was placed into one of four followup categories on the basis of their performance in the current intersite-comparison program study and in the two preceding studies.

For the followup studies, the site operators' reported values are converted into standardized z-values. Z-values are analogous to Z-scores described by Iman and Conover (1983), whereby nonparametric estimators replace the traditional parametric estimators. Z-values indicate the number of standard deviations between a measured value and the median. The sign of the z-value denotes whether it is in the left or right tail of the distribution. For example, a $\mathrm{z}$-value of +1 identifies the value to be approximately one standard deviation to the right of the median, whereas a $\mathrm{z}$-value of -2 is two standard deviations to the left of the median. Z-values outside \pm 3 standard deviations are considered to be outliers because approximately 99 percent of the data in a population is within three standard deviations of the median (Iman and Conover, 1983). The formulas for $\mathrm{Z}-$ scores and z-values are:

$$
\begin{aligned}
& \text { z-score }=\frac{x-\bar{x}}{\mathrm{~S}} \text {, and } \\
& \text { z-value }=\frac{x-\tilde{x}}{\mathrm{fps}},
\end{aligned}
$$

where $x=$ an individual observation, $\bar{x}=$ the mean of all observations,

$\tilde{X}=$ the median of all observations,

$\mathrm{S}=$ standard deviation of all observations, and

fps = f-pseudosigma of all observations:

$$
\frac{75 \text { th percentile }-25 \text { th percentile }}{1.349} \text {. }
$$

By using standardized z-values, each site operator's performance, relative to all other site operators, was evaluated statistically. The standardized z-values take into account the amount by which pH-measurement accuracy goals are missed, given the relative difficulty of measuring the $\mathrm{pH}$ of the solution. The relative difficulty of measuring the $\mathrm{pH}$ of the low-ionicstrength solutions is inversely related to the hydrogenion concentration of the solution-the lower the hydrogen-ion concentration, the more difficult the measurement. A cumulative $\mathrm{z}$-value total for the three most-recent studies was used to place each site operator failing to meet the accuracy goals into one of these followup study categories:

Level 1. Operators received a letter discussing common sources of measurement errors and were asked to voluntarily remeasure the intersite-comparison sample. 
Table 2. Site-operator responses and summary statistics for 2003 intersite-comparison program studies 50 and 51.

[ $\mu \mathrm{S} / \mathrm{cm}$, microsiemens per centimeter at 25 degrees Celsius]

\begin{tabular}{|c|c|c|}
\hline \multirow{2}{*}{ Site-operator responses } & \multicolumn{2}{|c|}{ Study number } \\
\hline & 50 & 51 \\
\hline Number of site operators receiving samples & 239 & 242 \\
\hline Number of site operators submitting $\mathrm{pH}$ values by closing date of study & 226 & 216 \\
\hline Number of site operators submitting specific conductance values by closing date of study & 226 & 217 \\
\hline Number of site operators responding late & 4 & 11 \\
\hline Number of nonresponding site operators & 9 & 14 \\
\hline Number of sites that were not in operation & 0 & 1 \\
\hline \multicolumn{3}{|l|}{ Number of site operators reporting equipment problems: } \\
\hline $\mathrm{pH}$ meter/electrode completely inoperable & 0 & 3 \\
\hline $\mathrm{pH}$ meter/electrode problems & 0 & 0 \\
\hline Specific conductance probe/meter completely inoperable & 0 & 1 \\
\hline Specific conductance probe/meter problems & 0 & 0 \\
\hline Median $\mathrm{pH}$, target $\mathrm{pH}$ & $4.56,4.50$ & $4.41,4.35$ \\
\hline Number of responding sites that met the $\mathrm{pH}$ accuracy goals & 195 & 187 \\
\hline Accuracy goals for $\mathrm{pH}$ : lower and upper acceptable values & $4.42,4.67$ & $4.29,4.50$ \\
\hline Percentage of responding sites that met the $\mathrm{pH}$ accuracy goals & 86.3 & 86.6 \\
\hline f-pseudosigma for $\mathrm{pH}$ & .044 & .059 \\
\hline Median specific conductance, target specific conductance, in $\mu \mathrm{S} / \mathrm{cm}$ & $13.1,13.3$ & $18.3,18.8$ \\
\hline Number of responding sites that met the specific conductance accuracy goals $( \pm 4 \mu \mathrm{S} / \mathrm{cm})$ & 220 & 209 \\
\hline Accuracy goals for specific conductance: lower and upper acceptable values, in $\mu \mathrm{S} / \mathrm{cm}$ & $9.1,17.1$ & $14.3,22.3$ \\
\hline Percentage of responding sites that met the specific conductance accuracy goals & 97.3 & 96.3 \\
\hline f-pseudosigma for specific conductance & .667 & .741 \\
\hline
\end{tabular}

Level 2. Operators received a letter discussing common sources of measurement errors and were asked to reanalyze the remaining portion of the intersitecomparison sample.

Level 3. Operators received a letter discussing common sources of measurement errors and were asked to reanalyze the original intersite-comparison sample plus one additional intersite-comparison sample.

Level 4. Operators received a letter discussing common sources of measurement errors and were asked to reanalyze the original intersite-comparison sample plus two additional intersite-comparison samples of different $\mathrm{pH}$ and specific conductance target values.

The additional intersite-comparison samples sent to Level 3 and 4 site operators were solutions that had been used in previous intersite-comparison studies and stored at $4{ }^{\circ} \mathrm{C}$ in their original unopened bottles. Previous studies (Peden and Skowron, 1978; Gordon and others, 1995) indicated that the stability of hydrogen-ion concentration over time was sufficient to allow the use of previous intersite samples in the followup analysis.

During 2002 and 2003, the number of site operators that were required to participate in Level 1, Level 2, Level 3, and
Level 4 intersite-comparison followup studies increased from 32 in spring 2002 to 56 in fall 2003. Figure 4 summarizes the followup results for studies 48 and 49 during 2002, and figure 5 summarizes the results for studies 50 and 51 during 2003. Before 2002, the followup studies proved to be effective in improving the quality of the onsite $\mathrm{pH}$ and specific conductance data (Wetherbee and others, 2004). However, the followup studies were not as effective during 2002-03, as indicated by a decrease in the percentage of successful intersite-comparison $\mathrm{pH}$ measurements during the study period as compared to results from 2000-2001 (fig. 6).

The 2002-03 intersite-comparison data were compared to data obtained in previous years to identify trends in operator performance. Site-operator performance for onsite $\mathrm{pH}$ and specific conductance measurement remained high over the years 1998-2003 (fig. 6). However, the percentage of successful pH measurements for the intersite-comparison program fell from 92.0 percent for study 48 to 86.3 percent for study 50 , whereas 94.4 to 97.5 percent of the site operators met accuracy goals for specific conductance. The data in figure 6 indicate a slight decrease in site-operator onsite-pH measurement performance during 2002-03. The data for intersite-comparison studies 4851 also indicate a decrease in site-operator participation for study number 50 . The bottom graph in figure 6 indicates a decrease in the number of successful followup study 
Intersite-comparison study 48 - June 2002
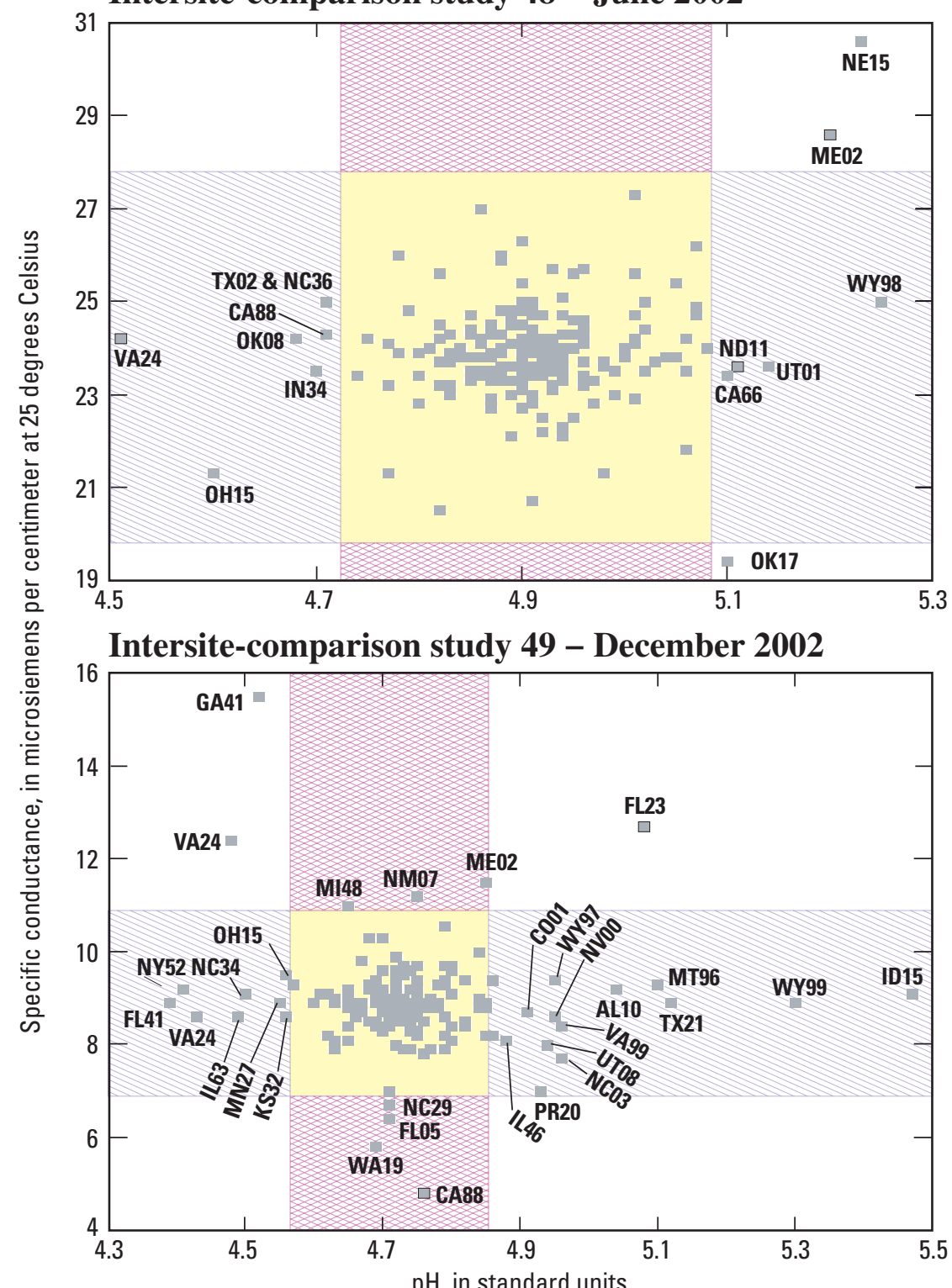

\section{EXPLANATION}

VA24 - Data point with four-character site code

Met National Atmospheric Deposition Program / National Trends Network (NADP/NTN) goals for $\mathrm{pH}$ only

Met NADP/NTN goals for $\mathrm{pH}$ and specific conductance

Met NADP/NTN goals for specific conductance only
These data pairs were off scale in study 48

\begin{tabular}{lccccc}
\hline $\begin{array}{l}\text { Site } \\
\text { code }\end{array}$ & $\mathrm{pH}$ & $\begin{array}{c}\text { Specific } \\
\text { conductance }\end{array}$ & $\begin{array}{l}\text { Site } \\
\text { code }\end{array}$ & $\begin{array}{c}\mathrm{pH} \\
\text { Specific } \\
\text { conductance }\end{array}$ \\
\hline CAN55 & 4.65 & 16.4 & FL23 & 4.75 & 11.0 \\
MS19 & 4.86 & 17.0 & NM01 & 6.85 & 22.1 \\
TX03 & 5.78 & 22.2 & UT08 & 5.52 & 21.4
\end{tabular}

These data pairs were off scale in study 49

\begin{tabular}{lccccc}
\hline $\begin{array}{l}\text { Site } \\
\text { code }\end{array}$ & $\mathrm{pH}$ & $\begin{array}{c}\text { Specific } \\
\text { conductance }\end{array}$ & $\begin{array}{c}\text { Site } \\
\text { code }\end{array}$ & $\begin{array}{c}\mathrm{pH} \\
\text { Specific } \\
\text { conductance }\end{array}$ \\
\hline ND08 & 5.60 & 8.70 & OH49 & 4.72 & 25.4 \\
TX39 & 4.85 & 18.1 & & &
\end{tabular}

Figure 2. Distribution of pH and specific conductance values for intersite-comparison studies 48 and 49. 
Intersite-comparison study 50 - June 2003

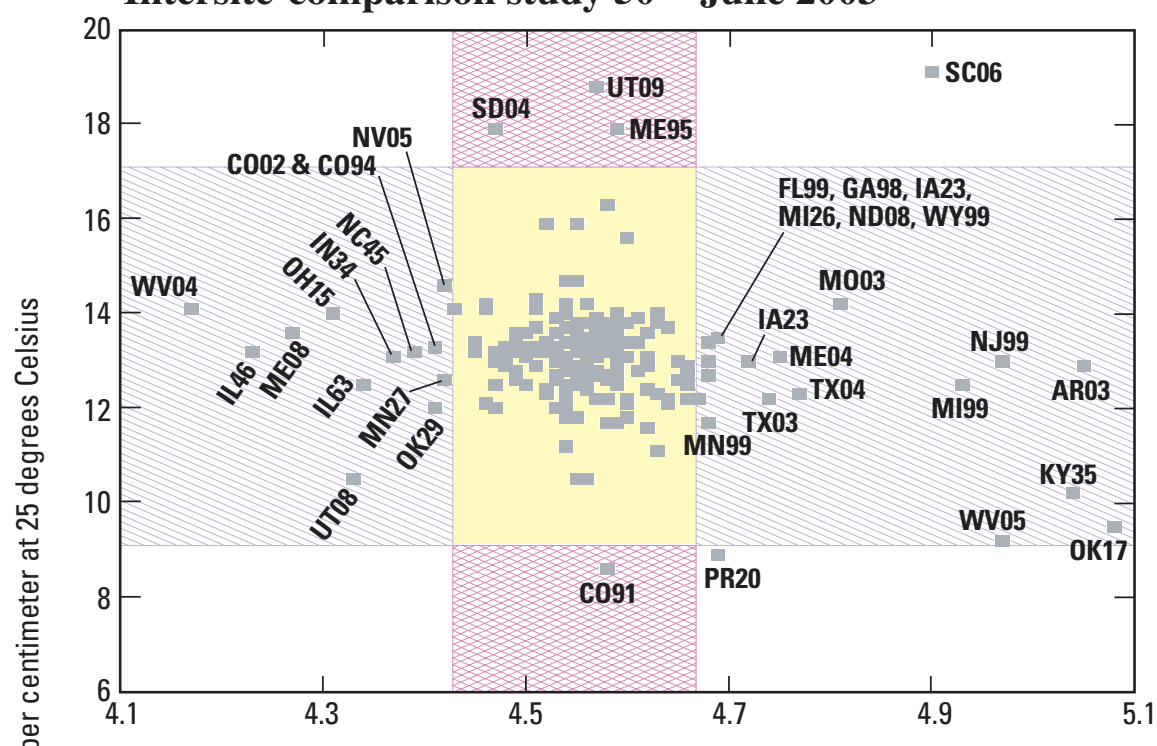

Intersite-comparison study 51 - December 2003

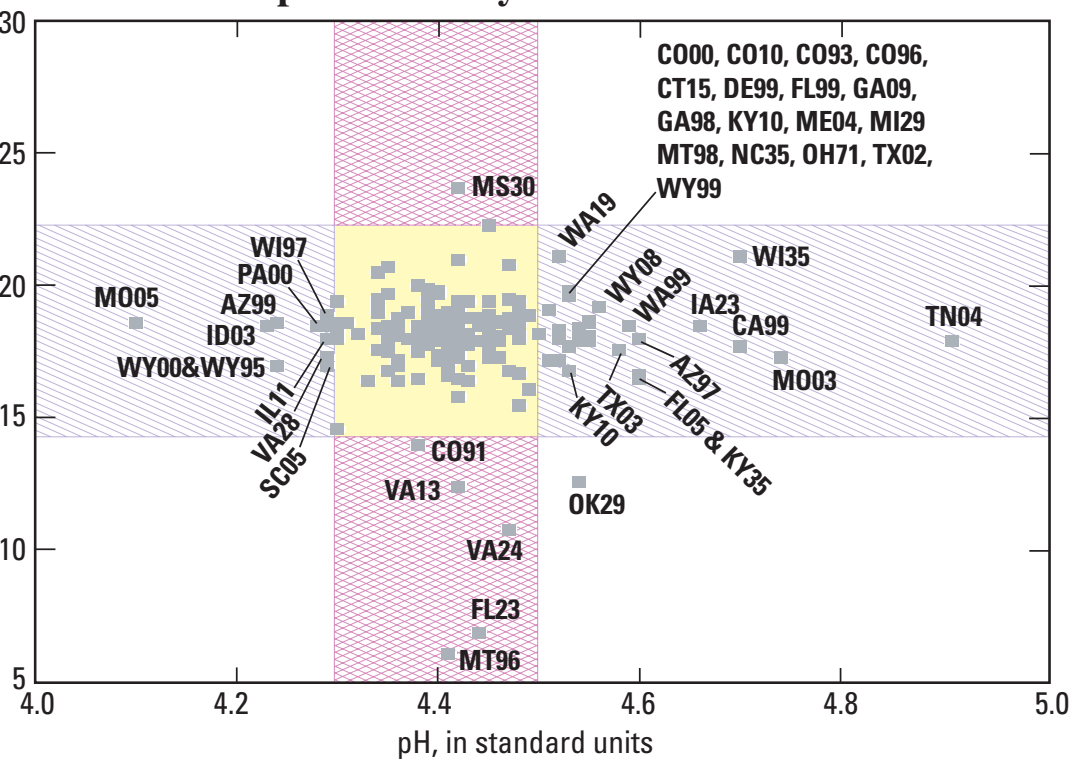

\section{EXPLANATION}

VA24 $\square$ Data point with four-character site code

Met National Atmospheric Deposition Program / National Trends Network (NADP/NTN) goals for $\mathrm{pH}$ only

Met NADP/NTN goals for $\mathrm{pH}$ and specific conductance

Met NADP/NTN goals for specific conductance only
These data pairs were off scale in study 50

\begin{tabular}{lccccc}
\hline $\begin{array}{l}\text { Site } \\
\text { code }\end{array}$ & $\mathrm{pH}$ & $\begin{array}{c}\text { Specific } \\
\text { conductance }\end{array}$ & $\begin{array}{c}\text { Site } \\
\text { code }\end{array}$ & $\begin{array}{c}\mathrm{pH} \\
\text { Specific } \\
\text { conductance }\end{array}$ \\
\hline ID15 & 4.40 & 4.4 & ME09 & 4.56 & 24.1 \\
M005 & 7.10 & 10.8 & MS10 & 12.3 & 12.3 \\
ND11 & 3.45 & 13.7 & NM08 & 5.71 & 2.2
\end{tabular}

These data pairs were off scale in study 51

\begin{tabular}{lccccc}
\hline $\begin{array}{l}\text { Site } \\
\text { code }\end{array}$ & $\mathrm{pH}$ & $\begin{array}{c}\text { Specific } \\
\text { conductance }\end{array}$ & $\begin{array}{c}\text { Site } \\
\text { code }\end{array}$ & $\begin{array}{c}\mathrm{pH} \\
\text { Specific } \\
\text { conductance }\end{array}$ \\
\hline TX39 & 4.41 & 64.2 & WV04 & 5.25 & 26.2
\end{tabular}

Figure 3. Distribution of $\mathrm{pH}$ and specific conductance values for intersite-comparison studies 50 and 51. 
Followup results for intersite-comparison study 48

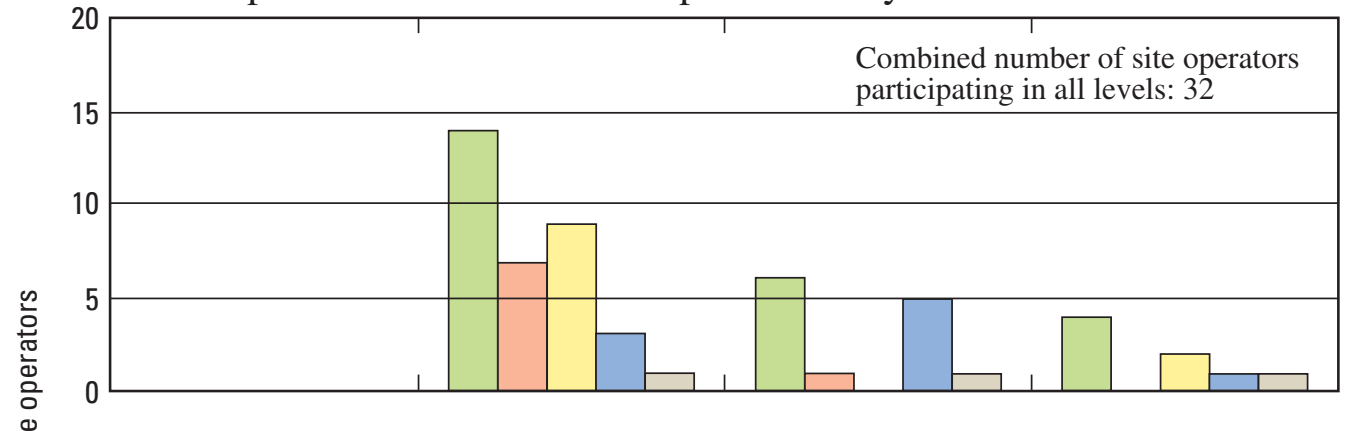

Followup results for intersite-comparison study 49

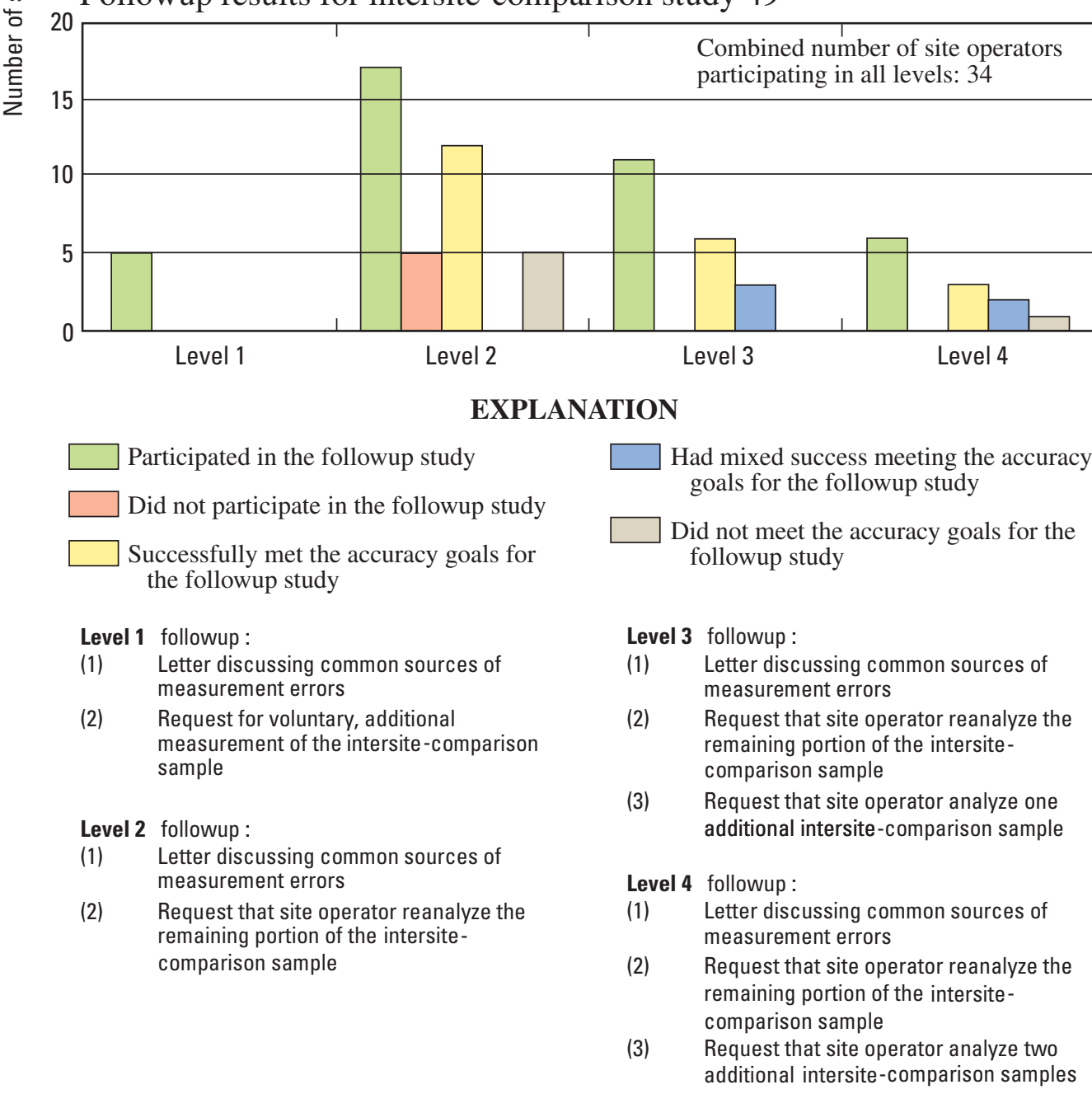

Figure 4. Summary of followup study results obtained during 2002 for intersite-comparison program.

measurements, on the basis of the total number of requested measurements, for study 50. Although the intersite-comparison program results indicate that a majority of NADP/NTN onsite measurements of $\mathrm{pH}$ and specific conductance were reliable for data users, the data obtained indicate lower onsite-data quality during 2003 than during 2001-02.

\section{Sample-Handling Variability and Bias}

Routine handling and processing procedures applied to wet-deposition samples have been identified as sources of contamination (Nilles and others, 1995; Gordon, 1999). Constituent loss from solution, due to adsorption to the collection bucket or other reactions, is possible. The effects of routine sample 
Followup results for intersite-comparison study 50

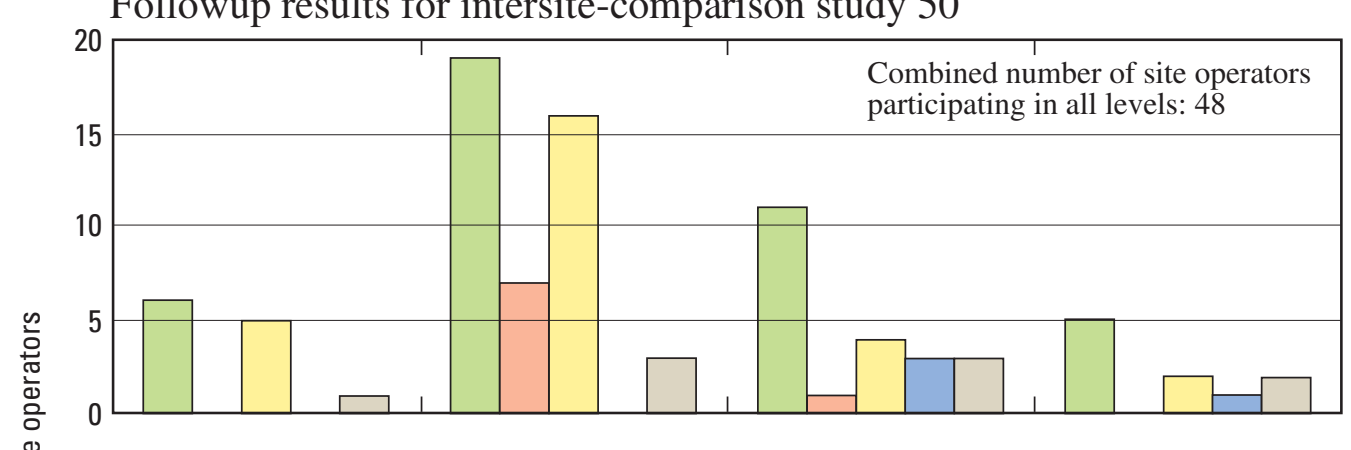

Followup results for intersite-comparison study 51

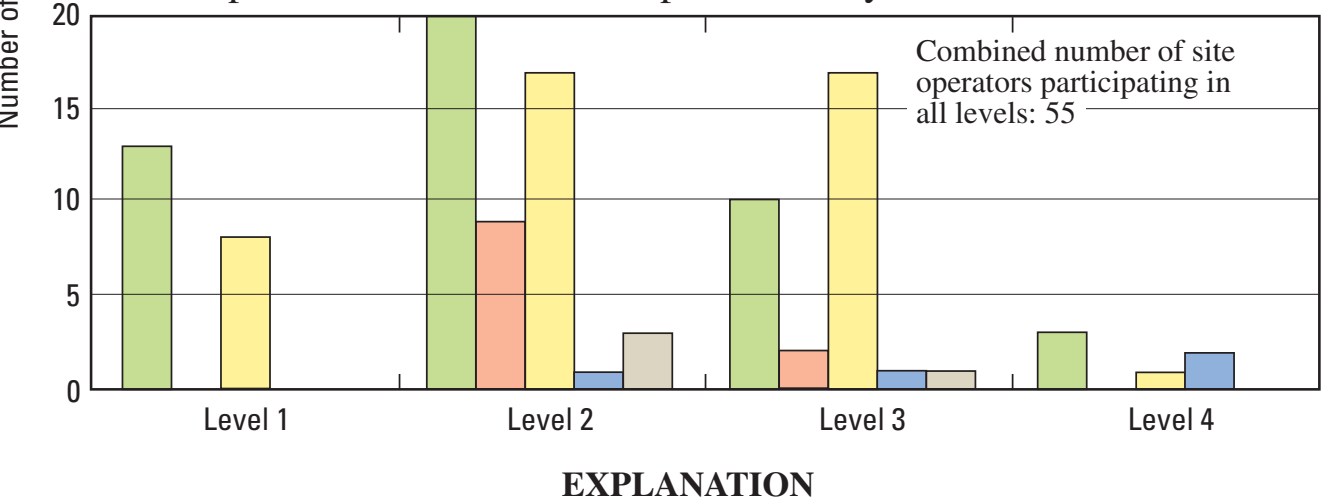

Participated in the followup study

Did not participate in the followup study

Successfully met the accuracy goals for the followup study

Had mixed success meeting the accuracy goals for the followup study

Did not meet the accuracy goals for the followup study

Level 1 followup:

(1) Letter discussing common sources of measurement errors

(2) Request for voluntary, additional measurement of the intersite-comparison sample

Level 3 followup :
$\begin{array}{ll}\text { (1) } & \text { Letter discussing common sources of } \\ \text { measurement errors }\end{array}$
(2) $\quad \begin{aligned} & \text { Request that site operator reanalyze the } \\ & \text { remaining portion of the intersite- } \\ & \text { comparison sample }\end{aligned}$
(3) $\quad \begin{aligned} & \text { Request that site operator analyze one } \\ & \text { additional intersite-comparison sample }\end{aligned}$
Level $4 \quad \begin{aligned} & \text { followup : } \\ & \text { (1) }\end{aligned}$
Letter discussing common sources of
(2) $\quad \begin{aligned} & \text { Request that site operator reanalyze the } \\ & \text { remaining portion of the intersite- }\end{aligned}$
(3) $\quad \begin{aligned} & \text { Request that site operator analyze two } \\ & \text { additional intersite-comparison samples }\end{aligned}$

Level 2 followup:

(1) Letter discussing common sources of measurement errors

(2) Request that site operator reanalyze the remaining portion of the intersitecomparison sample additional intersite-comparison samples

Figure 5. Summary of followup study results obtained during 2003 for intersite-comparison program.

handling, sample shipping, and chemical analysis of wetdeposition samples on analyte variability and bias were evaluated using the blind-audit program during 2002 and the samplehandling evaluation (SHE) program during 2003.

In the blind-audit and SHE programs, site operators processed and submitted a USGS-prepared, synthetic wet-

deposition sample to CAL for analysis. The operators poured 75 percent of the synthetic sample into a clean bucket obtained from the operators' stock supplied by CAL. The normal processing and handling steps of a regular weekly sample were applied to this "bucket portion" of the blind-audit and SHE samples. The remaining 25 percent of the synthetic sample in the bottle was subjected to minimal handling. This minimally handled "bottle sample" for the blind-audit program was sent to CAL for analysis in a separate mailer, but SHE bottle samples were shipped with the bucket samples. All bottle samples were analyzed independently of the bucket samples. Chemical 


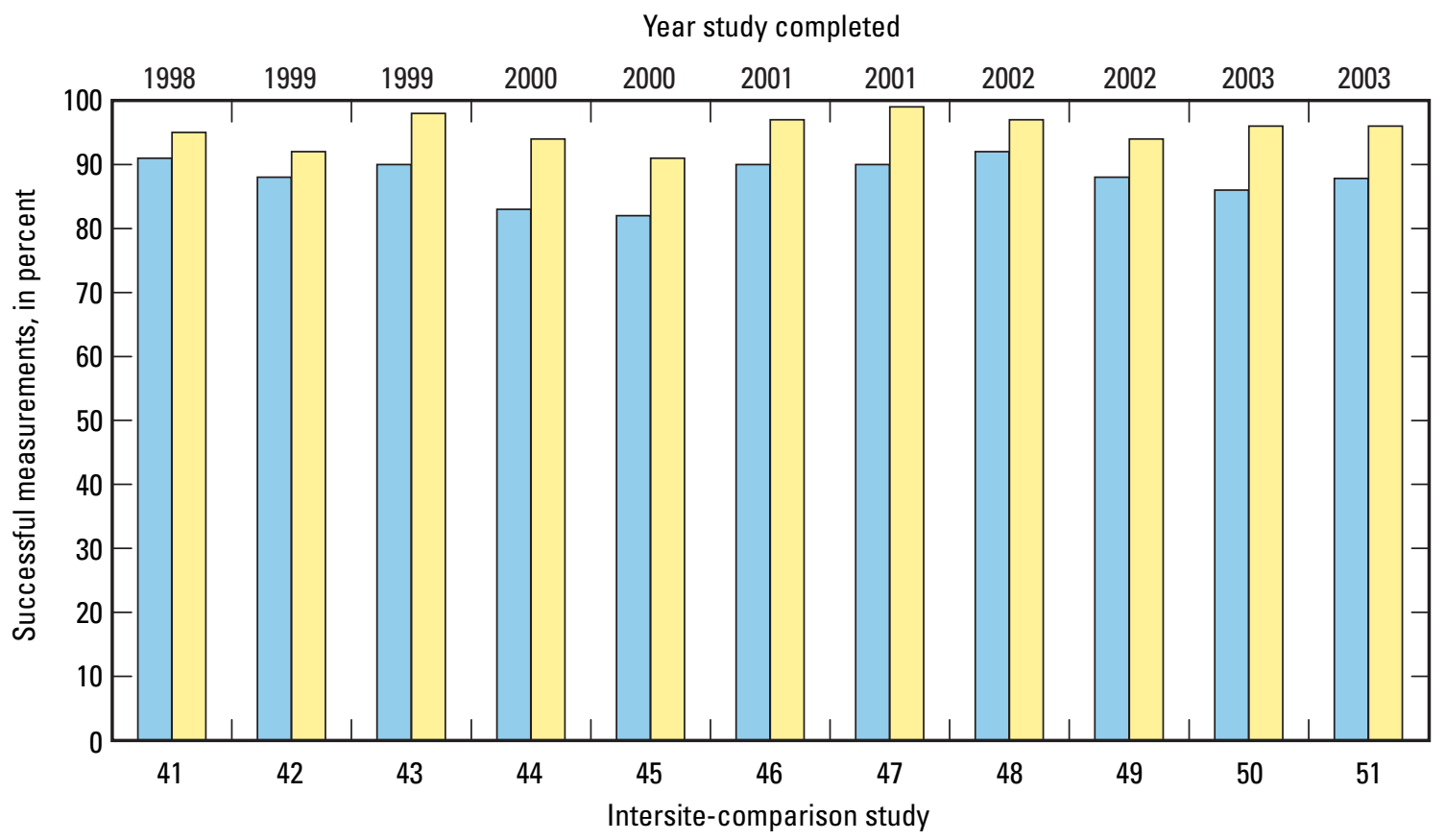

EXPLANATION

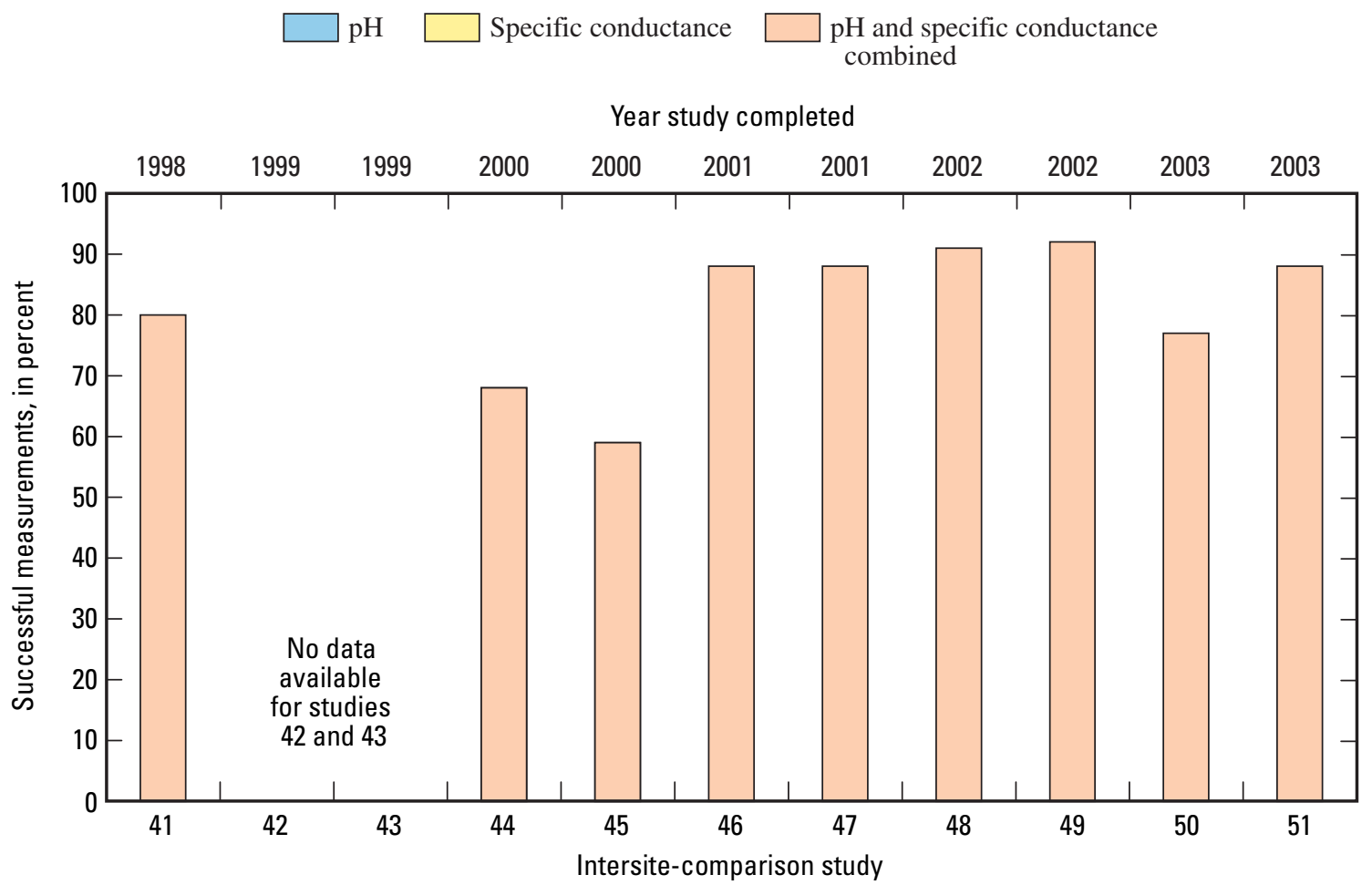

Figure 6. Percentage of successful pH and specific conductance measurements in intersite-comparison program during 1998-2003.

analysis results for the bucket portion were compared to the results for the bottle portion to determine if significant addition or loss of constituents had occurred from sample handling and shipping.

The operation of the blind-audit and SHE programs was nearly identical, with two differences. The most important difference was that the blind-audit program bucket samples were received by CAL as double-blind samples, meaning that QA samples were disguised as environmental samples, whereas SHE samples were not disguised (single-blind samples). The second difference is that the volumes of QA samples used for the SHE program were larger than those used for the blind-audit program. 
The SHE program replaced the blind-audit program in 2003 with the objective to limit data variability to obtain a better measurement of the effects of sample handling and shipping on sample integrity. Paired blind-audit samples were received by CAL in separate shipments, which commonly caused the samples to be analyzed on different days. However, the paired SHE samples were received in the same shipment, which allowed them to be analyzed closer together in time, thus limiting analytical variability. Figures 7 and 8 outline the components of the blind-audit program and SHE program, respectively. The solutions used in the blind-audit and SHE programs were intended to replicate the range of analyte concentrations typically measured in natural NADP/NTN precipitation samples. The median analyte concentrations for the solutions used in the blind-audit and SHE programs (other than ultrapure deionized water) were between the 25th and 75th percentiles of all natural wet-deposition samples collected at NADP/NTN sites. Many of the solutions used in the blind-audit and SHE programs also were used in the field-audit and interlaboratory-comparison programs. Descriptions of each solution are listed in table 3. The target values for these solutions are presented in table 4 .

Three different sample volumes of the solution matrices were distributed to operators of selected NADP/NTN sites to assess volume-related effects on biases. For the 2002 blindaudit program, sample volumes of 250,500 , and $1,000 \mathrm{~mL}$ of USGS solutions were used. For the 2003 SHE program, sample volumes of 250, 1,000, and 2,000 $\mathrm{mL}$ of USGS solutions were used. The volumes selected for the SHE program represent the interquartile range of NADP/NTN sample volumes. Larger volumes contact more surface area of the bucket and also dilute contaminants more than small volume samples. All NADP/NTN samples are filtered by CAL, and large volume samples flush the filters more thoroughly than small volume samples. These effects can be evaluated using the three different sample volumes for the blind-audit and SHE samples. Additional information regarding the blind-audit program is available in previous reports (See and others, 1990; Gordon and others, 1997; Gordon, 1999).

\section{Blind-Audit Program Results}

Twenty-five blind-audit samples were sent to the operators of selected NADP/NTN sites each quarter during 2002. Complete bucket and bottle analyses are available for 83 of the 100 blind-audit samples sent to site operators. Partial analyses are available for an additional 16 samples. Site operators were provided detailed blind-audit sample-processing instructions. The handling and processing steps of a regular weekly precipitation sample were duplicated as closely as possible. After a site successfully participated in the blind-audit program, the site was not selected again for the blind-audit program until the operators of all other NADP/NTN sites had a chance to participate.

\section{Assessment of Variability}

Paired bucket-minus-bottle differences were calculated to evaluate variability in the blind-audit data. Before determining paired bucket-minus-bottle differences, the bucket and bottle values reported as less than CAL's minimum detection limit (MDL) were set equal to one-half the MDL. There is evidence that this substitution method is not as defensible as estimation of the distribution of values less than the MDL (Helsel, 1990); nonetheless it is a convenient substitution for purposes of capturing reasonable estimates of bias and variability.

Table 5 contains summary statistics for the paired bucketminus-bottle differences for the 2002 blind-audit program. The median paired bucket-minus-bottle concentration differences for calcium, magnesium, potassium, and ammonium were consistently at or less than the MDLs. The median paired bucketminus-bottle concentration differences for sodium, chloride, and nitrate were slightly larger than two times the MDLs. The median bucket-minus-bottle difference for sulfate was larger than three times the MDL. Boxplots in figure 9 illustrate the distributions of the paired differences for the 2002 blindaudit data.

The environmental importance of the bucket-minus-bottle concentration differences was evaluated by comparing the median bucket-minus-bottle differences for each constituent to the median concentrations for all NADP/NTN weekly precipitation samples collected during 2002 (Rothert, 2004) (table 5). The absolute values of the median paired bucket-minus-bottle differences for the blind-audit results were less than 10 percent of the median of the measured NADP/NTN constituent concentrations for calcium, ammonium, nitrate, sulfate, and specific conductance. However, the median paired differences for magnesium, sodium, potassium, and chloride concentrations were slightly more than 10 percent of the median NADP/NTN constituent concentrations. The absolute value of the median paired difference for hydrogen-ion concentration was 19 percent of the median NTN hydrogen ion concentration for 2002. Therefore, error attributed to sample handling and shipping by the blind-audit program during 2002 was estimated to be environmentally important to data users.

\section{Relative and Absolute Percentage Differences}

Relative and absolute percentage differences were calculated for all of the paired blind-audit samples. The upper quartile, lower quartile, and median relative and absolute percentage differences during 2002 are listed in table 6 . Bucket-bottle data pairs were excluded for a given analyte if the target concentration was less than or equal to the MDL. Otherwise, the percentage differences would be inflated by the effect of large bucketbottle differences when the known concentration was less than or equal to the MDL (Nilles and others, 1995).

The data in table 6 indicate that the median absolute errors (MAEs) were less than 7 percent for all constituents. The MAEs were less than 3 percent for sodium, chloride, nitrate, 
Stock solutions prepared by commercial vendors and dilluted by the U.S. Geological Survey (USGS)

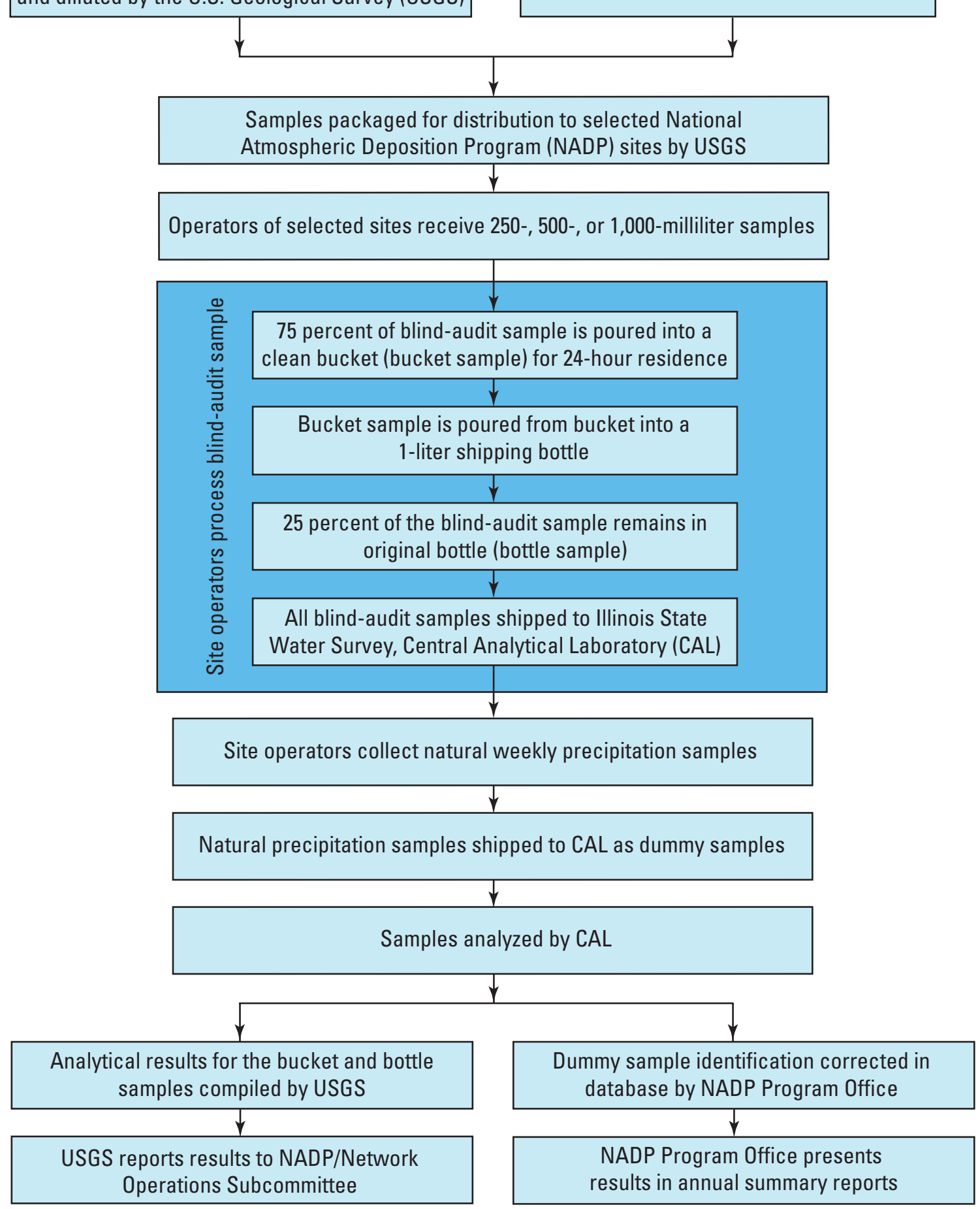

Figure 7. Blind-audit program of U.S. Geological Survey. 


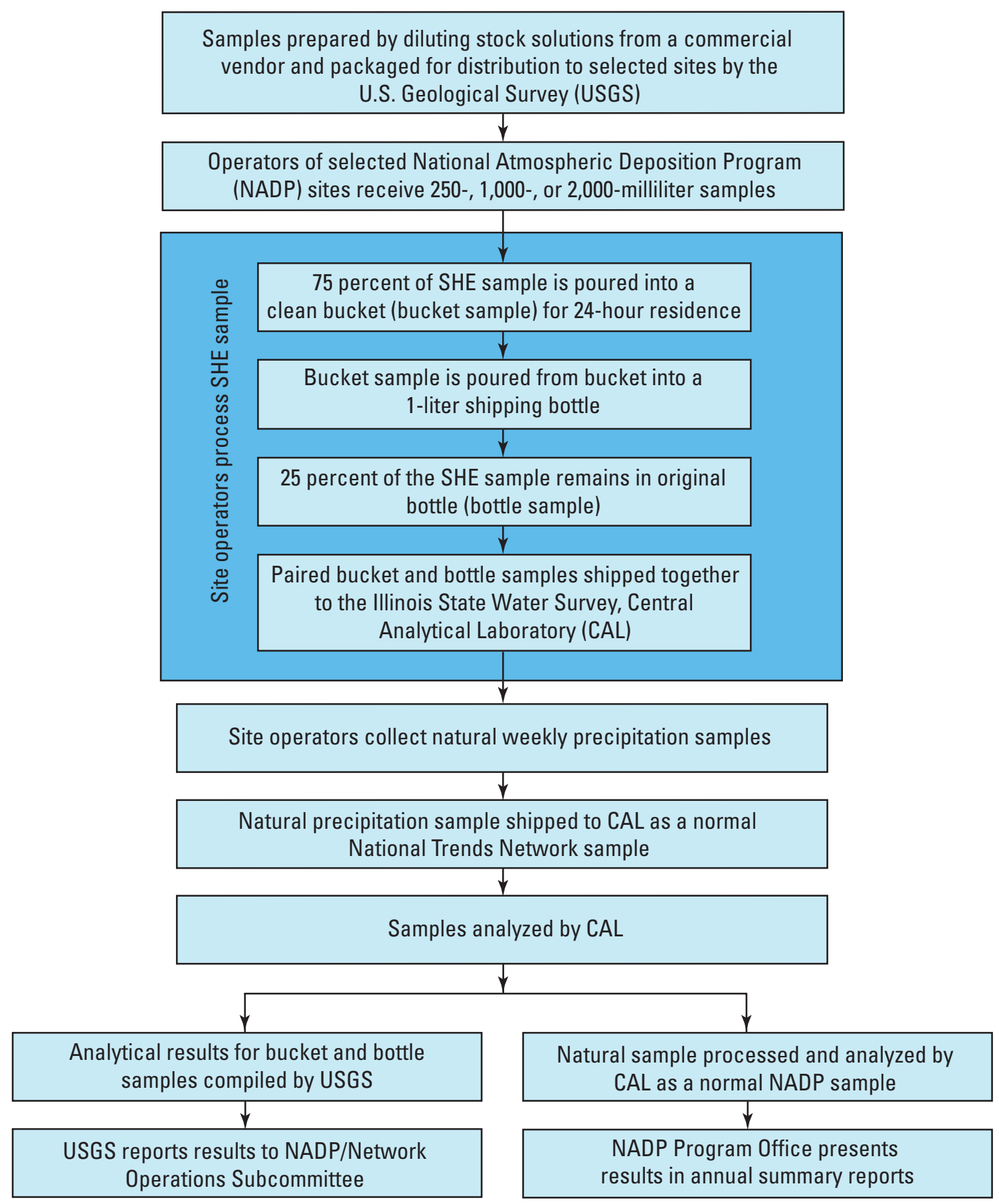

Figure 8. Sample-handling evaluation (SHE) program of U.S. Geological Survey.

and sulfate. The upper and lower quartiles for the relative differences were negative values for hydrogen ion and specific conductance, indicating loss of hydrogen ion resulting in lower specific conductance from contact of the sample with the sample bucket. These data indicate that a small amount of hydrogen ion is buffered by contact with the bucket. Therefore, there is a slight positive bias in NADP/NTN laboratory and onsite $\mathrm{pH}$ measurements due to contact of the wet deposition with the sample buckets.
During 2002, the median relative percentage differences for the blind-audit data, defined herein as the median percentage bias, were positive for all analytes except hydrogen ion and specific conductance (table 6). Negative bias was indicated for hydrogen-ion concentration and specific conductance. A Wilcoxon signed-rank test was used to test for bias within the blindaudit samples for 2002. The null hypothesis for the test was: "The median of the blind-audit bucket-minus-bottle paired differences is zero." The Wilcoxon signed-rank test results 
Table 3. Solutions used in 2002-03 blind-audit, sample-handling evaluation, field-audit, and interlaboratory-comparison programs.

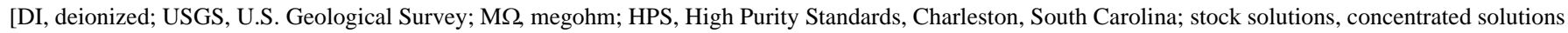
provided by vendor and diluted to specified concentrations by U.S. Geological Survey (USGS); CAL, Illinois State Water Survey, Central Analytical Laboratory, Champaign, Illinois; NADP/NTN, National Atmospheric Deposition Program/National Trends Network]

\begin{tabular}{|c|c|c|}
\hline Solution & Preparation & Remarks \\
\hline Ultrapure $\mathrm{DI}^{1,2,3,4}$ & USGS & $\begin{array}{l}\text { Deionized water with a measured resistivity greater } \\
\text { than } 16.7 \mathrm{M} \Omega \text {. }\end{array}$ \\
\hline CALNAT $^{2}$ & $\begin{array}{l}\text { CAL blends excess, natural NADP/NTN precipitation samples } \\
\text { and ships them to USGS. USGS prepares the samples for } \\
\text { analysis by participating laboratories. }\end{array}$ & $\begin{array}{l}\text { Most probable values for samples are the median } \\
\text { results obtained from participating laboratories. }\end{array}$ \\
\hline
\end{tabular}

identified statistically significant $(\alpha=0.05)$ differences for hydrogen-ion concentration. No other statistically significant bias was identified for the other constituents.

The median difference between bucket and bottle pairs for hydrogen ion during 2002 was -2.10 microequivalents per liter $(\mu \mathrm{eq} / \mathrm{L})($ table 5$)$. This bias was determined to be statistically significant at the 0.05 significance level by the Wilcoxon signed-rank test regardless of whether samples were qualified as contaminated (denoted by a "C" code in the NADP/NTN database) or not. The negative bias for hydrogen ion also was identified whether the buckets were dry or contained residual rinse water at the time that the blind-audit solution was added to the bucket.

\section{Sample-Handling Evaluation (SHE) Program Results}

Twenty-five SHE samples were sent to the operators of selected NADP/NTN sites each quarter during 2003. Complete bucket and bottle analyses were available for 80 of $100 \mathrm{SHE}$ samples sent to the site operators. Partial analyses were available for an additional 16 SHE samples. SHE samples were processed in the same way as the blind-audit program samples with the exception that the processed bucket and bottle portions of SHE samples were shipped together to CAL for analysis, and they were labeled as QA samples (single blind samples). Latysh and Wetherbee (2005) provide a detailed description of SHE program protocols.

\section{Assessment of Variability}

Paired bucket-minus-bottle differences were calculated to evaluate variability in SHE data. Before determining paired bucket-minus-bottle differences, the bucket and bottle values reported as less than the MDL were set equal to one-half the MDL. As previously mentioned, this substitution method was convenient for the purposes of capturing reasonable estimates of bias and variability.

Table 7 contains summary statistics for the paired bucketminus-bottle differences for the 2003 SHE program. The median paired bucket-minus-bottle concentration differences for the SHE program were less than CAL's MDLs for all constituents except sodium and sulfate. The absolute values of the median paired differences for SHE results were less than 10 percent of the median measured NADP/NTN constituent concentrations for all constituents except for hydrogen-ion concentration, which was 10.5 percent of the median NADP/NTN hydrogen-ion concentration.

\section{Relative and Absolute Percentage Differences}

Relative and absolute percentage differences were calculated for all of the SHE bucket-minus-bottle paired differences during 2003. The upper quartile, the lower quartile, and median relative and absolute percentage differences for SHE data obtained during 2003 are listed in table 8. Bucket-bottle data pairs were excluded for a given analyte if the target concentration was less than or equal to the MDL to control the effect of large bucket-bottle differences (Nilles and others, 1995). 
Table 4. Target values for solutions used in 2002-03 U.S. Geological Survey blind-audit, sample-handling evaluation, field-audit, and interlaboratory-comparison programs.

[Target values are the theoretical concentrations that are based on dilution of stock solutions with certified concentrations; Ultrapure DI, deionized water with a resistivity greater than 16.7 megohms (M $\Omega$ ) and assumed to have all constituent concentrations less than the minimum detection limit; $\mathrm{pH}$, in standard units; specific conductance, in microsiemens per centimeter at 25 degrees Celsius ( $\mu \mathrm{S} / \mathrm{cm}$ ); $<\mathrm{mdl}$, indicates value less than minimum detection limit; $\mathrm{Ca}^{2+}$, calcium; $\mathrm{Mg}^{2+}$, magnesium; $\mathrm{Na}^{+}$, sodium; $\mathrm{K}^{+}$, potassium; $\mathrm{NH}_{4}{ }^{+}$, ammonium; $\mathrm{Cl}^{-}$, chloride; $\mathrm{NO}_{3}{ }^{-}$, nitrate; $\mathrm{SO}_{4}{ }^{2-}$, sulfate; significant figures vary due to differences in laboratory precision; bold face indicates value was obtained as the median of all the field-audit, blind-audit, and interlaboratory-comparison samples]

\begin{tabular}{|c|c|c|c|c|c|c|c|c|c|c|}
\hline Solution & $\mathrm{Ca}^{2+}$ & $\mathrm{Mg}^{2+}$ & $\mathrm{Na}^{+}$ & $\mathrm{K}^{+}$ & $\mathrm{NH}_{4}^{+}$ & $\mathrm{Cl}^{-}$ & $\mathrm{NO}_{3}^{-}$ & $\mathrm{SO}_{4}{ }^{2-}$ & \multirow{2}{*}{$\begin{array}{c}\mathrm{pH}^{1} \\
\text { (standard } \\
\text { units) }\end{array}$} & \multirow{2}{*}{$\begin{array}{c}\text { Specific } \\
\text { conductance }^{2} \\
(\mu S / \mathrm{cm})\end{array}$} \\
\hline & \multicolumn{8}{|c|}{ (milligrams per liter) } & & \\
\hline Ultrapure $\mathrm{DI}^{3,4,5,6}$ & $<\mathrm{mdl}$ & $<\mathrm{mdl}$ & $<\mathrm{mdl}$ & $<\mathrm{mdl}$ & $<\mathrm{mdl}$ & $<\mathrm{mdl}$ & $<\mathrm{mdl}$ & $<\mathrm{mdl}$ & 5.55 & 1.3 \\
\hline $\mathrm{SP} 1^{3,4,5}$ & 0.460 & 0.092 & 0.420 & 0.076 & 0.680 & 0.590 & 2.10 & 3.850 & 4.42 & 29.7 \\
\hline $\mathrm{SP} 2^{3,4,5,6}$ & .460 & .070 & .360 & .060 & .560 & .450 & 3.00 & 2.334 & 4.51 & 24.8 \\
\hline $\mathrm{SP} 3^{6}$ & .159 & .049 & .111 & .023 & .140 & .170 & 1.08 & .960 & 4.78 & 11.2 \\
\hline $\mathrm{SP}^{3,4,5}$ & .575 & .168 & .454 & .083 & .710 & .720 & 2.55 & 4.510 & 4.33 & 35.5 \\
\hline $\mathrm{SP}^{3} 7^{3,4,5}$ & .130 & .019 & .024 & .017 & .290 & .054 & 1.18 & 1.140 & 5.20 & 11.9 \\
\hline SP9 $8^{3}$ & .013 & .024 & .208 & .056 & .120 & .230 & .570 & 2.410 & 4.43 & 22.6 \\
\hline $\mathrm{SP} 8 \mathrm{c}^{3,4,5}$ & .016 & .038 & .208 & .061 & .120 & .234 & .570 & 2.428 & 4.14 & 20.4 \\
\hline
\end{tabular}

${ }^{1} \mathrm{pH}$ not certified by the National Institute of Standards and Technology.

${ }^{2}$ At 25 degrees Celsius and 1 atmosphere pressure (Dean, 1979; Hem, 1985).

${ }^{3}$ Solution used for the blind-audit program.

${ }^{4}$ Solution used for the interlaboratory-comparison program.

${ }^{5}$ Solution used for the sample-handling evaluation.

${ }^{6}$ Solution used for the field-audit program. 
Table 5. Selected statistics for paired bucket-sample minus bottle-sample concentration differences in blind-audit program during 2002.

[All units in milligrams per liter except hydrogen ion, in microequivalents per liter, and specific conductance, in microsiemens per centimeter at 25 degrees Celsius; N, number of samples; Q1, the lower quartile in the data distribution; Q3, the upper quartile in the data distribution; interquartile range, the difference between the upper and lower quartiles in the distribution (Q3 minus Q1); na, not applicable; CAL, Central Analytical Laboratory; MDL, minimum detection limit; Median NADP/NTN concentration, median value of all National Atmospheric Deposition Program/National Trends Network (NADP/NTN) measured concentrations for 2002 (Rothert, 2004)]

\begin{tabular}{|c|c|c|c|c|c|c|c|c|c|}
\hline \multirow{3}{*}{ Analyte } & \multicolumn{7}{|c|}{ Bucket-minus-bottle paired differences } & \multirow{2}{*}{\multicolumn{2}{|c|}{ Data for comparison }} \\
\hline & \multirow[b]{2}{*}{$\mathrm{N}$} & \multirow[b]{2}{*}{ Minimum } & \multirow[b]{2}{*}{ Median } & \multicolumn{2}{|c|}{ Quartiles } & \multirow[b]{2}{*}{ Maximum } & \multirow[b]{2}{*}{ Interquartile range } & & \\
\hline & & & & 01 & 03 & & & $\begin{array}{l}\mathrm{CAL} \\
\mathrm{MDL}\end{array}$ & $\begin{array}{l}2002 \text { median NADP/NTN } \\
\text { concentration }\end{array}$ \\
\hline Calcium & 83 & -0.058 & 0.003 & -0.008 & 0.013 & 0.065 & 0.021 & 0.009 & 0.111 \\
\hline Magnesium & 83 & -.018 & .003 & .001 & .007 & .025 & .006 & .003 & .023 \\
\hline Sodium & 83 & -.097 & .007 & 0 & .012 & .067 & .012 & .003 & .053 \\
\hline Potassium & 84 & -.027 & .002 & -.001 & .005 & .067 & .006 & .003 & .017 \\
\hline Ammonium & 83 & -.170 & .020 & 0 & .040 & .090 & .040 & .020 & .240 \\
\hline Chloride & 85 & -.041 & .011 & .005 & .021 & .068 & .016 & .005 & .108 \\
\hline Nitrate & 83 & -.031 & .024 & .012 & .048 & .207 & .036 & .010 & 1.075 \\
\hline Sulfate & 83 & -.120 & .037 & .014 & .086 & .300 & .072 & .010 & .998 \\
\hline Hydrogen ion & 99 & -9.40 & -2.10 & -4.21 & -.672 & 6.50 & 3.54 & na & 11 \\
\hline Specific conductance & 99 & -5.1 & -.50 & -1.5 & 0 & 1.9 & 1.5 & .05 & 12 \\
\hline
\end{tabular}



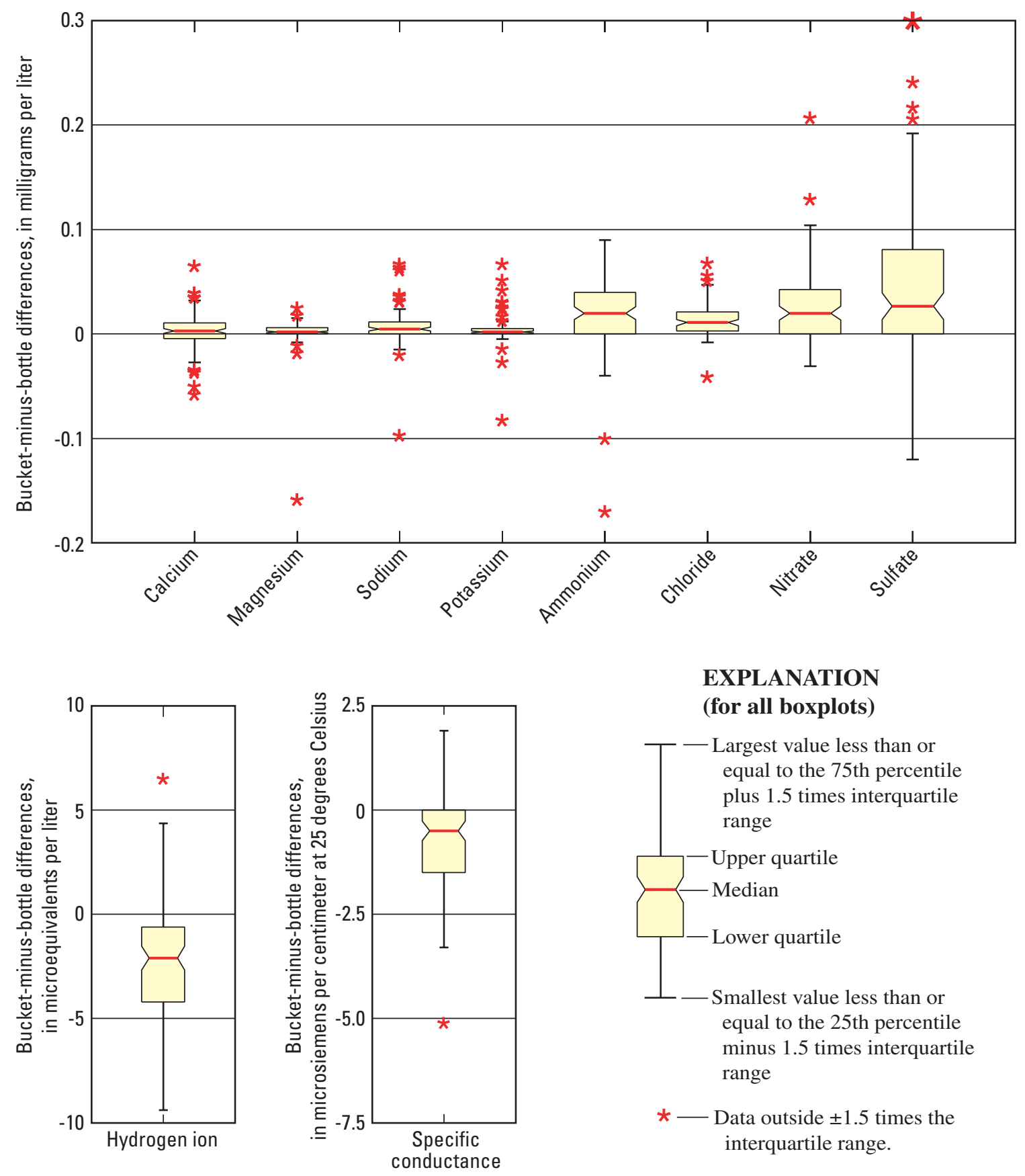

EXPLANATION

(for all boxplots)

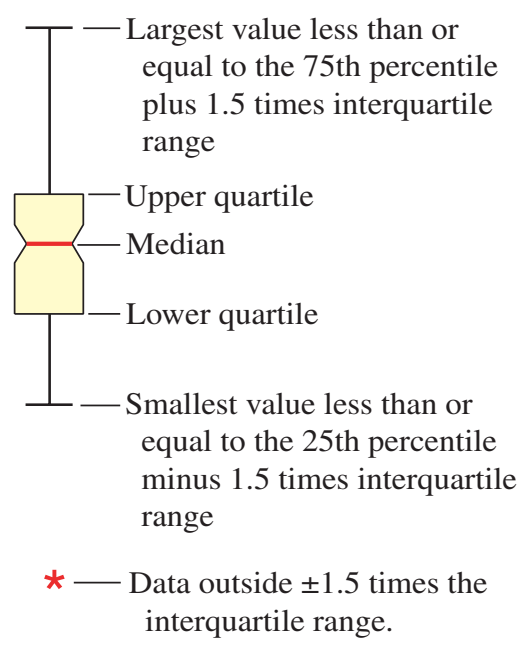

Figure 9. Paired bucket-sample minus bottle-sample measurement differences for blind-audit program during 2002.

The data in table 8 indicate that MAEs for the 2003 SHE program were less than or equal to 3 percent for all analytes except ammonium and hydrogen ion. The relative bucketminus-bottle differences expressed as percentages of the target concentrations were positive for most of the measured constituents except for hydrogen ion and specific conductance (table 8). Therefore, positive bias was indicated for all constituents except hydrogen-ion concentration and specific conductance. The negative bias for hydrogen ion and specific conductance indicate loss of hydrogen ion and decreased specific conductance from contact of the NADP/NTN samples with the bucket. Therefore, SHE results are similar to the blind-audit results, which indicate a slight positive bias in NADP/NTN pH 
Table 6. Relative and absolute bucket-minus-bottle differences calculated as a percentage of target concentration or value for each analyte during 2002 for blind-audit program.

\begin{tabular}{|c|c|c|c|c|c|c|}
\hline \multirow{3}{*}{ Analyte } & \multirow{2}{*}{\multicolumn{3}{|c|}{$\begin{array}{l}\text { Relative bucket-minus-bottle differences } \\
\text { expressed as a percentage of corresponding } \\
\text { target bottle concentration } \\
\text { (selected data pairs only) }\end{array}$}} & \multirow{2}{*}{\multicolumn{3}{|c|}{$\begin{array}{c}\text { Absolute bucket-minus-bottle differences } \\
\text { expressed as a percentage of corresponding } \\
\text { target bottle concentration } \\
\text { (selected data pairs only) }\end{array}$}} \\
\hline & & & & & & \\
\hline & 25th & Median & 75th & 25th & Median & 75th \\
\hline Calcium & -1.8 & 1.1 & 4.0 & 1.4 & 3.7 & 8.0 \\
\hline Magnesium & 1.4 & 4.3 & 8.7 & 2.4 & 4.8 & 8.9 \\
\hline Sodium & 0 & 2.0 & 4.0 & .96 & 2.6 & 4.1 \\
\hline Potassium & -1.7 & 3.5 & 8.3 & 3.3 & 5.8 & 12 \\
\hline Ammonium & 0 & 4.2 & 7.1 & 1.8 & 5.4 & 10 \\
\hline Chloride & 1.4 & 2.4 & 4.2 & 1.8 & 2.4 & 4.3 \\
\hline Nitrate & .43 & 1.3 & 2.4 & .63 & 1.3 & 2.4 \\
\hline Sulfate & .22 & 1.5 & 2.3 & .86 & 1.5 & 2.3 \\
\hline Hydrogen ion & -10 & -6.4 & -2.3 & 4.3 & 6.5 & 10 \\
\hline Specific conductance & -7.5 & -2.6 & -.29 & 1.5 & 3.3 & 7.8 \\
\hline
\end{tabular}

measurement due to contact of the wet deposition with the sample buckets.

A Wilcoxon signed-rank test was used to test for bias in the SHE data for 2003. The null hypothesis for the test was: "The median of the SHE bucket-minus-bottle paired differences is zero." The Wilcoxon signed-rank test results identified no statistically significant $(\alpha=0.05)$ bias for any SHE constituents in 2003. No statistically significant bias was identified by the Wilcoxon signed-rank test regardless of whether samples were qualified as contaminated (denoted by a "C" code in the NADP/NTN database) or not, nor whether the buckets were dry or contained residual rinse water at the time that the SHE solution was added to the bucket.

\section{Comparison of Blind-Audit and SHE Program Variability and Bias Estimates}

Boxplots in figure 10 graphically depict the paired bucketminus-bottle concentration differences for all the major ions for the 2002 blind-audit program and the 2003 SHE program. Boxplots in figure 11 depict the paired bucket-minus-bottle concentration differences for $\mathrm{pH}$ and specific conductance for the 2002 blind-audit program and the 2003 SHE program. The boxplots show that there generally is less variability in the SHE data than in the blind-audit data. A Kruskal-Wallis analysis of variance test was used to test the null hypothesis, "There is no difference between the bucket-minus-bottle differences for the blind-audit and SHE programs." The results indicate that the blind-audit and SHE bucket-minus-bottle differences are significantly $(\alpha=0.05)$ different for magnesium, chloride, nitrate, and sulfate. Less variability in the SHE data was suspected to be due to submittal of the SHE bucket and bottle samples to CAL together, which increased the likelihood that samples were analyzed together; thus limiting analytical variability. The blindaudit samples typically arrived at CAL on different days. Consequently, the SHE data were regarded as more representative of the variability and bias introduced by sample handling and shipping than the blind-audit data.

The blind-audit and SHE data were evaluated for constituent concentration effects on data variability. The paired bucketminus-bottle differences were grouped by target concentrations, and a Kruskal-Wallis analysis of variance test was used to test the null hypothesis, "There is no relation between constituent concentration and the variability of the paired differences." For the 2002 blind-audit data, a significant $(\alpha=0.05)$ relation between the paired differences and concentration was found for magnesium, chloride, nitrate, and sulfate. For the 2003 SHE data, a significant $(\alpha=0.05)$ relation between the paired differences and concentration was found for all constituents except calcium. For both the blind-audit and SHE data, variability in the paired bucket-minus-bottle differences increased with increasing concentration.

The blind-audit and SHE data were evaluated for sample volume effects on data variability. The paired bucket-minusbottle differences were grouped by target concentrations, and a Kruskal-Wallis analysis of variance test was used to test the null hypothesis, "There is no relation between sample volume and the variability of the paired differences." A significant $(\alpha=0.05)$ relation between sample volume and the variability of the paired differences was found for magnesium, nitrate, and sulfate in the 2002 blind-audit data. A significant $(\alpha=0.05)$ 
Table 7. Selected statistics for paired bucket-sample minus bottle-sample concentration differences for sample-handling evaluation program during 2003.

[All units in milligrams per liter except hydrogen ion, in microequivalents per liter, and specific conductance, in microsiemens per centimeter at 25 degrees Celsius; $\mathrm{N}$, number of samples: Q1, 25th percentile in the data distribution; Q3, 75th percentile in data distribution; interquartile range, difference between upper and lower quartiles in distribution (Q3 minus Q1); na, not applicable; CAL, Central Analytical Laboratory; MDL, minimum detection limit; median NADP/NTN concentration, median value of all National Atmospheric Deposition Program/National Trends Network (NADP/NTN) measured concentrations for 2002 (Rothert, 2004)]

\begin{tabular}{|c|c|c|c|c|c|c|c|c|c|}
\hline \multirow{3}{*}{ Analyte } & \multicolumn{7}{|c|}{ Bucket-minus-bottle paired differences } & \multicolumn{2}{|c|}{ Data for comparison } \\
\hline & \multirow{2}{*}{$\mathrm{N}$} & \multirow{2}{*}{ Minimum } & \multirow{2}{*}{ Median } & \multicolumn{2}{|c|}{ Quartiles } & \multirow{2}{*}{ Maximum } & \multirow{2}{*}{ Interquartile range } & \multirow{2}{*}{$\begin{array}{l}\text { CAL } \\
\text { MDL }\end{array}$} & \multirow{2}{*}{$\begin{array}{c}2002 \text { median NADP/NTN } \\
\text { concentration }\end{array}$} \\
\hline & & & & 01 & 03 & & & & \\
\hline Calcium & 82 & -0.040 & 0.002 & -0.009 & 0.011 & 0.113 & 0.020 & 0.009 & 0.111 \\
\hline Magnesium & 81 & -.032 & .002 & 0 & .004 & .012 & .004 & .003 & .023 \\
\hline Sodium & 82 & -.009 & .004 & .001 & .009 & .328 & .008 & .003 & .053 \\
\hline Potassium & 82 & -.016 & .001 & -.001 & .003 & .065 & .004 & .003 & .017 \\
\hline Ammonium & 81 & -.130 & .010 & 0 & .030 & .110 & .030 & .020 & .240 \\
\hline Chloride & 80 & -.046 & .004 & -.001 & .010 & .119 & .011 & .005 & .108 \\
\hline Nitrate & 80 & -.098 & .009 & -.002 & .034 & .124 & .036 & .010 & 1.075 \\
\hline Sulfate & 80 & -.093 & .013 & -.006 & .037 & .169 & .043 & .010 & .998 \\
\hline Hydrogen ion & 96 & -8.19 & -1.15 & -2.95 & 0 & 3.44 & 2.95 & na & 11 \\
\hline Specific conductance & 96 & -5.8 & -.5 & -.9 & -.1 & 1.4 & .8 & .05 & 12 \\
\hline
\end{tabular}


Table 8. Relative and absolute bucket-minus-bottle differences calculated as a percentage of target concentration or value for each analyte during 2003 for sample-handling evaluation program.

\begin{tabular}{|c|c|c|c|c|c|c|}
\hline \multirow{3}{*}{ Analyte } & \multirow{2}{*}{\multicolumn{3}{|c|}{$\begin{array}{c}\text { Relative bucket-minus-bottle differences expressed as a } \\
\text { percentage of corresponding target bottle concentration } \\
\text { or value } \\
\text { Percentiles }\end{array}$}} & \multirow{2}{*}{\multicolumn{3}{|c|}{$\begin{array}{c}\begin{array}{l}\text { Absolute bucket-minus-bottle differences expressed as a } \\
\text { percentage of corresponding target bottle concentration } \\
\text { or value }\end{array} \\
\text { Percentiles }\end{array}$}} \\
\hline & & & & & & \\
\hline & 25th & 50th & 75th & 25th & 50th & 75th \\
\hline Calcium & -1.7 & 0.52 & 3.8 & 1.3 & 2.8 & 6.3 \\
\hline Magnesium & 0 & 2.2 & 5.7 & 1.2 & 3.0 & 7.1 \\
\hline Sodium & .44 & 1.4 & 3.3 & .88 & 1.8 & 3.6 \\
\hline Potassium & -1.2 & 1.3 & 4.0 & 1.2 & 2.6 & 6.0 \\
\hline Ammonium & 0 & 2.9 & 7.1 & 1.4 & 3.4 & 8.9 \\
\hline Chloride & -.28 & 1.1 & 3.0 & .68 & 1.2 & 3.7 \\
\hline Nitrate & -.12 & .43 & 1.6 & .38 & .76 & 1.8 \\
\hline Sulfate & -.24 & .38 & 1.3 & .31 & .70 & 1.4 \\
\hline Hydrogen ion & -8.8 & -5.2 & -1.6 & 2.0 & 6.0 & 9.0 \\
\hline Specific conductance & -4.6 & -2.5 & -.91 & 1.2 & 2.6 & 4.9 \\
\hline
\end{tabular}

relation between the variability of the paired differences and sample volume was found for magnesium, potassium, ammonium, chloride, nitrate, hydrogen ion, and specific conductance in the 2003 SHE data.

Boxplots of the paired differences grouped by sample volume for hydrogen ion and specific conductance are shown in figures 12 and 13, respectively. The boxplots in figures 12 and 13 show that similar results were obtained for the 2002 blindaudit data and the 2003 SHE data. Negative bias in hydrogen ion concentration paired differences and specific conductance paired differences were indicated for both programs (figs. 12 and 13). Therefore, the blind-audit and SHE data infer that reported NADP/NTN hydrogen-ion concentrations and specific conductance are slightly underestimated due to contact of the samples with the buckets and subsequent sample handling. The median paired hydrogen-ion concentration differences are increasingly negative with increasing sample volume for the blind-audit data. These data imply that more acidity is neutralized when more of the sample contacts a larger surface area of the bucket. However, this result was not observed for the SHE data.

The variability in the bucket-minus-bottle hydrogen-ion concentration differences increase with increasing sample volume for both the blind-audit and SHE data. Therefore, larger volume NADP/NTN samples inherently are prone to more variability from sample handling than smaller volume samples. Nonetheless, the SHE results indicate that the effects of sample handling and shipping do not appear to be environmentally significant and do not affect the analysis and interpretation of NADP/NTN data.

\section{Field-Audit Program}

The field-audit program is intended to help quantify chemical changes to NADP/NTN precipitation samples resulting from onsite exposure of the sample-collection apparatus. Estimates of variability and bias from the field-audit program data are assumed to represent the combined effects of onsite exposure of the sample plus sample handling and shipping. Every Tuesday morning at all sites across the NADP/NTN, the sample from the previous week is removed, and a new sample-collection bucket is installed in the Aerochem Metrics wetdeposition collector. The sample-collection bucket is covered with a foam pad attached to a rigid aluminum lid. The site operators' standard operating procedures (SOPs) specify monthly cleaning of the foam pad and lids and lid replacement every 12 months (Dossett and Bowersox, 1999). Nonetheless, when precipitation is not occurring, small amounts of windblown contamination can enter the bucket between the lid and the bucket. For example, small amounts of dust can enter the sample-collection bucket, particularly when the foam lid pad has started to wear and the seal between the bucket and lid is compromised. Small amounts of dust or debris can fall into the bucket when the lid is in motion. The net effect of these factors can change the chemistry of the precipitation sample.

Like the blind-audit and SHE programs, the field-audit program uses a paired sample design to detect statistically significant differences in analyte concentrations between solutions that come in contact with collector buckets and solutions that are not exposed to collector buckets. But unlike the blind-audit and SHE programs, the field-audit program measures the added effects of onsite exposure of the buckets. Although the blindaudit and SHE programs used clean buckets from the site operators' stock, the field-audit program uses buckets that have 


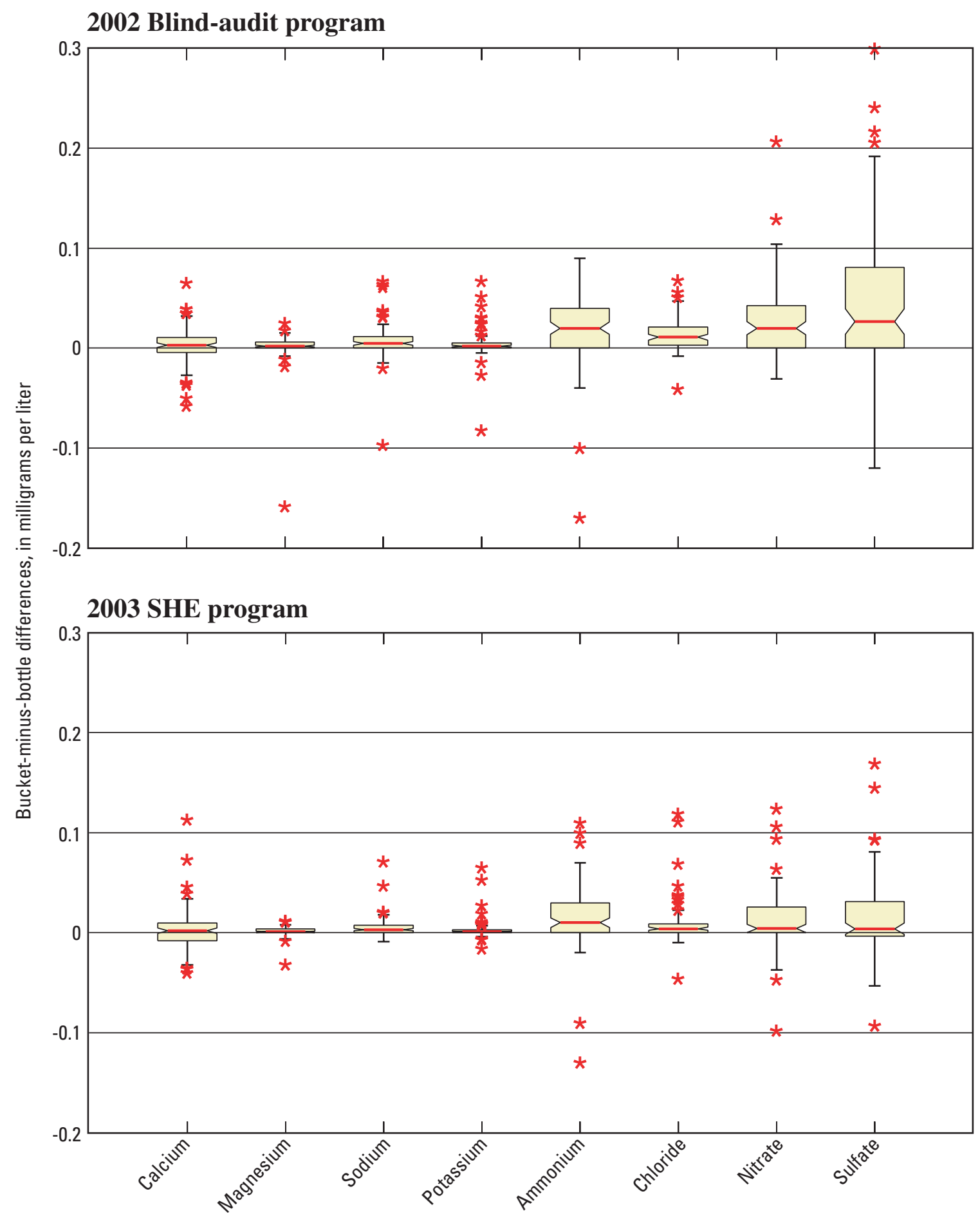

Figure 10. Comparison of distributions of bucket-minus-bottle concentration differences for 2002 blind-audit program and 2003 sample-handling evaluation (SHE) program (see figure 9 for explanation of boxplots). 


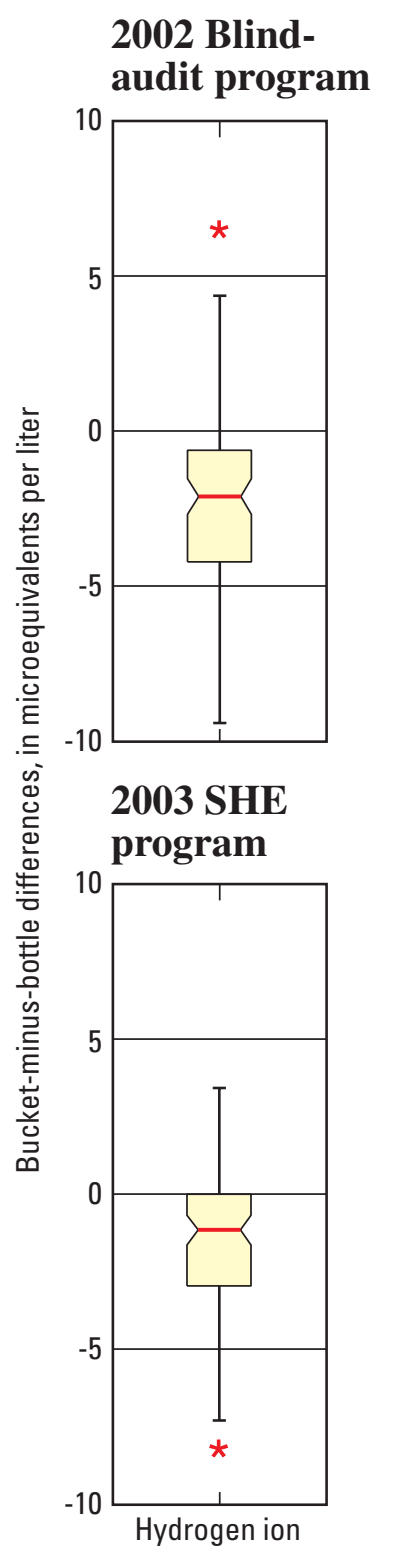

site operator is instructed to check the rain-gage chart to make sure the Aerochem Metrics collector lid did not open and uncover the wet-side bucket during the sampling period (Dossett and Bowersox, 1999).

If all of the requirements are met for processing a fieldaudit sample, the operator pours approximately 75 percent of the field-audit solution, supplied by USGS, into the samplecollection bucket. The operator swirls the solution in the bucket and seals the bucket with its lid. The solution is left in the sealed bucket for at least 24 hours, and then the solution is transfered to a clean 1-L sample bottle for shipment to CAL. The 25-percent portion of the sample remaining in the original sample bottle and the sample that resided in the bucket are both shipped to CAL for separate analysis.

Three different sample volumes of the solution matrices were distributed to operators of selected NADP/NTN sites (Berthouex and Brown, 1995) to investigate a possible relation between sample volume collected weekly at NADP/NTN sites and the amount of contamination introduced through onsite exposure and shipping and handling procedures. The program design used sample volumes of 250,500 , and $1,000 \mathrm{~mL}$ during 2002. The sample volumes were changed for 2003 to 250 , 1,000 , and $2,000 \mathrm{~mL}$ to better represent the quartile values for NADP/NTN sample volumes. Three different solution matrices were used, including ultrapure deionized water, solution SP2, and solution SP3 (table 4).

\section{Assessment of Field-Audit Data}

Samples submitted as part of the field-audit program are referred to as field-audit samples. Site operators had 1 year from the time of sample receipt to process their field-audit samples. For example, an operator receiving a sample in the fourth quarter had until the end of the fourth quarter of the following year to submit a field-audit sample. If the site was located in an area with a wet climate and extremely high humidity, the probability of a week with no lid openings was very low. Therefore, some of the field-audit samples that were shipped to wet or humid regions were not processed because some of the samplers in these regions recorded precipitation every week during the field-audit sample-processing period.

Of the 100 field-audit samples mailed to site operators in 2002, 58 were submitted for analysis by the end of the third quarter 2003. Of the 100 field-audit samples mailed to site operators in 2003, 58 were submitted for analysis by the second quarter of 2004. Overall, there were 116 complete sample pairs for the study period.

Prior to processing the field-audit sample, the site operators inspected the wet-side bucket to ensure that it was at least as dry as it was when it was installed the previous week; if there were a few drops of rinse water in the bucket when it was installed, it is conceivable that the water was still present. A bucket was considered "wet" if there was rinse water in the bucket when the bucket was installed and if the rinse water remained at the end of the week during which there were no lid

and submit a QC sample after a standard 7-day, Tuesday-to-

Tuesday sampling period when no precipitation occurred. The 

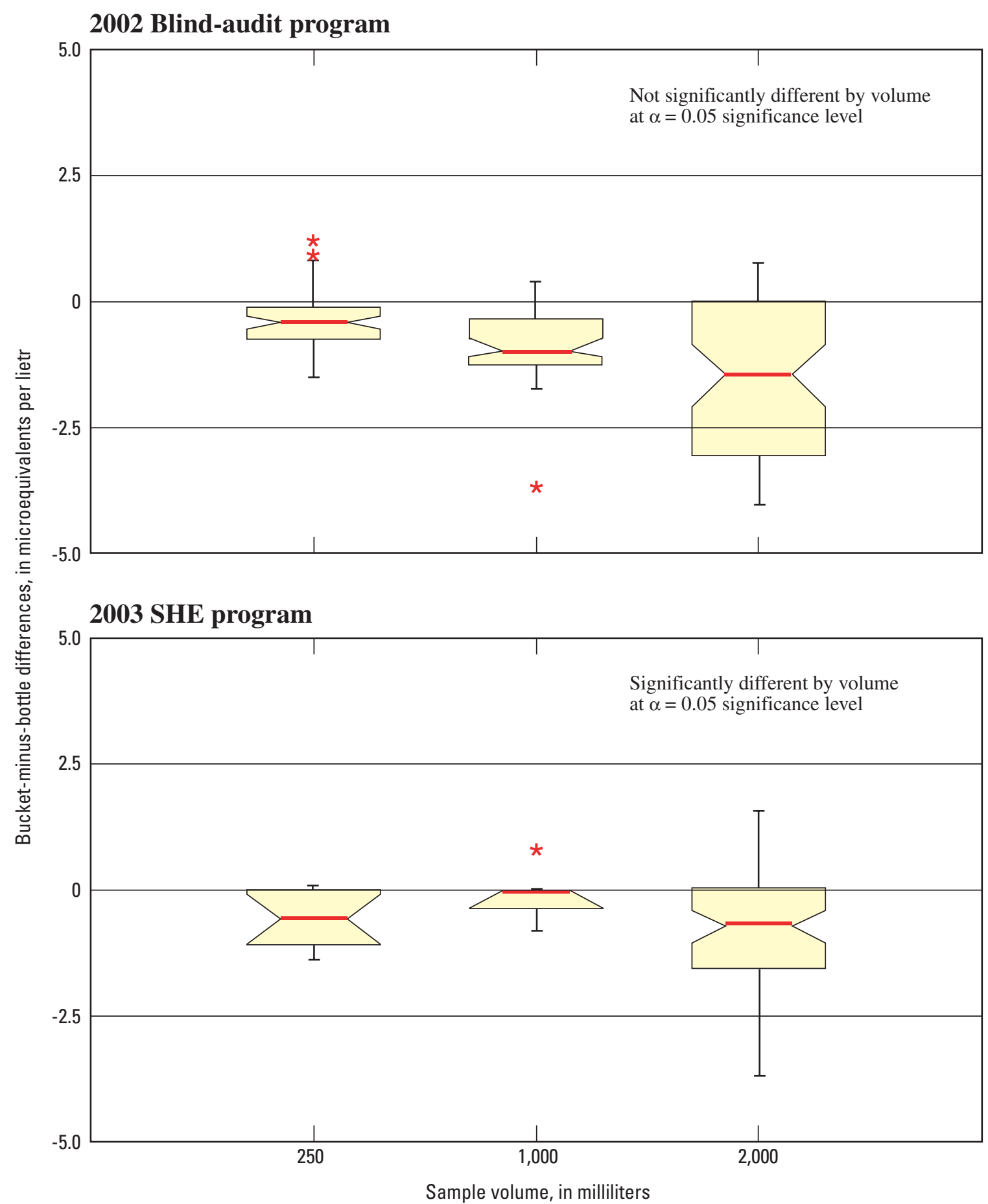

Figure 12. Relation of bucket-minus-bottle hydrogen-ion concentration differences and sample volume for 2002 blind-audit data and 2003 sample-handling evaluation (SHE) data (see figure 9 for explanation of boxplots).

openings. A bucket was considered "dry" if no rinse water was present. Regardless of the final reported sample chemistry, bucket and bottle field-audit samples containing extrinsic material were assigned a "C" code by CAL to indicate samples with visible contamination, such as detritus, dust, or other materials.

Eleven of the 116 field-audit samples were assigned " $\mathrm{C}$ " codes during the study period. Because field-audit samples can be poured either into a dry bucket or a bucket with rinse water, the data initially were separated depending on whether the sample data were coded as "wet" or "dry." Of the 116 samples analyzed, 14 were processed with rinse water present as "wet" buckets, and 102 were processed as "dry" buckets.

Before determining paired bucket-minus-bottle differences for the field-audit program, bucket and bottle values reported as less than the MDLwere set equal to one-half 


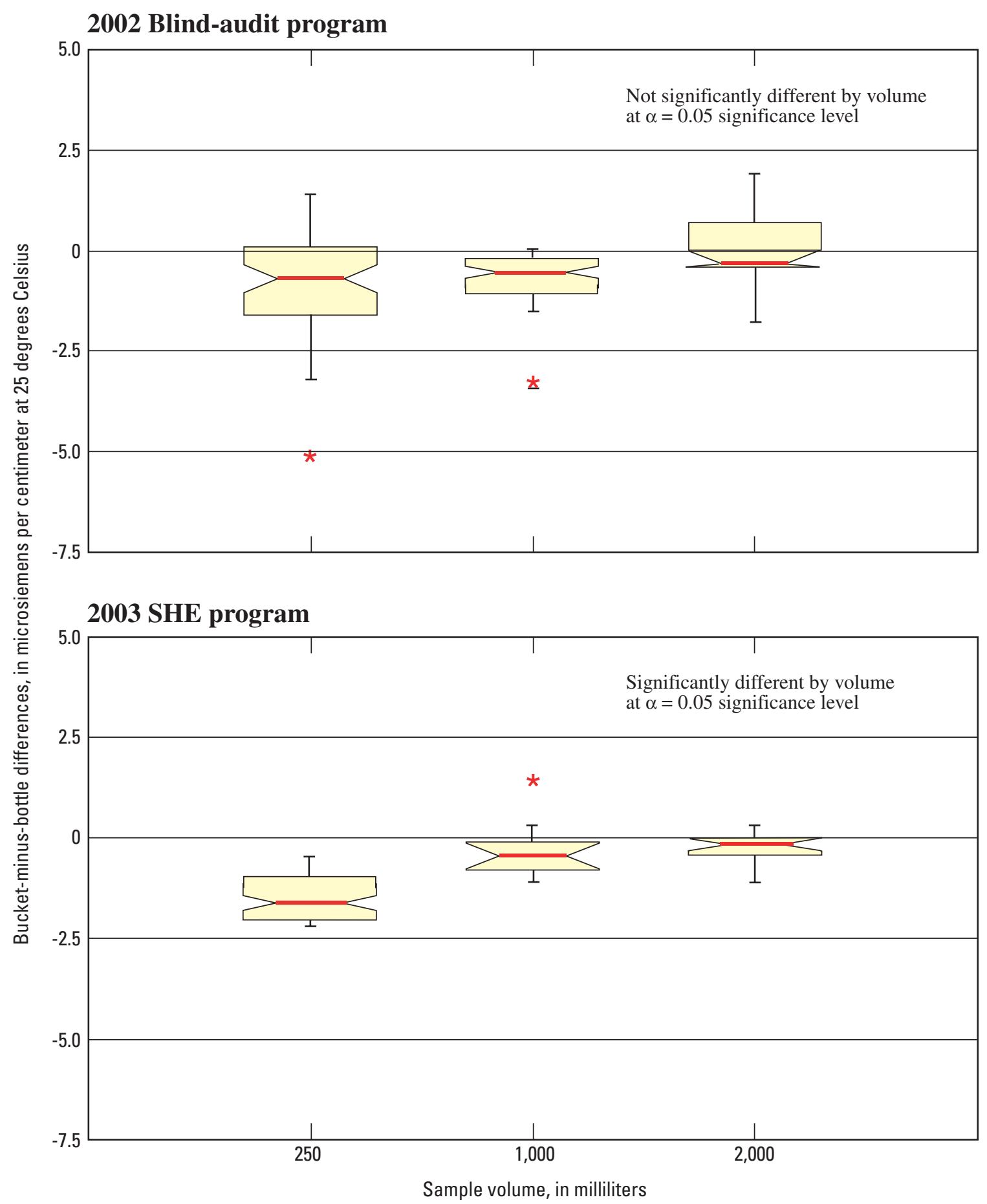

Figure 13. Relation of paired bucket-minus-bottle specific conductance differences and sample volume for 2002 blind-audit data and 2003 sample-handling evaluation (SHE) data (see figure 9 for explanation of boxplots). 
Samples prepared and packaged for distribution to operators of selected National Atmospheric Deposition Program/National Trends Network (NADP/NTN) sites by U.S. Geological Survey (USGS)

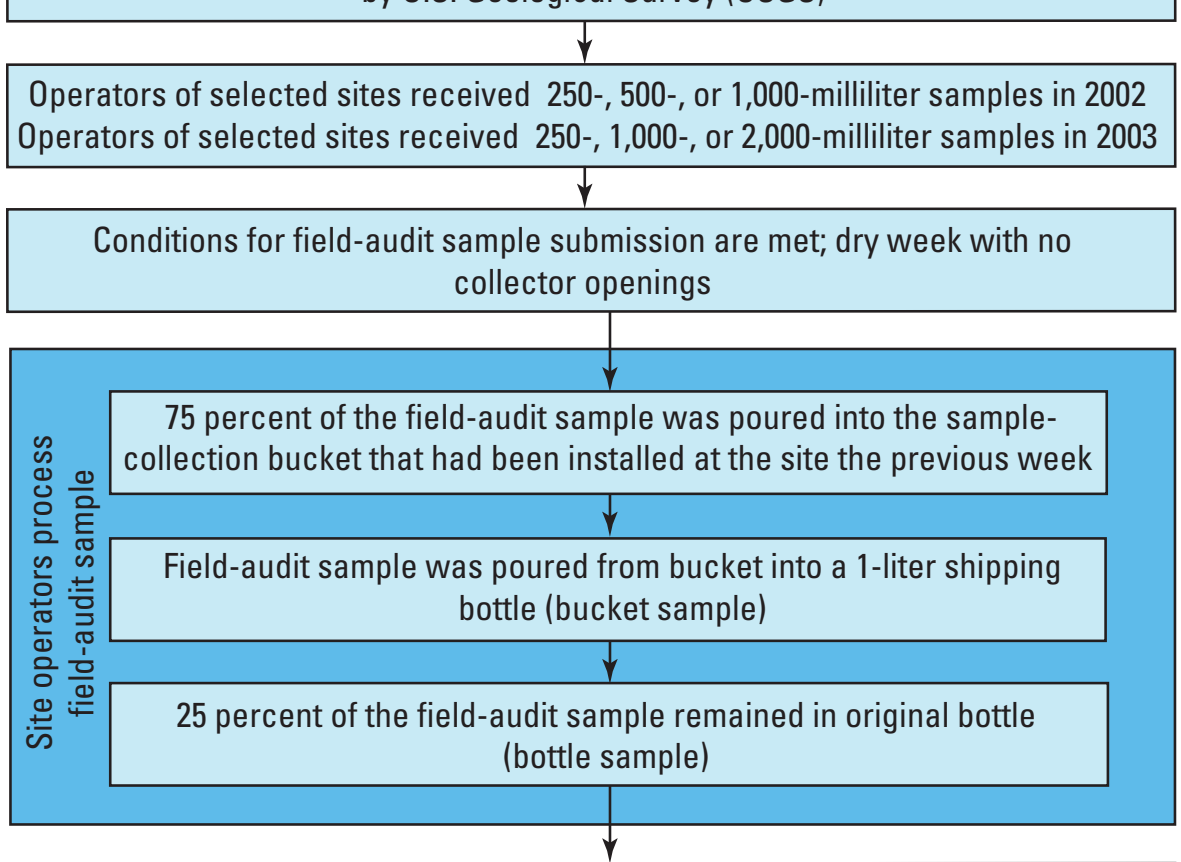

All field-audit samples shipped to Illinois State Water Survey, Central Analytical Laboratory (CAL)

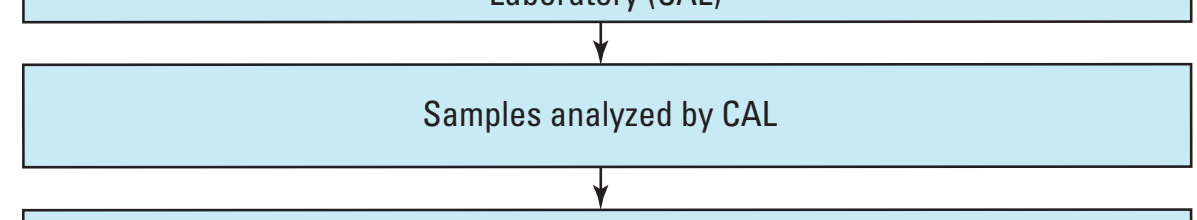

Analytical results for bucket and bottle samples compiled by USGS

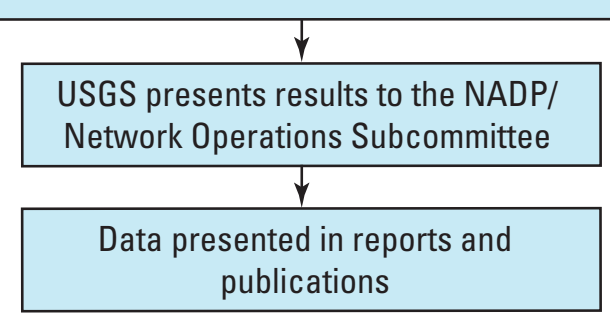

Figure 14. Field-audit program of U.S. Geological Survey.

the MDL for computation of statistics. Only minor differences resulted from how the less than MDL values were treated, such as substituting values reported less than MDLs with zero or with the MDLs themselves. Therefore, all of the values less than the MDL were set equal to one-half the MDL, which was a convenient substitution for purposes of capturing reasonable estimates of bias and variability.

\section{Assessment of Variability and Bias}

The Wilcoxon signed-rank test was used to compare the ion concentrations and specific conductance of the two groups of field-audit samples (C-coded samples and samples without $\mathrm{C}$ codes). For all constituents, no statistically significant differences were found at the $\alpha=0.05$ level during the study period for any of the analytes. Therefore, data from the 11 field-audit samples assigned $\mathrm{C}$ codes during the study period were included in the overall statistical analysis of field-audit samples.

The Wilcoxon signed-rank test also was used to evaluate if there were statistically significant differences in the field-audit results on the basis of the presence or absence of rinse water in the sample-collection buckets. Unlike previous years, a statistically significant $(\alpha=0.05)$ difference was indicated between the paired bucket-minus-bottle analyses for hydrogen ion in 
2002 for the wet-coded samples, but not in 2003, nor for any other analyte during the study period.

A statistical summary of paired bucket-minus-bottle results for the "wet" and "dry" field-audit samples is shown in table 9. In most instances, the median values for the differences between bucket and bottle samples were similar for the "wet"coded samples where rinse water was present and for the "dry"coded samples where rinse water was absent. The differences between the two groups was small, and the interquartile ranges and median values also were similar for the "wet" and "dry" sample groups. The 2002-03 median bucket-minus-bottle paired differences obtained for the "dry"-coded field-audit data (table 9) were less than 10 percent of the median concentrations determined for all NADP/NTN concentration measurements made during 2002 (table 5).

The interquartile ranges of the field-audit hydrogen ion concentration differences were between -1.36 and $-0.18 \mu \mathrm{eq} / \mathrm{L}$ for the wet-coded samples and between -1.30 and $0 \mu \mathrm{eq} / \mathrm{L}$ for dry-coded samples (table 9). The interquartile ranges for hydrogen ion concentration differences for wet and dry samples were slightly larger for the study period than for 2000-2001

(Wetherbee and others, 2004). The field-audit program data for hydrogen-ion concentrations for the study period indicated that exposure of NADP/NTN wet-deposition samples to onsite conditions generally tended to neutralize the acidity of the samples but typically by less than $1.0 \mu \mathrm{eq} / \mathrm{L}$ as indicated by the median bucket-minus-bottle differences in table 9 .

Boxplots graphically depict the paired bucket-minusbottle concentration differences for all the major ions (fig. 15) and for hydrogen ion and specific conductance (fig. 16) for the field-audit program during 2002-03. Figure 15 shows that the median bucket-minus-bottle differences for all major-ion concentrations were greater than zero and near zero, indicating that onsite exposure of the samples tended to slightly increase the concentration of most of the analytes. The estimated increase in major-ion concentration was typically less than $10 \mu \mathrm{g} / \mathrm{L}$ for all analytes. The median differences were less than 10 percent of NADP/NTN median values for 2002 data.

Results of a Kruskal-Wallis analysis of variance test indicated a statistically significant $(\alpha=0.05)$ relation between the solution target values and the magnitude of paired field-audit bucket-minus-bottle differences for nitrate, sulfate, and specific conductance during 2002 and for magnesium, sodium, nitrate, sulfate, and specific conductance during 2003. The KruskalWallis analysis of variance results combined with the boxplots of the paired differences in figures 15 and 16 indicate that onsite exposure, sample handling, and shipping caused less than $\mathrm{a}+20-\mu \mathrm{g} / \mathrm{L}$ change to nitrate and sulfate concentrations and a less than $-1-\mu \mathrm{S} / \mathrm{cm}$ change to specific conductance during the study period.

\section{Low-Level Contamination Detection in Ultrapure Deionized-Water Samples}

The number of ultrapure deionized-water (DI) samples processed and analyzed as part of the field-audit program was 24 in 2002 and 18 in 2003 (table 10). The most common analyte detected greater than the MDL during 2002 in DI samples was chloride, which was detected in 75 percent of the onsiteexposed bucket samples and in 13 percent of the minimally handled bottle samples. During 2003, the most common analyte detected greater than the MDL in DI samples was ammonium, which was detected in 44 percent of the onsite-exposed bucket samples but not in the minimally handled bottle samples (table 10). Calcium was the second-most detected constituent

Table 9. Selected statistics for paired bucket-sample minus bottle-sample concentration differences for field-audit program during 2002-03 for wet- and dry-coded samples.

[All units in milligrams per liter except hydrogen ion, in microequivalents per liter, and specific conductance, in microsiemens per centimeter at 25 degrees Celsius; Q1, the lower quartile in the data distribution; Q3, the upper quartile in the data distribution]

\begin{tabular}{|c|c|c|c|c|c|c|}
\hline \multirow{3}{*}{ Analyte } & \multicolumn{3}{|c|}{ Wet samples } & \multicolumn{3}{|c|}{ Dry samples } \\
\hline & \multirow{2}{*}{ Median } & \multicolumn{2}{|c|}{ Quartiles } & \multirow{2}{*}{ Median } & \multicolumn{2}{|c|}{ Quartiles } \\
\hline & & Q1 & 03 & & 01 & Q3 \\
\hline Calcium & 0.010 & 0 & 0.018 & 0.008 & 0.003 & 0.015 \\
\hline Magnesium & 0 & -.001 & .001 & .001 & 0 & .003 \\
\hline Sodium & .003 & 0 & .007 & .002 & 0 & .005 \\
\hline Potassium & 0 & -.001 & .004 & .001 & 0 & .004 \\
\hline Ammonium & .005 & 0 & .010 & 0 & 0 & .010 \\
\hline Chloride & .008 & .001 & .016 & .007 & 0 & .015 \\
\hline Nitrate & .002 & 0 & .026 & .010 & 0 & .032 \\
\hline Sulfate & .012 & 0 & .032 & 0 & -.001 & .012 \\
\hline Hydrogen ion & -.473 & -1.36 & -.180 & -.372 & -1.30 & 0 \\
\hline Specific conductance & 0 & -.4 & .3 & -.1 & -.8 & .2 \\
\hline
\end{tabular}




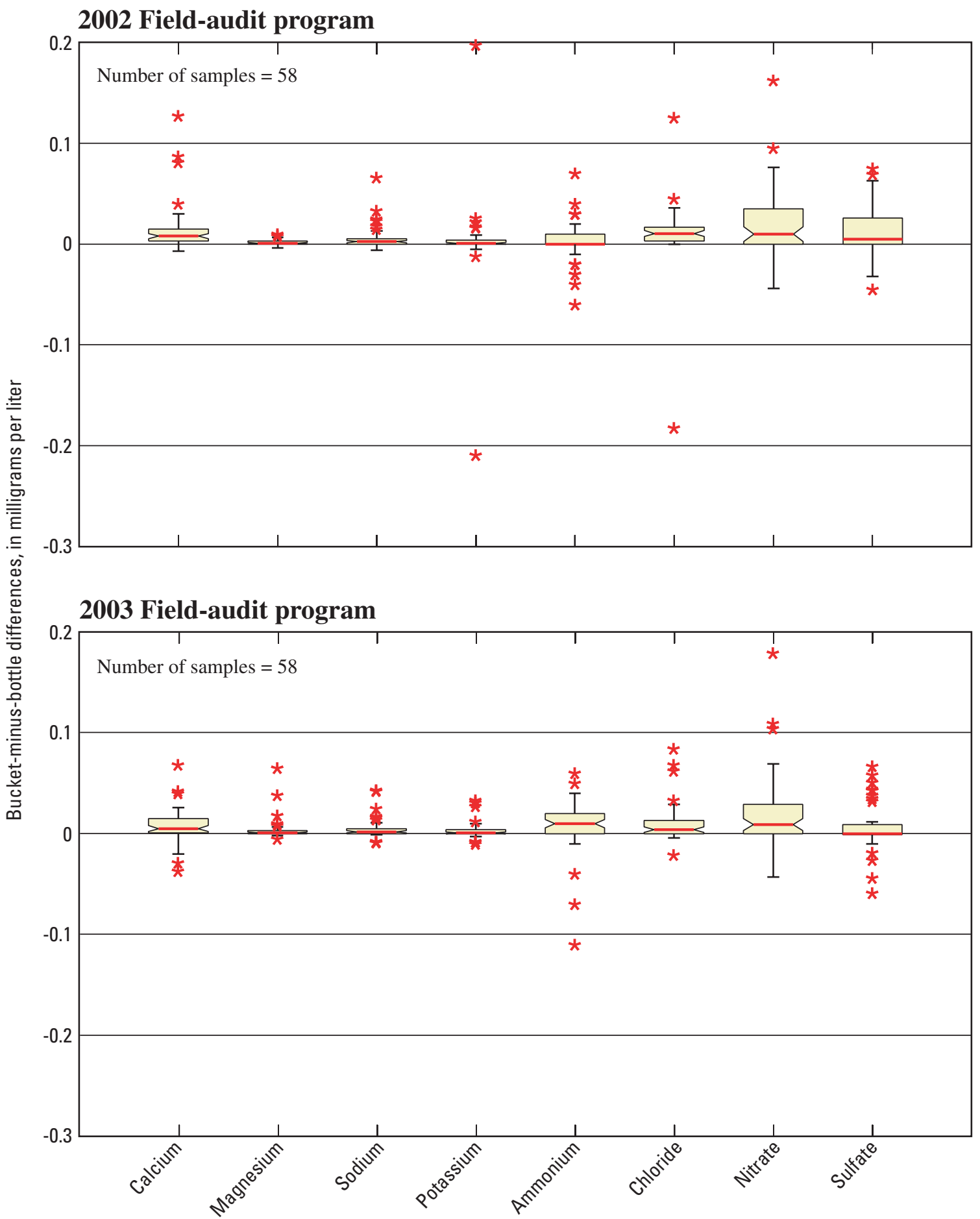

Figure 15. Bucket-minus-bottle concentration differences for 2002-03 field-audit major ions (see figure 9 for explanation of boxplots).

in the onsite-exposed bucket samples in 2003, occurring in 39 percent of the samples.

The number of detections of each analyte in the minimally handled bottle samples during 2002 was similar to the number of detections in the bottle samples during 2003, but slightly less contamination was indicated during 2003 than 2002 except for ammonium. There were more detections of all major-ion constituents in the onsite-exposed bucket samples than in the minimally handled bottle samples during the study period, which indicates that differences in the number of detections in the onsite-exposed bucket samples collected during 2002 and 2003 


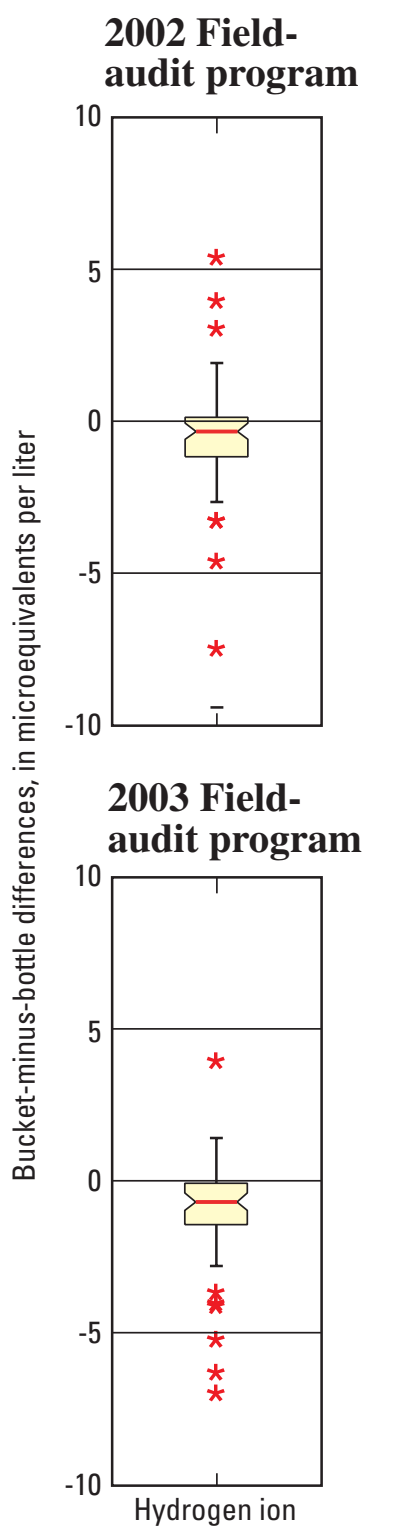

audit program during the study period was ammonium (5.4 percent) (table 11 ).

As in previous years, a minor positive bias was measured for the bucket samples for all analytes except for hydrogen ion and specific conductance during the study period. The negatively biased results for conductivity appear counterintuitive because addition of the major ions should increase the specific conductance of the solution. However, hydrogen-ion activity can account for a substantial portion of specific conductance, especially in low ionic strength solutions.

\section{Relation of Sample Volume and Field-Audit Data Variability and Bias}

To determine if there was a statistically significant relation between paired field-audit differences and sample volume, a Kruskal-Wallis analysis of variance test was performed. The null hypothesis, "There is no difference in the variability of the paired bucket-minus-bottle concentration differences between samples pooled by sample volume for the field-audit data," was tested using the Kruskal-Wallis analysis of variance. The analysis of variance results for the study period indicate a significant $(\alpha=0.05)$ relation between paired field-audit sample concentration or value differences and sample volume for magnesium, nitrate, and sulfate during 2002 and for calcium, magnesium, sodium, chloride, nitrate, sulfate, and specific conductance during 2003. When paired differences for major ions were converted to units of mass by multiplying the concentration by the sample volume, the outcome of the Kruskal-Wallis analysis of variance indicated a significant $(\alpha=0.05)$ difference only for nitrate during 2003.

The results obtained for the 2002 data were similar to the results obtained for the field-audit program from 1997 to 2001 (Gordon and others, 2003; Wetherbee and others, 2004). However, during 2003, a significant $(\alpha=0.05)$ relation between the magnitude of the paired differences and sample volume was observed for calcium and sodium for the first time in the 7-year history of the field-audit program. The sample-volume range increased to include 2,000-mL samples in 2003. The 2,000-mL sample volume contacted a larger surface area of the bucket than the smaller sample volumes. Therefore, presumably more contaminants could be incorporated into the 2,000-mL sample. Boxplots of the paired field-audit bucket-minus-bottle differences for all analytes indicate that the data for the largest sample volumes $(1,000 \mathrm{~mL}$ in 2002 and $2,000 \mathrm{~mL}$ in 2003) generally had the greatest variability, except for specific conductance (figs. 17, 18, and 19). Because median sample volumes are site specific due to climatic differences throughout NTN (Nilles and others, 1993; Gordon, 1999; Wetherbee and others, 2005), it is reasonable to expect that sample-volume differences could affect the spatial distribution in data variability throughout NTN.

In general, the boxplots of the paired bucket-minus-bottle differences coupled with the results of the Kruskal-Wallis analysis of variance show that minor amounts of contaminant
2004) for all analytes except calcium, ammonium, and specific conductance. The analyte with the largest MAE for the field-

\section{matl analytes, was within a range of -3.7 to 3.1 percent (table 11).} MAEs, estimated by the absolute values of the bucket-minus bottle differences, were smaller for the field-audit data obtained during 2002-03 than during 2000-2001 (Wetherbee and others, 
Table 10. Number of determinations exceeding minimum detection limit for 24 ultrapure deionized-water samples submitted in 2002 and for 18 ultrapure deionized-water samples submitted in 2003 as part of field-audit program.

[CAL MDL, Central Analytical Laboratory minimum detection limit obtained from Rothert (2004); mg/L, milligrams per liter]

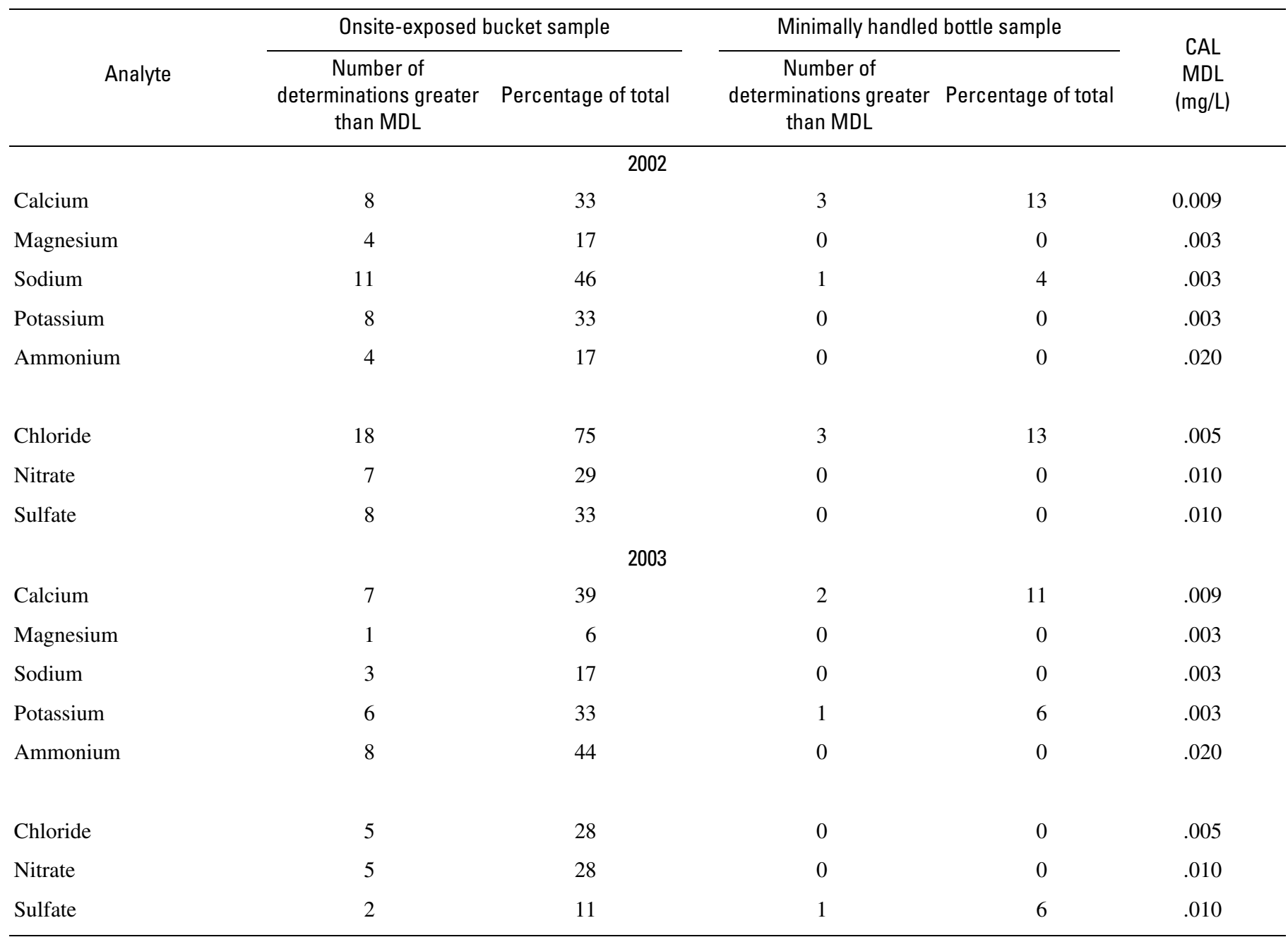

material were entrained into the solutions from the onsiteexposed buckets. The data also show some loss of constituents by virtue of the negative values for the bucket-minus-bottle concentration differences. It is unclear how much of the apparent loss was due to adsorption to the buckets and (or) other chemical reactions. Analytical variability for hydrogen-ion concentrations is estimated herein to be less than 1 percent (see "Interlaboratory-Comparison Program" section).

Constituents that appear to be introduced to the precipitation samples by onsite exposure of the sample buckets, evidenced by positive bucket-minus-bottle differences, are calcium, magnesium, sodium, potassium, chloride, nitrate, and sulfate. The positive bias that results from the minor amount of contamination appears to affect the chemical results by as much as +11 percent, which is the 75 th percentile relative percentage difference shown in table 11 for calcium. Despite this evidence of apparent addition of contaminants to the samples from onsite exposure, the median relative bucket-minus-bottle difference for specific conductance is negative, indicating loss of ions from solution (table 11), which might be associated with hydrogen-ion loss. Hydrogen-ion loss due to onsite exposure and sample handling also appears to impart a bias of approximately -3.7 percent, as indicated by the median relative percentage bias shown in table 11. Like all environmental data, fieldaudit data contain a portion of the variability introduced by laboratory analysis.

\section{Interlaboratory-Comparison Program}

The two objectives of the interlaboratory-comparison program are (1) to estimate the analytical variability and bias of CAL and (2) to help facilitate integration of data from various monitoring networks - not accounting for the different onsite protocols used by different monitoring networks. A flowchart 
Table 11. Relative and absolute bucket-minus-bottle differences calculated as a percentage of target concentration or value for each analyte in field-audit program during 2002-03.

\begin{tabular}{|c|c|c|c|c|c|c|}
\hline \multirow{3}{*}{ Analyte } & \multirow{2}{*}{\multicolumn{3}{|c|}{$\begin{array}{c}\text { Relative bucket-minus-bottle differences, expressed as a } \\
\text { percentage of corresponding target bottle concentration } \\
\text { or value } \\
\text { Percentiles }\end{array}$}} & \multirow{2}{*}{\multicolumn{3}{|c|}{$\begin{array}{c}\text { Absolute bucket-minus-bottle differences, } \\
\text { expressed as a percentage of corresponding } \\
\text { target bottle concentration or value }\end{array}$}} \\
\hline & & & & & & \\
\hline & 25 th & 50th & 75th & 25th & 50th & 75th \\
\hline Calcium & 0.22 & 3.1 & 11 & 1.7 & 4.1 & 13 \\
\hline Magnesium & 0 & 2.0 & 6.1 & 1.4 & 2.9 & 6.1 \\
\hline Sodium & -.9 & .4 & 3.6 & .28 & 1.4 & 3.6 \\
\hline Potassium & -4.4 & 1.7 & 10 & 0 & 4.4 & 13 \\
\hline Ammonium & -1.8 & 0 & 7.1 & 1.8 & 5.4 & 7.1 \\
\hline Chloride & 1.1 & 2.7 & 5.8 & 1.2 & 2.9 & 6.0 \\
\hline Nitrate & .17 & .93 & 2.0 & .46 & 1.1 & 2.0 \\
\hline Sulfate & -.30 & .26 & 1.6 & .30 & .94 & 2.0 \\
\hline Hydrogen ion & -8.8 & -3.7 & 0 & 2.2 & 5.0 & 9.9 \\
\hline Specific conductance & -6.1 & -1.2 & 1.7 & 1.6 & 5.3 & 13 \\
\hline
\end{tabular}

of the interlaboratory-comparison program is shown in figure 20. Eight laboratories participated in the interlaboratorycomparison program during the study period. Each of the eight participating laboratories received four samples from USGS every 2 weeks for chemical analysis, except for Shepard Analytical (Simi Valley, California), which received one-half of the sample load. The samples were synthetic precipitation solutions, ultrapure deionized water, or natural precipitation. The laboratories submitted chemical-analysis data to USGS for evaluation and reporting. Data from each laboratory were compared against most probable values (MPVs) and evaluated within statistical limits using control charts. The medians of all of the concentration values obtained from the eight laboratories were considered to be the MPVs for solutions used in the interlaboratory-comparison program. MPVs for the synthetic precipitation solutions are listed in table 12. Control charts and other data summaries are posted on the World Wide Web for each laboratory's use at http://bqs.usgs.gov/precip/ project_overview/interlab/ilab_intro.htm

The following laboratories participated in the interlaboratory-comparison program during 2002 through 2003: (1) Acid Deposition and Oxidant Research Center (ADORC) in Niigatashi, Japan; (2) Illinois State Water Survey, Central Analytical Laboratory (CAL) in Champaign, Illinois; (3) MACTEC, Inc. (formerly ESE) in Gainesville, Florida; (4) Ontario Ministry of Environment and Energy, Dorset Research Facility (MOEE) in Dorset, Ontario, Canada; (5) Meteorological Service of Canada (MSC) in Downsview, Ontario, Canada; (6) Norwegian Institute for Air Research (NILU) in Kjeller, Norway; (7) New York State Department of Environmental Conservation (NYSDEC) in Albany, New York; and (8) Shepard Analytical (SA) in Simi Valley, California. Many of the major global atmosphericdeposition monitoring networks are united into this single program designed to measure laboratory data quality, which aids in data comparison between monitoring networks worldwide.

Many of the samples used in the interlaboratorycomparison program were made from stock solutions prepared by High Purity Standards (HPS), Charleston, South Carolina, which were diluted, bottled, labeled, and shipped by USGS to the participating laboratories. Three sources of samples were used in the interlaboratory-comparison program during 2002 through 2003: (1) natural wet-deposition samples collected at NADP/NTN sites and blended by CAL, which were sent to USGS for bottling and shipping to the interlaboratorycomparison laboratories (Latysh and Wetherbee, 2005); (2) synthetic precipitation standard reference samples prepared by HPS and diluted and bottled by USGS; and (3) ultrapure deionized-water samples prepared by USGS. Table 3 contains information on the preparation of the solutions made either by HPS, USGS, or CAL, as well as the names of solutions with concentrations traceable to NIST reference materials (NISTtraceable samples).

Natural wet-deposition samples collected at NADP/NTN sites with sufficient volume (samples in excess of $750 \mathrm{~mL}$ ) were selected randomly by CAL for use in the interlaboratorycomparison program. These samples, collectively called CALNAT samples, were bottled in $60-$ and $125-\mathrm{mL}$ polyethylene bottles and shipped in chilled, insulated containers to USGS in Denver, Colorado. USGS keeps CALNAT samples refrigerated and ships the samples on ice to participating laboratories within a few weeks of receiving them. CALNAT samples are not preserved, and a maximum sample hold time is not specified for the nutrient constituents in these samples. Variability in hold times among the different laboratories could have an effect on the variability in the nutrient data among laboratories analyzing CALNAT samples because the nutrients may be used by 
2002
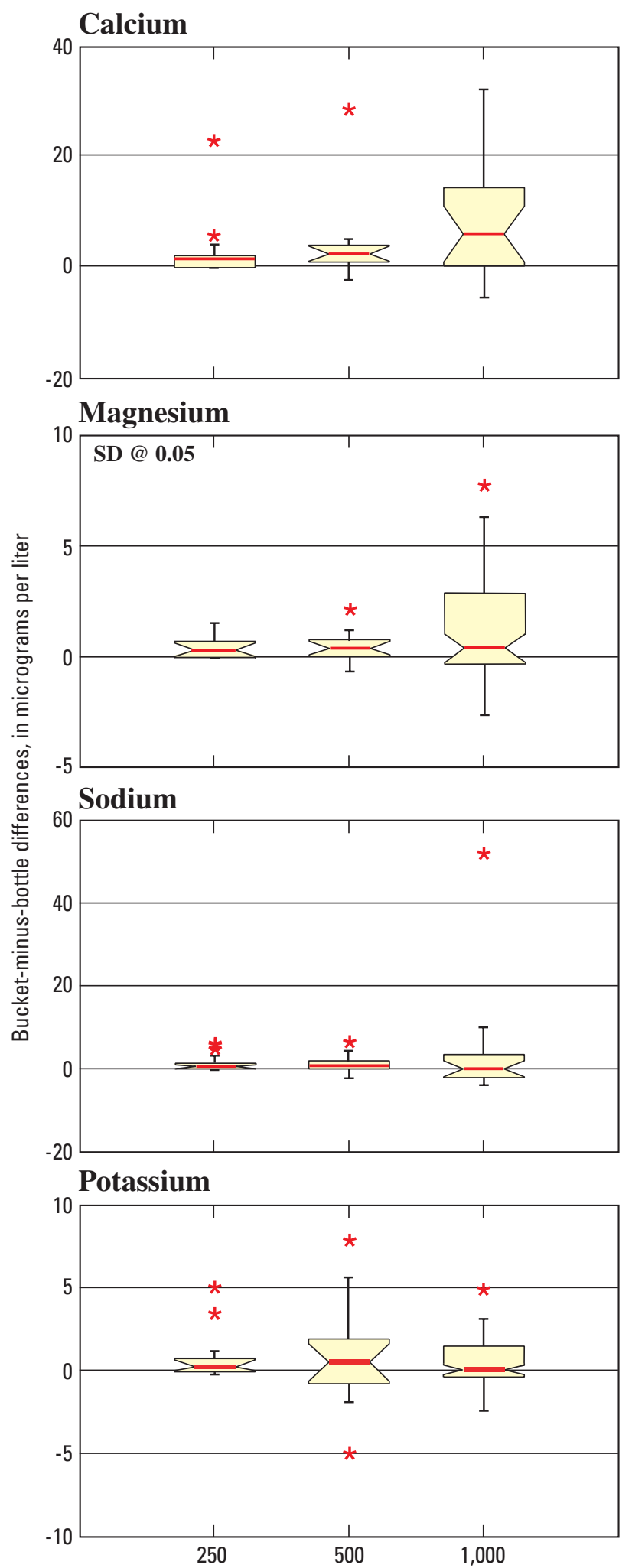

Calcium

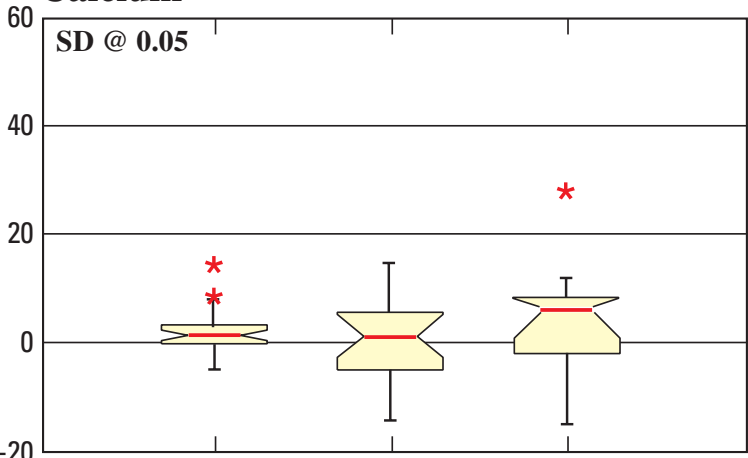

Magnesium
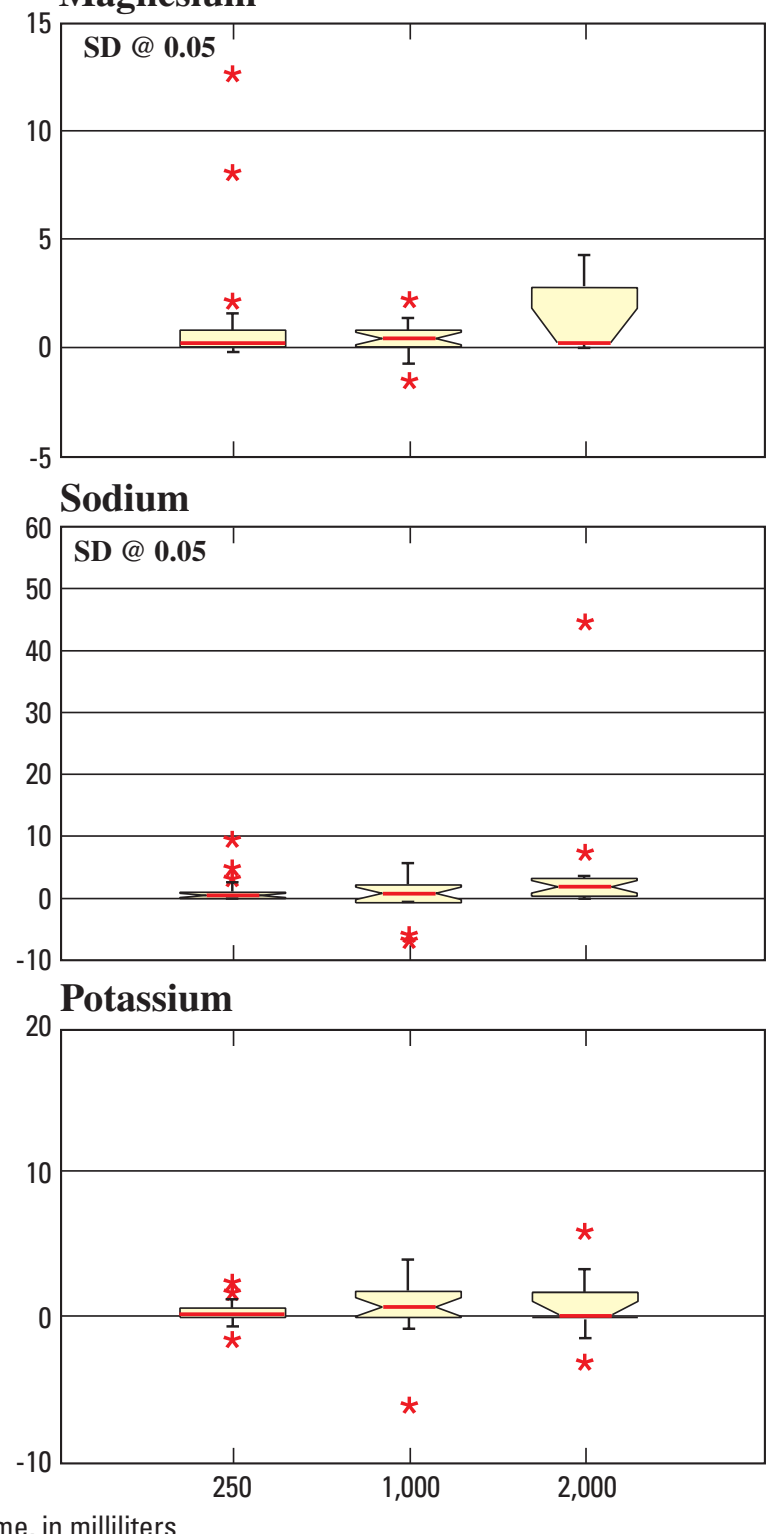

EXPLANTION

SD @ 0.05-Significant difference between different volumes with 95-percent confidence

Figure 17. Relation of paired bucket-minus-bottle major cation concentration differences and sample volume for 2002-03 field-audit data (see figure 9 for explanation of boxplots). 
2002

2003
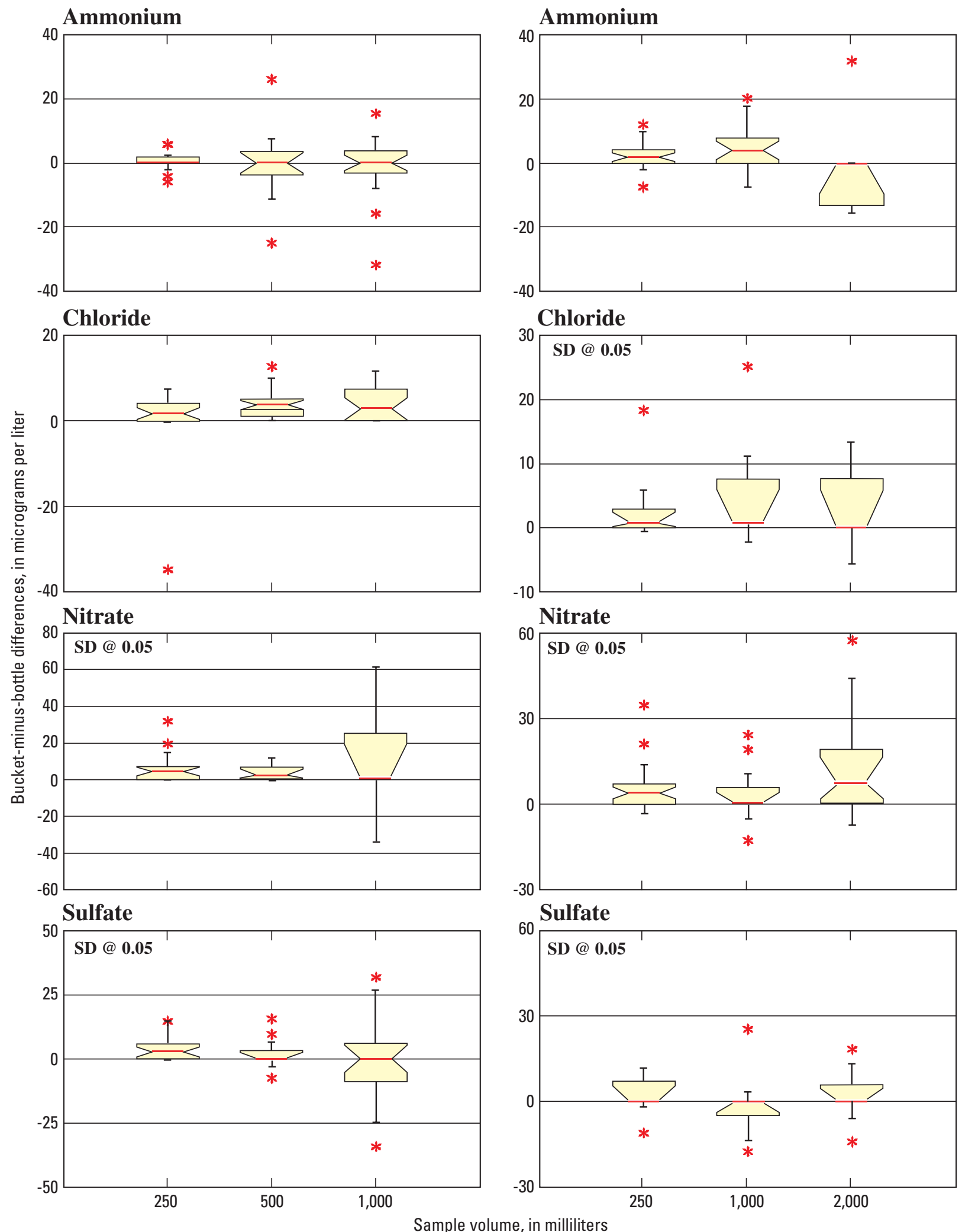

\section{EXPLANTION}

SD @ 0.05-Significant difference between different volumes with 95-percent confidence

Figure 18. Relation of paired bucket-minus-bottle ammonium and major anion concentration differences and sample volume for 2002-03 field-audit data (see figure 9 for explanation of boxplots). 
2002
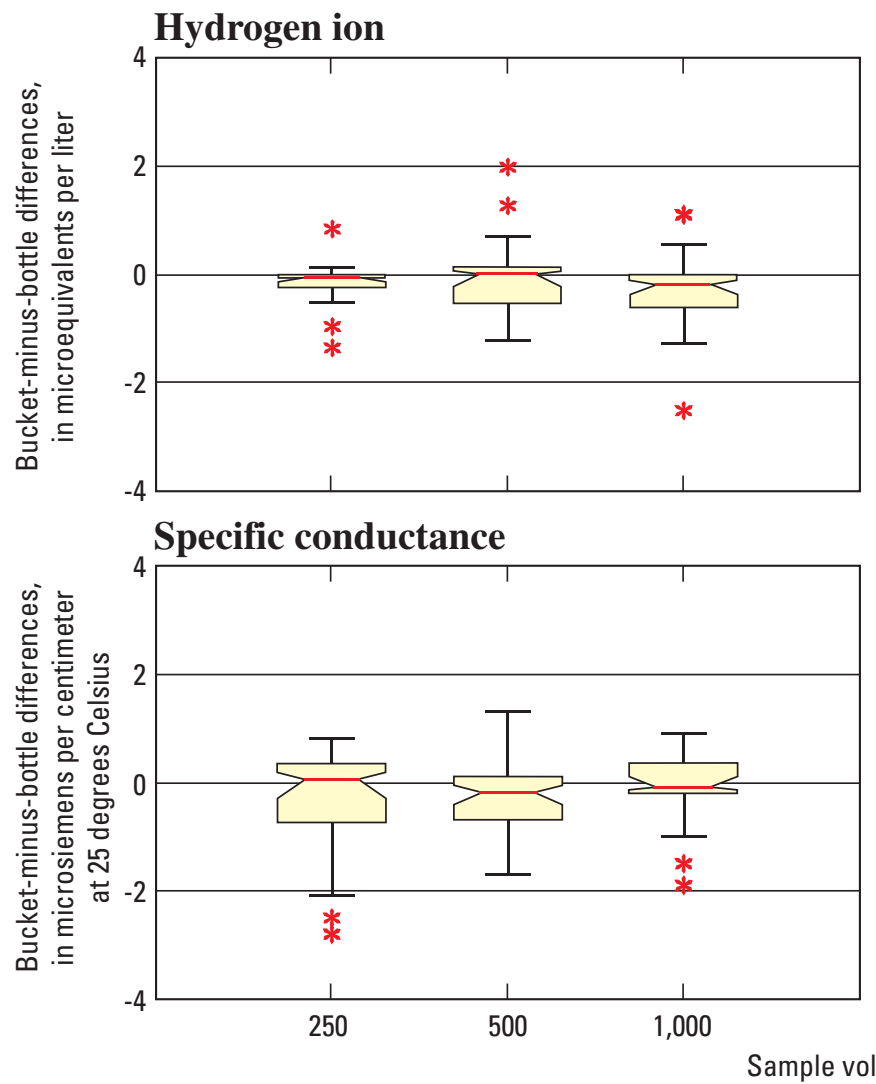

2003

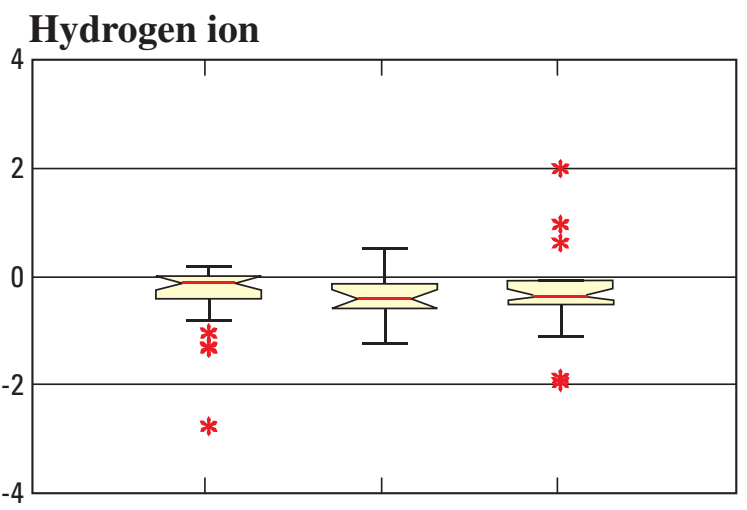

Specific conductance

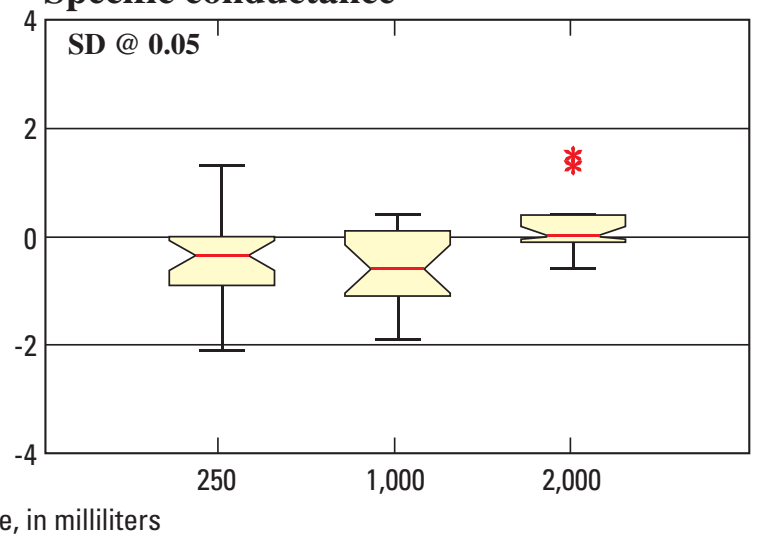

\section{EXPLANTION}

SD @ 0.05-Significant difference between different volumes with 95-percent confidence

Figure 19. Relation of paired bucket-minus-bottle differences for hydrogen-ion concentration and specific conductance to sample volume for 2002-03 field-audit data (see figure 9 for explanation of boxplots).

bacteria, which can affect ammonium, nitrate, and sulfate concentrations in the samples (Tchobanoglous and Schroeder, 1987).

During 2002-03, seven of the eight participating laboratories received 104 samples annually. Of the 104 samples, 52 were CALNAT samples. Of the remaining samples, 44 were synthetic precipitation solutions made by HPS and diluted by USGS, which were referred to as: SP1 solution; (9 samples); SP2 solution, (9 samples); SP5 solution, (8 samples); SP97 solution, (9 samples); and SP98c solution, (9 samples). Eight samples were ultrapure deionized-water samples bottled by USGS. SA received only the synthetic precipitation solution samples and ultrapure deionized-water samples.

\section{Variability and Bias}

Variability was evaluated for each laboratory and each analyte by comparing the distributions of the differences between reported results and MPVs. Analyte concentrations reported as less than MDL were set equal to one-half MDL before computing differences for each laboratory.

Evaluation of the interlaboratory variability was done in several steps. First, the differences between the reported results and MPVs were calculated as follows:

$$
\text { Concentration difference }=\mathrm{C}_{\mathrm{lab}}-\mathrm{MPV} \text {, }
$$

where $\mathrm{C}_{\text {lab }}=$ concentration reported by a laboratory for an analyte in a test solution, and

MPV = most probable value, which is the median of all concentration analyses submitted by participating laboratories for a test solution during 2002-03.

Next, the differences were pooled for all eight laboratories to obtain the overall f-pseudosigma of the differences $\left(\mathrm{fps}_{\mathrm{o}}\right)$, which is the (75th percentile of all concentration differences 25 th percentile of all concentration differences) divided by 1.349. Then, the f-pseudosigma for the differences was calculated for each laboratory's data $\left(\mathrm{fps}_{\mathrm{lab}}\right)$, which is the 


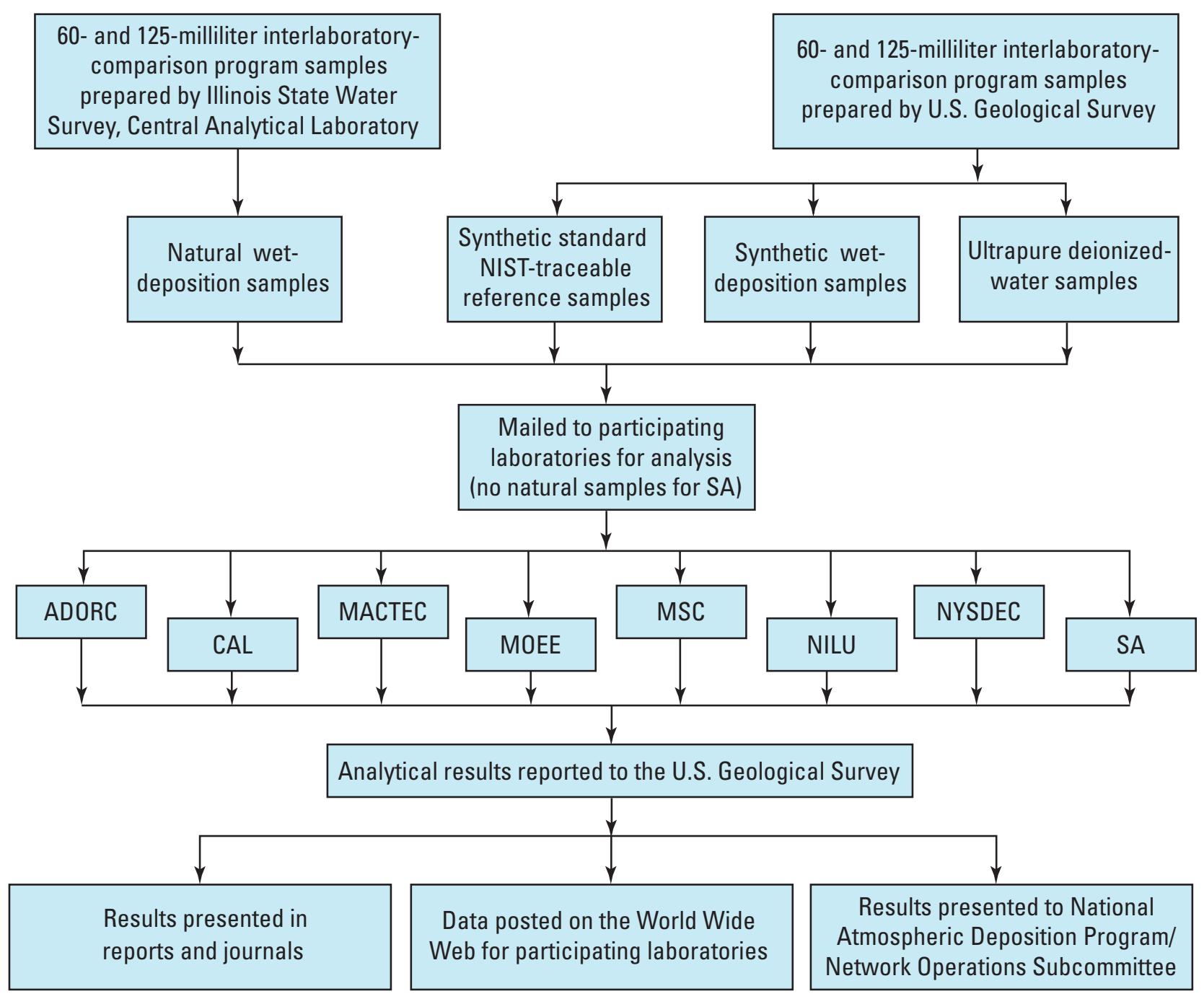

\section{EXPLANATION}

NIST: $\quad$ National Institute of Standards and Technology

ADORC: Acid Deposition and Oxidant Research Center, Niigata-shi, Japan

CAL: $\quad$ Central Analytical Laboratory, Illinois State Water Survey, Champaign, Illinois

MACTEC: MACTEC, Inc., Gainesville, Florida

MOEE: Ontario Ministry of Environment and Energy, Dorset Research Facility, Dorset, Ontario, Canada

MSC: $\quad$ Meteorological Service of Canada, Downsview, Ontario, Canada

NILU: $\quad$ Norwegian Institute for Air Research, Kjeller, Norway

NYSDEC: New York State Department of Environmental Conservation, Albany, New York

SA: $\quad$ Shepard Analytical, Simi Valley, California

Figure 20. Interlaboratory-comparison program of U.S. Geological Survey.

(75th percentile of concentration differences -25 th percentile of concentration differences) divided by 1.349. Finally, the ratio of f-pseudosigma of differences for each laboratory to the overall f-pseudosigma (fps ratio) was computed and expressed as a percentage for each analyte:

$$
\text { fps } \operatorname{ratio}(\%)=\left(\frac{f p s_{\text {lab }}}{f p s_{0}}\right) \times 100 \text {. }
$$

An fps ratio larger than 100 percent indicated that the results provided by a laboratory had more variability than the overall variability, whereas an fps ratio smaller than 100 percent indicated less variability than overall.

Table 13 shows the fps ratios obtained for each laboratory and for each constituent for data obtained during the study period. The results in table 13 show that the fps ratio for CAL's ammonium data was 189 percent, indicating that variability in 
Table 12. Most probable values for solutions used in 2002-03 U.S. Geological Survey interlaboratory-comparison program.

[Most probable values are the median values of reported results from eight laboratories. $\mathrm{Ca}^{2+}$, calcium; $\mathrm{Mg}^{2+}$, magnesium; $\mathrm{Na}^{+}$, sodium; $\mathrm{K}^{+}$, potassium; $\mathrm{NH}_{4}^{+}$, ammonium; $\mathrm{Cl}^{-}$, chloride; $\mathrm{NO}_{3}{ }^{-}$, nitrate; $\mathrm{SO}_{4}{ }^{2-}$, sulfate; $\mathrm{pH}$, in standard units; specific conductance, in microsiemens per centimeter at 25 degrees Celsius]

\begin{tabular}{|c|c|c|c|c|c|c|c|c|c|c|}
\hline Solution & $\mathrm{Ca}^{2+}$ & $\mathrm{Mg}^{2+}$ & $\mathrm{Na}^{+}$ & $\mathrm{K}^{+}$ & $\mathrm{NH}_{4}^{+}$ & $\mathrm{Cl}^{-}$ & $\mathrm{NO}_{3}^{-}$ & $\mathrm{SO}_{4}{ }^{2-}$ & $\mathrm{pH}$ & $\begin{array}{c}\text { Specific } \\
\text { conductance }\end{array}$ \\
\hline$\overline{\text { SP1 }}$ & 0.456 & 0.090 & 0.413 & 0.077 & 0.673 & 0.580 & 2.071 & 3.79 & 4.53 & 38 \\
\hline SP2 & .452 & .070 & .352 & .060 & .551 & .442 & 2.980 & 2.30 & 4.62 & 30 \\
\hline SP5 & .574 & .167 & .445 & .082 & .700 & .710 & 2.526 & 4.46 & 4.45 & 48 \\
\hline SP97 & .130 & .019 & .025 & .019 & .290 & .052 & 1.150 & 1.11 & 4.94 & 17 \\
\hline SP98c & .014 & .038 & .209 & .060 & .120 & .226 & .562 & 2.40 & 4.67 & 39 \\
\hline
\end{tabular}


CAL's ammonium data was nearly double the overall variability. CAL's ammonium data were more variable than ammonium data for any other participating laboratory during the study period. CAL's ammonium data had considerable variability during 2000-2001 as well (Wetherbee and others, 2004).

The fps ratios for all constituents were less than 100 percent for MSC, indicating slight variability relative to the other participating laboratories. MACTEC also showed consistent, slight variability for all constituents with a maximum fps ratio of 106 percent for ammonium. Data obtained from NYSDEC had the most overall variability, especially for sodium, potassium, and sulfate. The 2002-03 results for MOEE indicated a considerable reduction in analytical variability compared to 2000-2001 results (Wetherbee and others, 2004). The 2002-03 results for SA indicated more variability than the results obtained for SA during 2000-2001 (Wetherbee and others, 2004).

Intralaboratory bias (bias within a single laboratory) is defined as a systematic difference between the measured and expected values arising from sample handling and analysis procedures within a specific laboratory. Potential intralaboratory bias for the participating laboratories was evaluated by the following methods: (1) comparison of the medians of the differences between laboratory results and MPVs, (2) hypothesis testing using the Sign test, and (3) comparison of laboratory results for ultrapure deionized-water samples.

The median differences between reported concentrations and MPVs are presented in table 13. The arithmetic signs of the median differences indicate whether the reported results for each constituent were positively or negatively biased. The absolute values of the median differences reported by CAL were all less than or equal to MDLs (table 5) except for nitrate, sulfate, and specific conductance. The median differences for data reported by CAL for nitrate and sulfate were approximately three and five times their respective MDLs. The median differences for CAL were comparable to those computed for the other participating laboratories.

The Sign test for a median (Kanji, 1993) was used to evaluate bias for each laboratory. The null hypothesis for the test is, "The median of the differences between laboratory-reported values and MPVs is zero." The test results shown in table 13 were evaluated at the $\alpha=0.05$ significance level for a two-tailed test. Rejection of the null hypothesis, as indicated by the shaded values in the table, implies that laboratory results were biased. The results in table 13 indicate that the calcium, magnesium, and ammonium data reported by CAL during the study period were negatively biased and that the sodium, potassium, chloride, nitrate, sulfate, hydrogen ion, and specific conductance data were positively biased. As shown in table 13 , significant $(\alpha=0.05)$ bias was identified for selected constituents for all of the participating laboratories, but in nearly all cases, the magnitude of the biases was small compared to MPVs (table 12).

To detect possible low-level sample contamination resulting from laboratory analyses, eight ultrapure deionized-water samples were included among the samples submitted to the participating laboratories each year during the study period. The results obtained for the ultrapure deionized-water samples, which are not expected to contain detectable analyte concentrations, were compared to each laboratory's MDLs. Table 14 lists the number of times each laboratory reported a concentration greater than MDL for the ultrapure deionized-water samples. The small number of detections (one in 2002 and two in 2003) in the ultrapure deionized-water samples indicates that contamination was not a problem for CAL, which infers that laboratory contamination was not a problem for NADP/NTN data during the study period. The number of detections in ultrapure deionized-water samples obtained by MOEE decreased from eight in 2002 to four in 2003. The number of detections in ultrapure deionized-water samples obtained by NILU increased from 2 in 2002 to 15 in 2003. ADORC, MACTEC, and MSC reported no detections greater than their MDLs for ultrapure deionizedwater samples during the study period.

\section{Median Absolute Error in Chemical Analyses}

Chemical analysis error is only one component of the overall error in NADP/NTN data, which also are affected by other error sources such as sampling equipment, contamination from onsite exposure, and sample handling, to name a few. Comparison of the chemical analysis error to the overall error in NADP/NTN measurements requires computation of errors in absolute terms. Therefore, median absolute differences (MADs) were calculated for replicate chemical analyses of synthetic precipitation solutions. The f-pseudosigma of the absolute differences also was computed as a measure of variability about the median (table 15).

Overall, the MAD values computed for the analysis of replicate samples for the study period were comparable to 20002001 results for the interlaboratory-comparison program (Wetherbee and others, 2004). During the study period, cation precision estimates were similar among laboratories, with nearly all MAD less than or equal to $0.005 \mathrm{mg} / \mathrm{L}$, but anion precision estimates exhibited greater variability among laboratories. During 2002-03, all of the participating laboratories had MAD values less than or equal to $0.030 \mathrm{mg} / \mathrm{L}$ for the anions. By comparison, the maximum MAD value for anions among participating laboratories during 2000-2001 was $0.020 \mathrm{mg} / \mathrm{L}$ (Wetherbee and others, 2004).

MAD values for hydrogen-ion concentration exhibited slight variability during 2002 ranging from 0 to $0.886 \mu \mathrm{eq} / \mathrm{L}$ for all participating laboratories. Variability in MAD values for hydrogen-ion concentration increased during 2003, ranging from 0 to $1.539 \mu \mathrm{eq} / \mathrm{L}$ for all participating laboratories. During the study period, MADs for CAL's hydrogen-ion concentrations were less than 10 percent of the median hydrogen-ion concentration for NADP/NTN data (table 5).

Seven laboratories routinely reported specific conductance results during the study period. The MSC laboratory did not report specific conductance measurements. Overall, there was little variability among laboratories in their reported specific conductance measurements as MAD values ranged from 0 to 


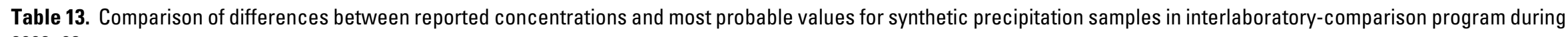
2002-03.

[Overall f-psig., f-pseudosigma calculated for all results from all participating laboratories; Median diff., median of differences between each laboratory's individual results and the most probable value (MPV),

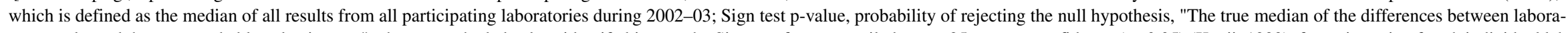

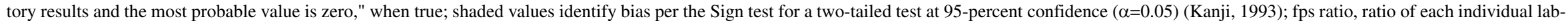
oratory's f-pseudosigma to the overall f-pseudosigma, expressed as a percentage; ADORC, Acid Deposition and Oxidant Research Center; CAL, Central Analytical Laboratory, Illinois State Water Survey;

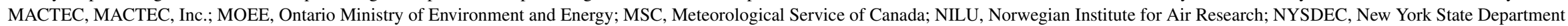
of Environmental Conservation; SA, Shepard Analytical; mg/L, milligrams per liter; \%, percent; <, less than; --, not calculated]

\begin{tabular}{|c|c|c|c|c|c|c|c|c|c|c|c|c|c|}
\hline \multirow{3}{*}{ Analyte } & \multirow{3}{*}{$\begin{array}{l}\text { Overall } \\
\mathrm{f}-\mathrm{psig} . \\
\text { (mg/L) }\end{array}$} & \multicolumn{12}{|c|}{ Laboratory } \\
\hline & & \multicolumn{3}{|c|}{ ADORC } & \multicolumn{3}{|c|}{ CAL } & \multicolumn{3}{|c|}{ MACTEC } & \multicolumn{3}{|c|}{ MOEE } \\
\hline & & $\begin{array}{c}\text { Median } \\
\text { diff. } \\
\text { (mg/L) }\end{array}$ & $\begin{array}{c}\text { Sign test } \\
p \text {-value }\end{array}$ & $\begin{array}{c}\text { fps ratio } \\
(\%)\end{array}$ & $\begin{array}{l}\text { Median diff. } \\
\text { (mg/L) }\end{array}$ & $\begin{array}{c}\text { Sign test } \\
p \text {-value }\end{array}$ & $\begin{array}{c}\text { fps ratio } \\
(\%)\end{array}$ & $\begin{array}{c}\text { Median } \\
\text { diff. } \\
\text { (mg/L) }\end{array}$ & $\begin{array}{c}\text { Sign test } \\
p \text {-value }\end{array}$ & $\begin{array}{c}\text { fps ratio } \\
(\%)\end{array}$ & $\begin{array}{c}\text { Median } \\
\text { diff. } \\
\text { (mg/L) }\end{array}$ & $\begin{array}{c}\text { Sign test } \\
p \text {-value }\end{array}$ & $\begin{array}{c}\text { fps ratio } \\
(\%)\end{array}$ \\
\hline Calcium & 0.021 & -0.002 & 0.0088 & 107 & -0.003 & $<0.0001$ & 54 & 0.005 & $<0.0001$ & 50 & -0.011 & $<0.0001$ & 100 \\
\hline Magnesium & .004 & -.002 & .0067 & 133 & -.002 & $<.0002$ & 67 & -.001 & .0344 & 67 & .002 & $<.0001$ & 33 \\
\hline Sodium & .010 & .003 & .1284 & 108 & .002 & .0049 & 77 & -.005 & $<.0001$ & 69 & -.001 & .5900 & 131 \\
\hline Potassium & .005 & -.001 & .3261 & 186 & .001 & .0103 & 43 & 0 & .9122 & 86 & -.004 & .0006 & 114 \\
\hline Ammonium & .013 & .007 & .0021 & 128 & -.008 & .0003 & 189 & .004 & .0314 & 106 & .010 & $<.0001$ & 100 \\
\hline Chloride & .010 & -.012 & $<.001$ & 150 & .003 & $<.0001$ & 64 & -.001 & .0845 & 36 & -.002 & .5831 & 143 \\
\hline Nitrate & .040 & -.003 & .5900 & 167 & .030 & $<.0001$ & 96 & -.017 & $<.0001$ & 41 & .018 & .0046 & 111 \\
\hline Sulfate & .059 & .006 & .2723 & 110 & .050 & $<.0001$ & 79 & -.010 & .0073 & 63 & -.014 & .0032 & 90 \\
\hline Hydrogen ion & 3.08 & -1.80 & .0003 & 81 & .820 & $<.0001$ & 51 & -2.11 & .0821 & 54 & 1.40 & .0152 & 222 \\
\hline \multirow[t]{2}{*}{ Specific conductance } & 1.8 & -.2 & $<.0001$ & 30 & 1.0 & .0073 & 29 & .3 & $<.0001$ & 84 & -1.0 & $<.0001$ & 79 \\
\hline & & \multicolumn{3}{|c|}{ MSC } & \multicolumn{3}{|c|}{ NILU } & \multicolumn{3}{|c|}{ NYSDEC } & \multicolumn{3}{|c|}{ SA } \\
\hline Calcium & .021 & -.003 & .1093 & 79 & .006 & $<.0001$ & 79 & .026 & $<.0001$ & 161 & -.018 & $<.0001$ & 125 \\
\hline Magnesium & .004 & 0 & .4095 & 67 & .003 & $<.0001$ & 100 & .005 & $<.0002$ & 167 & -.003 & $<.0001$ & 117 \\
\hline Sodium & .010 & .003 & $<.0001$ & 38 & 0 & .8264 & 85 & -.014 & $<.0003$ & 238 & 0 & 1.0000 & 62 \\
\hline Potassium & .005 & .002 & .0014 & 71 & .001 & .0005 & 100 & .006 & .0034 & 371 & -.002 & $<.0001$ & 43 \\
\hline Ammonium & .013 & -.004 & .0002 & 44 & -.003 & .0008 & 117 & -.004 & .0040 & 72 & .002 & .0056 & 50 \\
\hline Chloride & .010 & .004 & $<.0001$ & 71 & -.003 & .0007 & 107 & -.003 & .1606 & 207 & .003 & .0003 & 71 \\
\hline Nitrate & .040 & -.011 & .2345 & 74 & -.009 & .3318 & 74 & -.003 & .9152 & 196 & 0 & .3620 & 74 \\
\hline Sulfate & .059 & -.013 & .0178 & 60 & .060 & $<.0001$ & 134 & -.091 & $<.0001$ & 478 & -.022 & .0001 & 74 \\
\hline Hydrogen ion & 3.08 & -2.09 & $<.0001$ & 82 & -.120 & $<.0001$ & 98 & .650 & $<.0001$ & 55 & 4.20 & $<.0001$ & 72 \\
\hline Specific conductance & 1.8 & No data & -- & -- & 1.0 & .8304 & 21 & -2.0 & .0011 & 157 & -2.0 & $<.0001$ & 98 \\
\hline
\end{tabular}


Table 14. Number of analyte determinations greater than minimum detection limits for each participating laboratory and each ion for ultrapure deionized-water samples during 2002-03.

[Eight determinations per year per laboratory; ADORC, Acid Deposition and Oxidant Research Center; CAL, Central Analytical Laboratory, Illinois State Water Survey; MACTEC, MACTEC, Inc.; MOEE, Ontario Ministry of Environment and Energy; MSC, Meteorological Service of Canada; NILU, Norwegian Institute for Air Research; NYSDEC, New York State Department of Environmental Conservation; SA, Shepard Analytical]

\begin{tabular}{|c|c|c|c|c|c|c|c|c|}
\hline Analyte & ADORC & CAL & MACTEC & MOEE & MSC & NILU & NYSDEC & SA \\
\hline \multicolumn{9}{|c|}{2002} \\
\hline Calcium & 0 & 0 & 0 & 0 & 0 & 2 & 1 & 0 \\
\hline Magnesium & 0 & 0 & 0 & 0 & 0 & 0 & 0 & 0 \\
\hline Sodium & 0 & 1 & 0 & 1 & 0 & 0 & 0 & 0 \\
\hline Potassium & 0 & 0 & 0 & 1 & 0 & 0 & 0 & 0 \\
\hline Ammonium & 0 & 0 & 0 & 4 & 0 & 0 & 0 & 0 \\
\hline Chloride & 0 & 0 & 0 & 0 & 0 & 0 & 1 & 0 \\
\hline Nitrate & 0 & 0 & 0 & 2 & 0 & 0 & 0 & 0 \\
\hline Sulfate & 0 & 0 & 0 & 0 & 0 & 0 & 0 & 0 \\
\hline \multicolumn{9}{|c|}{2003} \\
\hline Calcium & 0 & 0 & 0 & 0 & 0 & 4 & 1 & 0 \\
\hline Magnesium & 0 & 0 & 0 & 0 & 0 & 1 & 0 & 0 \\
\hline Sodium & 0 & 1 & 0 & 0 & 0 & 2 & 0 & 1 \\
\hline Potassium & 0 & 1 & 0 & 0 & 0 & 3 & 0 & 0 \\
\hline Ammonium & 0 & 0 & 0 & 0 & 0 & 2 & 3 & 0 \\
\hline Chloride & 0 & 0 & 0 & 0 & 0 & 1 & 1 & 0 \\
\hline Nitrate & 0 & 0 & 0 & 4 & 0 & 1 & 4 & 0 \\
\hline Sulfate & 0 & 0 & 0 & 0 & 0 & 1 & 4 & 0 \\
\hline
\end{tabular}

$0.3 \mu \mathrm{S} / \mathrm{cm}$ in 2002 and from 0 to $0.8 \mu \mathrm{S} / \mathrm{cm}$ in 2003 for all participating laboratories.

\section{Control Charts}

A visual comparison of interlaboratory differences between each laboratory's analyte concentrations and MPVs are presented in the control charts shown in figures 21-30. The control limits are placed at $\pm 3 \mathrm{f}$-pseudosigmas from the zero difference line. The f-pseudosigma was defined previously (equation 1) and is assumed to be a nonparametric analogue of the standard deviation (Hoaglin and others, 1983). Control limits (3-sigma) define the bounds of virtually all values (99 percent) produced by a system in statistical control. Modern control charts commonly have additional limits called warning limits (2-sigma) within which most (95 percent) of the values should lie (Taylor, 1987). The warning limits are positioned at \pm 2 f-pseudosigmas from the zero difference line. The independent axis for the control charts is time of sample analysis, in this report January 1, 2002, to December 31, 2003.

Graphs in figures 21-30 depict the control charts for each analyte for the eight participating laboratories. The plotted points are color- and symbol-coded by solution type to provide visual indication of potential bias for specific solutions. No such solution-specific bias was identified in the data for any of the participating laboratories. The data for the CAL in figures 22 through 29 indicate brief time periods when CAL's analytical precision for magnesium, sodium, potassium, ammonium, chloride, nitrate, sulfate, and hydrogen ion was not within the control limits. However, CAL data were within statistical control approximately 90 percent of the time during the study period. The control chart data indicate that CAL's precision is consistent with that of other laboratories performing analysis of low-ionic strength environmental samples.

Visual comparison of the control charts for the eight laboratories indicates that CAL, MACTEC, and MSC exhibited similar, consistent statistical control characteristics for all analytes. ADORC, NILU, NYSDEC, and SA laboratories reported a small number of data outside of statistical control for magnesium. MOEE and NYSDEC produced a number of data outside of statistical control for chloride, and NYSDEC data for sulfate was not within statistical control for approximately 2 months in early 2002 and for approximately 4 months during middle to late 2003. SA produced specific conductance data outside of statistical control in middle to late 2002, which was uncharacteristic of past SA performance. 
Table 15. Summary of absolute differences for analysis of replicate, synthetic-precipitation solution samples determined by eight laboratories participating in 2002-03 interlaboratory-comparison program.

[All units in milligrams per liter except hydrogen ion, in microequivalents per liter, and specific conductance, in microsiemens per centimeter at 25 degrees Celsius; MAD, median absolute difference; f-psig., f-pseudosigma; ADORC, Acid Deposition and Oxidant Research Center; CAL, Illinois State Water Survey, Central Analytical Laboratory; MACTEC, MACTEC, Inc.; MOEE, Ontario Ministry of Environment and Energy; MSC, Meteorological Service of Canada; NILU, Norwegian Institute for Air Research; NYSDEC, New York State Department of Environmental Conservation; SA, Shepard Analytical; --, not calculated]

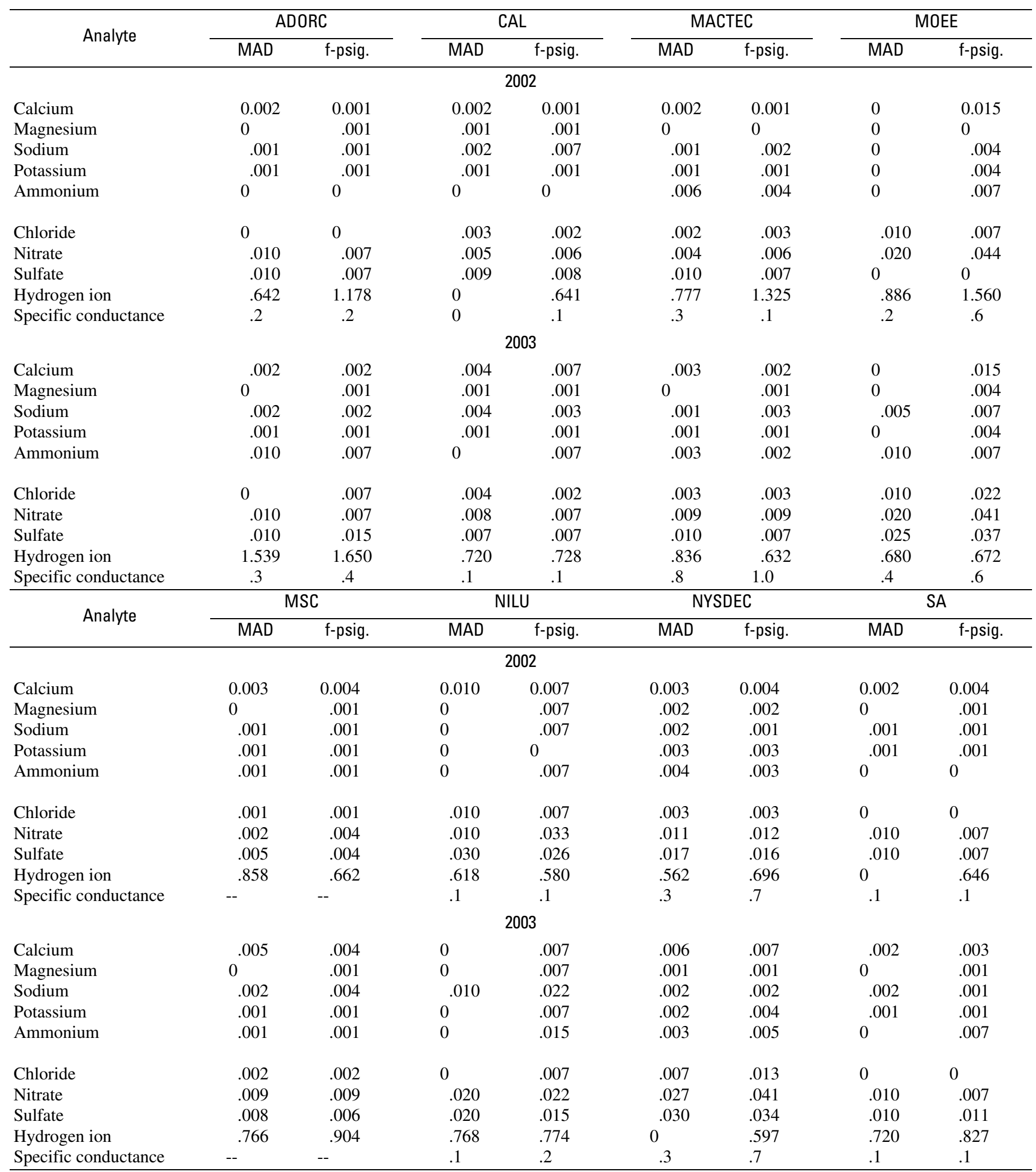



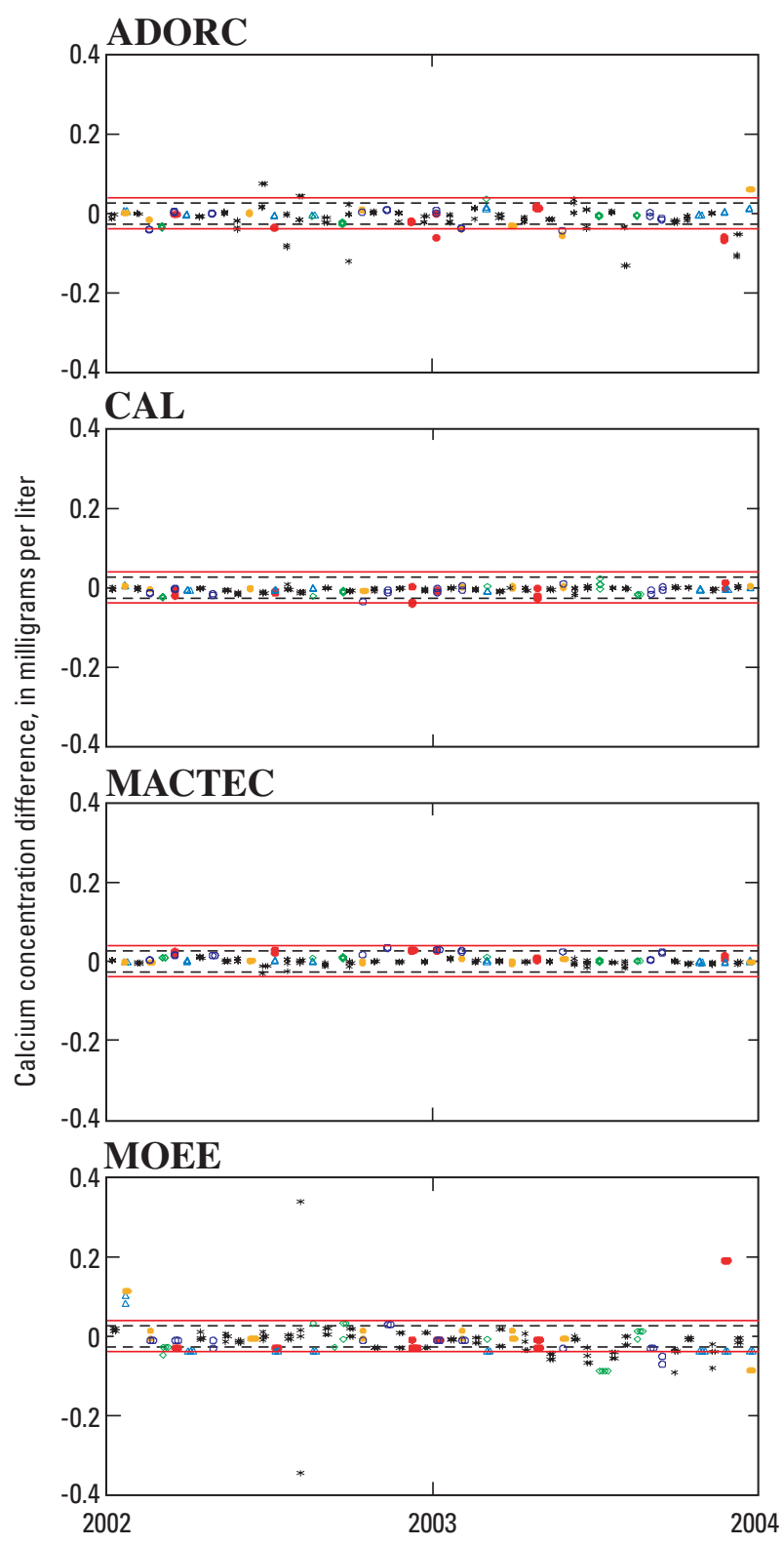

\section{EXPLANATION}

- - - Warning limits (+2 and -2 f-pseudosigmas from zero difference line)

- Control limits ( +3 and -3 f-pseudosigmas from zero difference line)

Solutions:

- SP1 - SP5 $\triangle$ SP98c

- SP2 - SP97 * Natural precipitation (CALNAT)

\section{Laboratories:}

ADORC: Acid Deposition and Oxidant Research Center, Niigata-shi, Japan

CAL: $\quad$ Central Analytical Laboratory, Champaign, Illinois

MACTEC: MACTEC Inc., Gainesville, Florida

MOEE: Ontario Ministry of Environment and Energy, Dorset Research Facility, Dorset, Ontario, Canada

MSC: Meteorological Service of Canada, Downsview, Ontario, Canada

NILU: $\quad$ Norwegian Institute of Air Research, Kjeller, Norway

NYSDEC: New York State Department of Environmental Conservation, Albany, New York

SA: $\quad$ Shepard Analytical, Simi Valley, California

Figure 21. Difference between measured calcium concentration values and median calcium concentration value calculated by solution for all participating laboratories in interlaboratory-comparison program during 2002-03. 

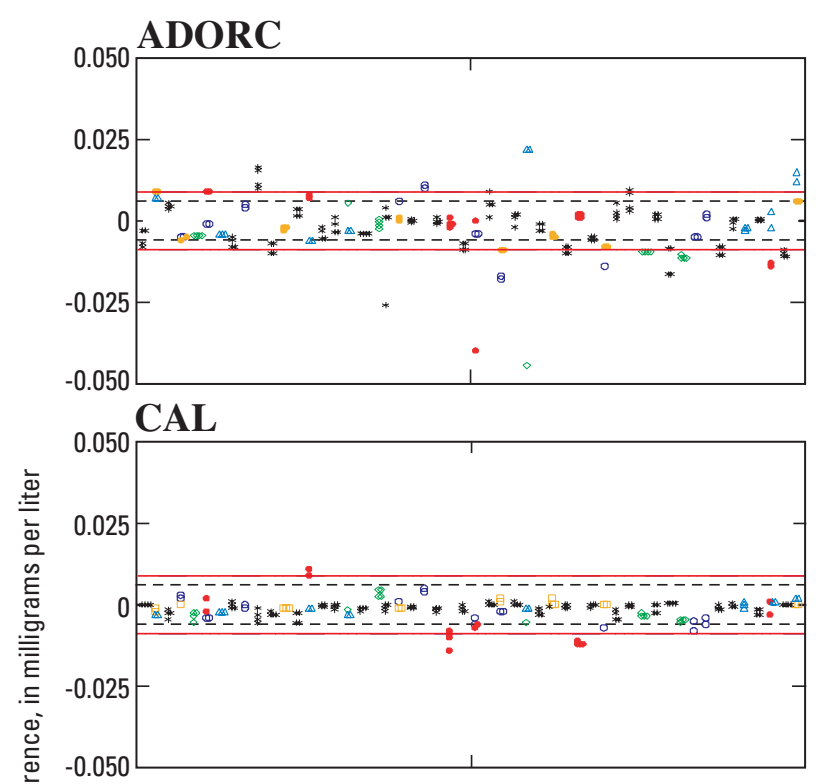

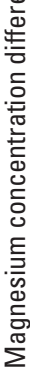
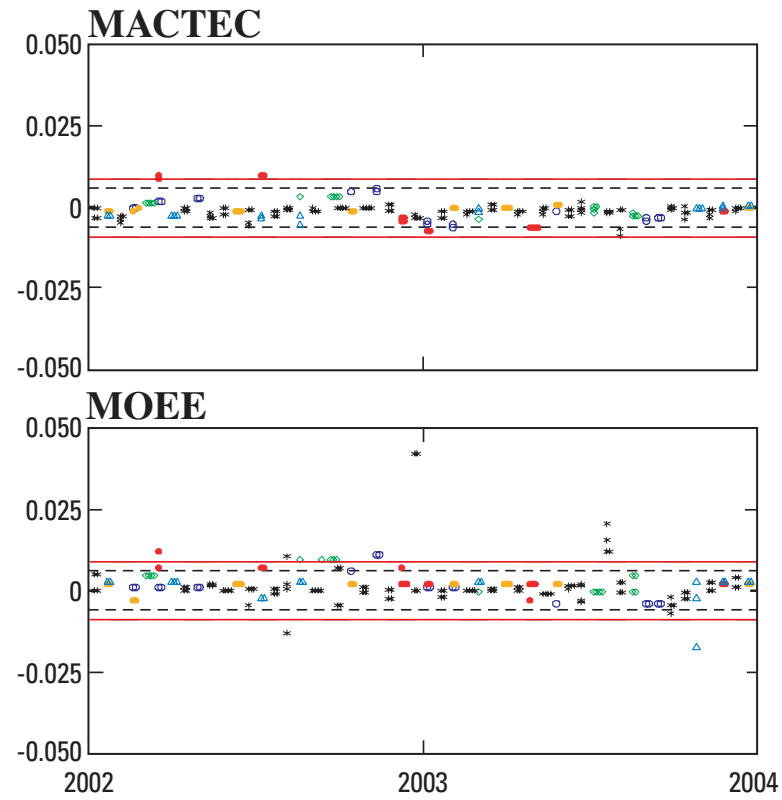

20042002
MSC

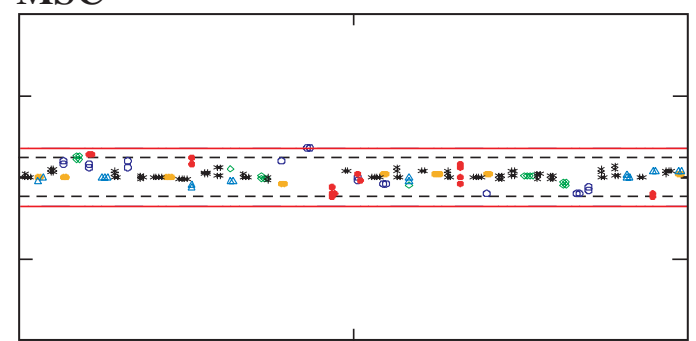

NILU

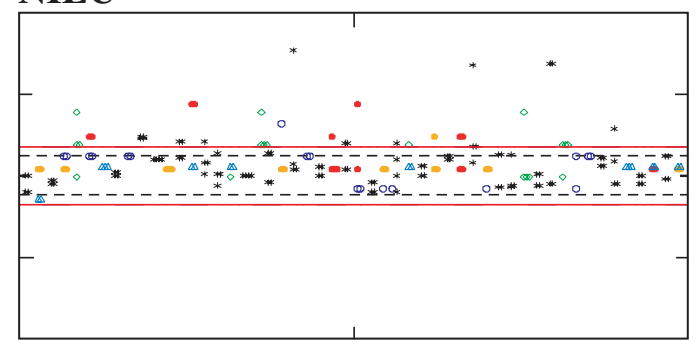

NYSDEC

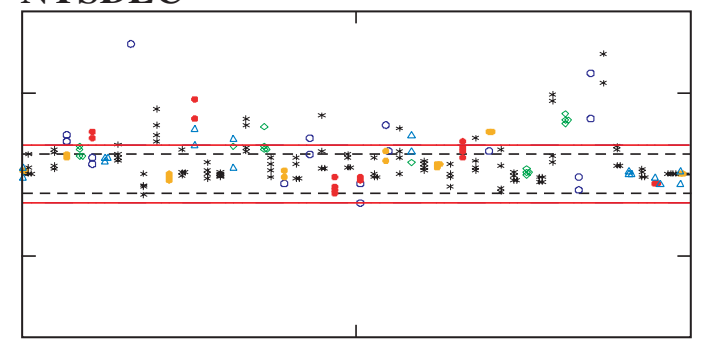

SA

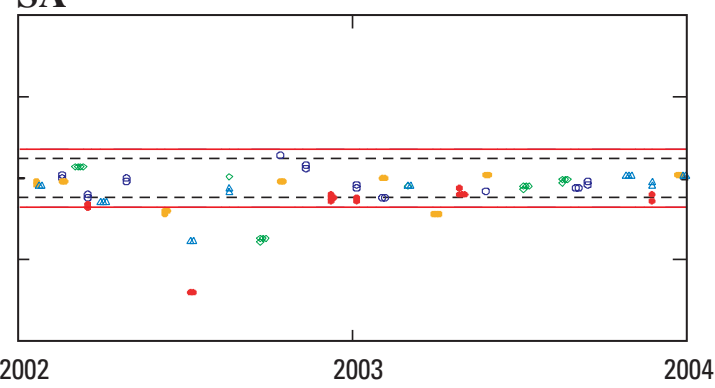

EXPLANATION

- - - Warning limits (+2 and -2 f-pseudosigmas from zero difference line)

Control limits (+3 and -3 f-pseudosigmas from zero difference line)

Solutions:

- SP1 - SP5 $\triangle$ SP98c

-SP2 -SP97 * Natural precipitation (CALNAT)

Laboratories:

ADORC: Acid Deposition and Oxidant Research Center, Niigata-shi, Japan

CAL: $\quad$ Central Analytical Laboratory, Champaign, Illinois

MACTEC: MACTEC Inc., Gainesville, Florida

MOEE: Ontario Ministry of Environment and Energy, Dorset Research Facility, Dorset, Ontario, Canada

MSC: $\quad$ Meteorological Service of Canada, Downsview, Ontario, Canada

NILU: $\quad$ Norwegian Institute of Air Research, Kjeller, Norway

NYSDEC: New York State Department of Environmental Conservation, Albany, New York

SA: $\quad$ Shepard Analytical, Simi Valley, California

Figure 22. Differences between measured magnesium concentration values and median magnesium concentration value calculated by solution for all participating laboratories in interlaboratory-comparison program during 2002-03. 


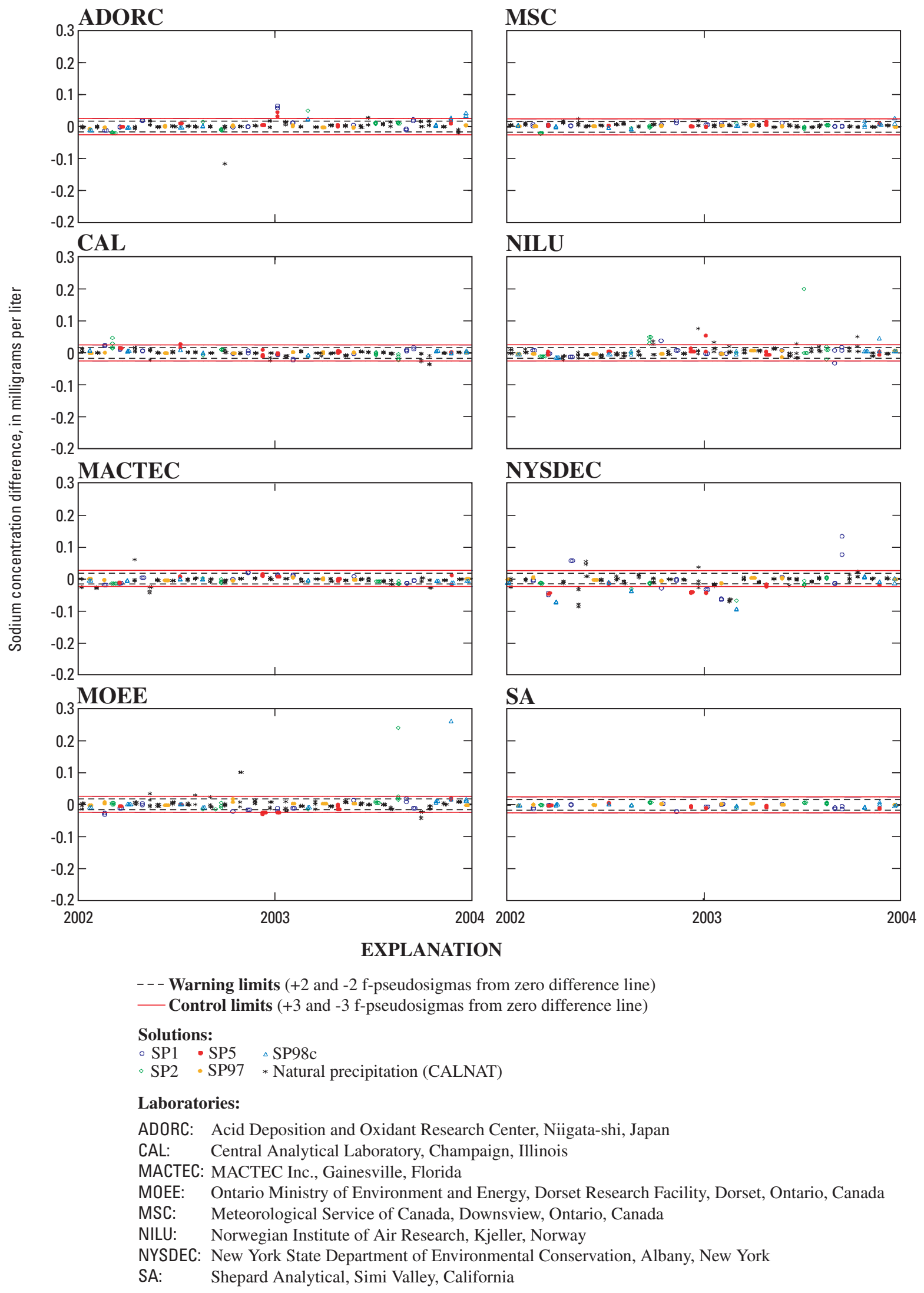

Figure 23. Difference between measured sodium concentration values and median sodium concentration value calculated by solution for all participating laboratories in interlaboratory-comparison program during 2002-03. 

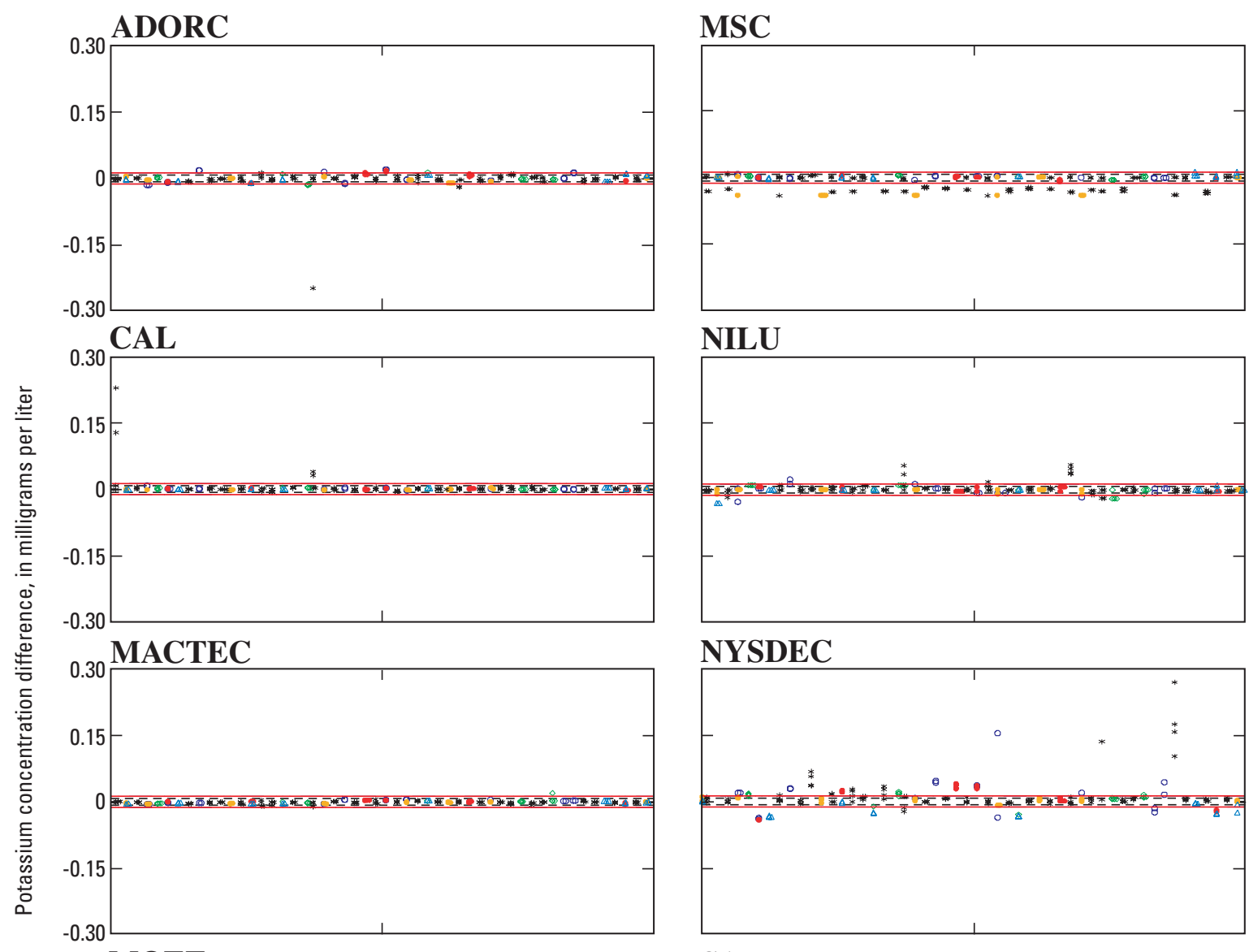

NILU
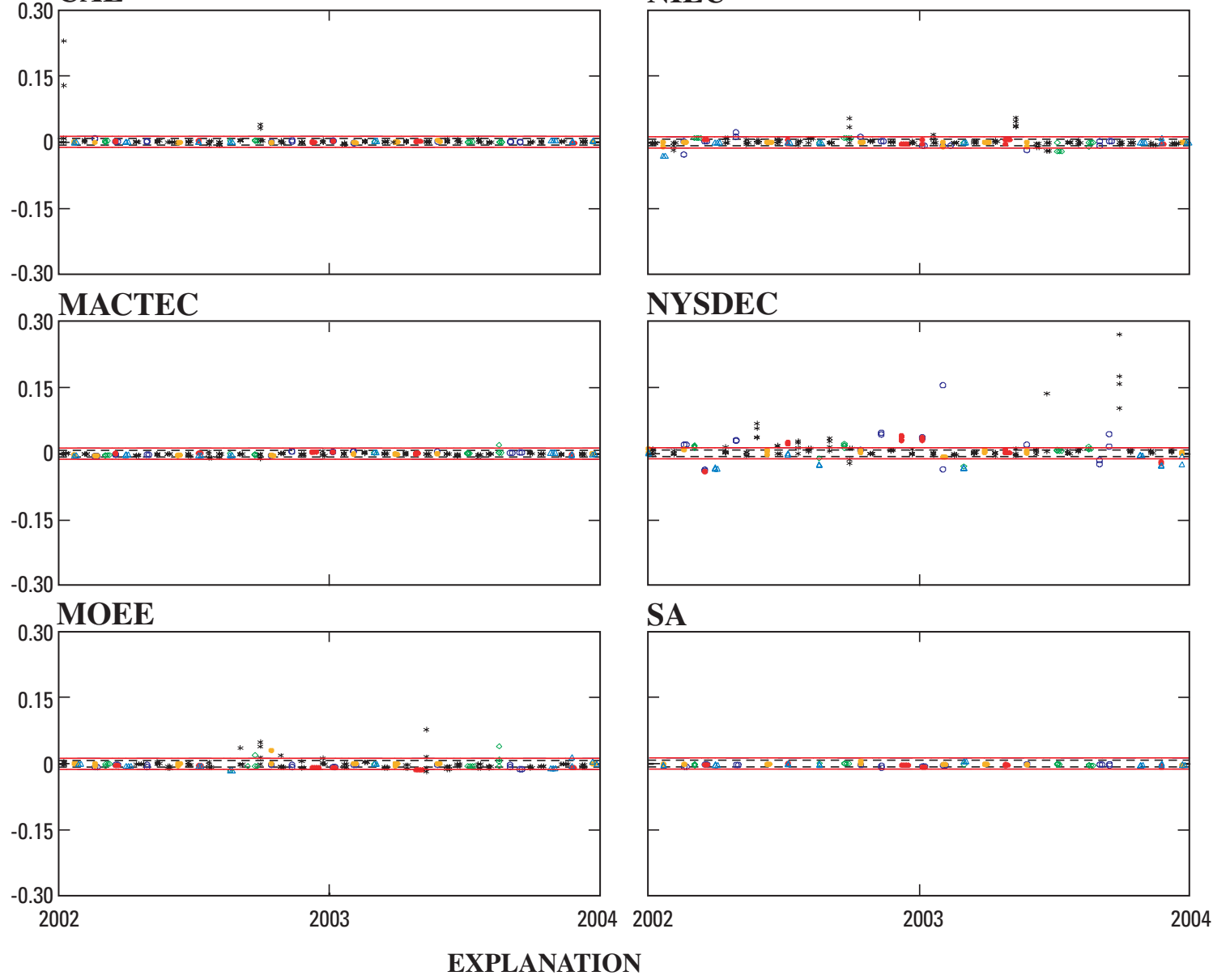

- - - Warning limits (+2 and -2 f-pseudosigmas from zero difference line)

- Control limits ( +3 and -3 f-pseudosigmas from zero difference line)

Solutions:

- SP1 - SP5 $\triangle$ SP98c

- SP2 -SP97 * Natural precipitation (CALNAT)

Laboratories:

ADORC: Acid Deposition and Oxidant Research Center, Niigata-shi, Japan

CAL: $\quad$ Central Analytical Laboratory, Champaign, Illinois

MACTEC: MACTEC Inc., Gainesville, Florida

MOEE: Ontario Ministry of Environment and Energy, Dorset Research Facility, Dorset, Ontario, Canada

MSC: $\quad$ Meteorological Service of Canada, Downsview, Ontario, Canada

NILU: $\quad$ Norwegian Institute of Air Research, Kjeller, Norway

NYSDEC: New York State Department of Environmental Conservation, Albany, New York

SA: $\quad$ Shepard Analytical, Simi Valley, California

Figure 24. Difference between measured potassium concentration values and median potassium concentration value calculated by solution for all participating laboratories in interlaboratory-comparison program during 2002-03. 


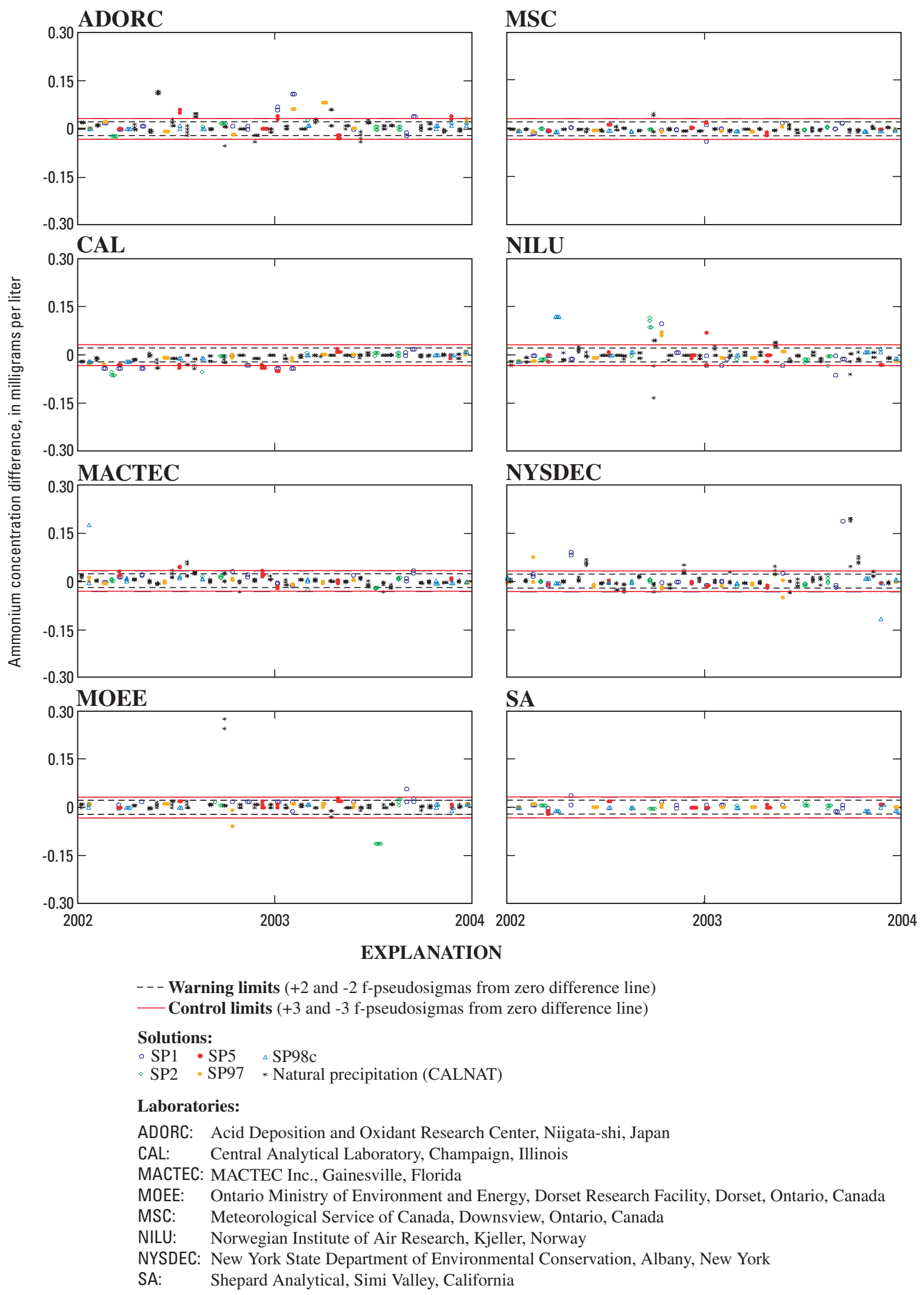

Figure 25. Difference between measured ammonium concentration values and median ammonium concentration value calculated by solution for all participating laboratories in interlaboratory-comparison program during 2002-03. 

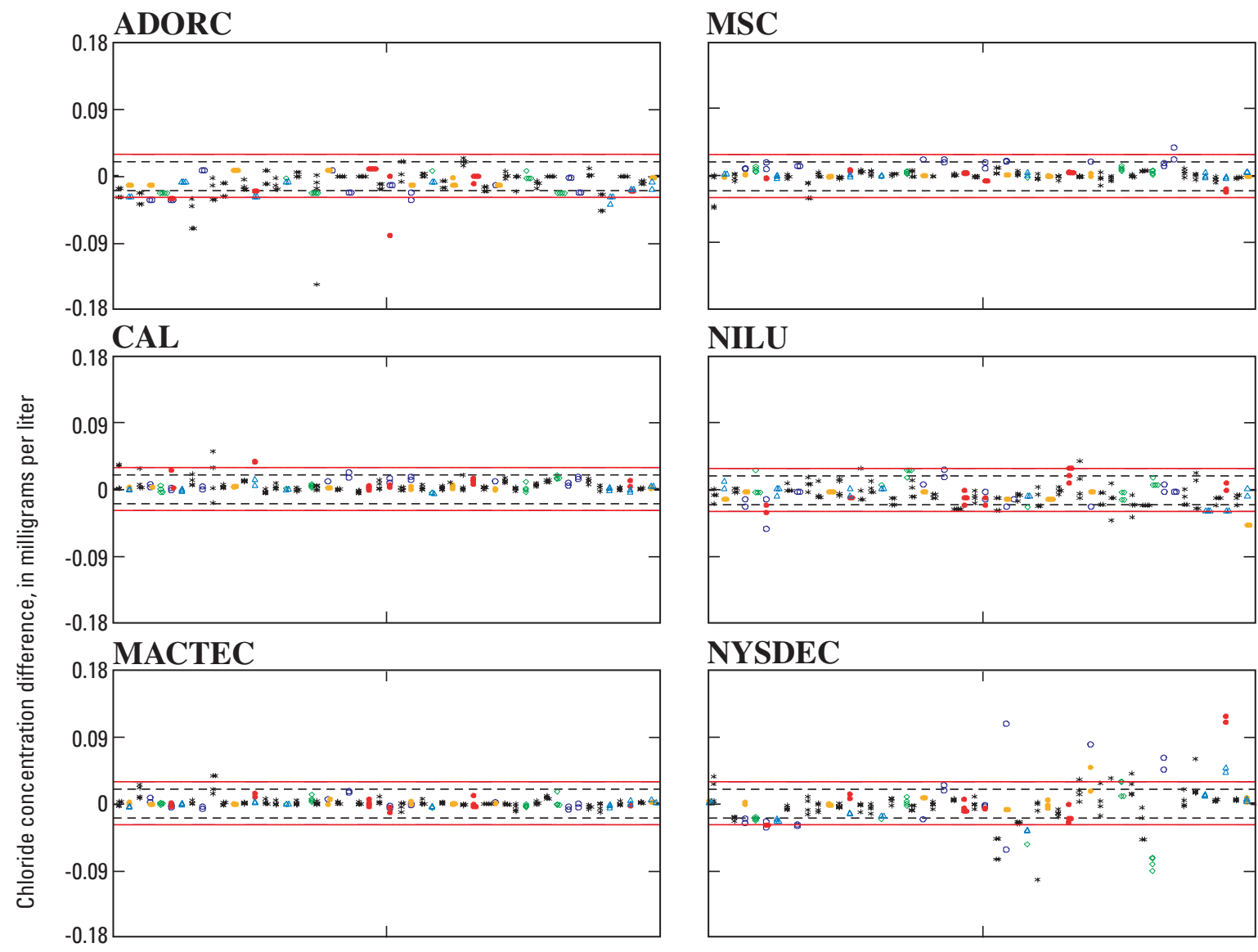

NILU
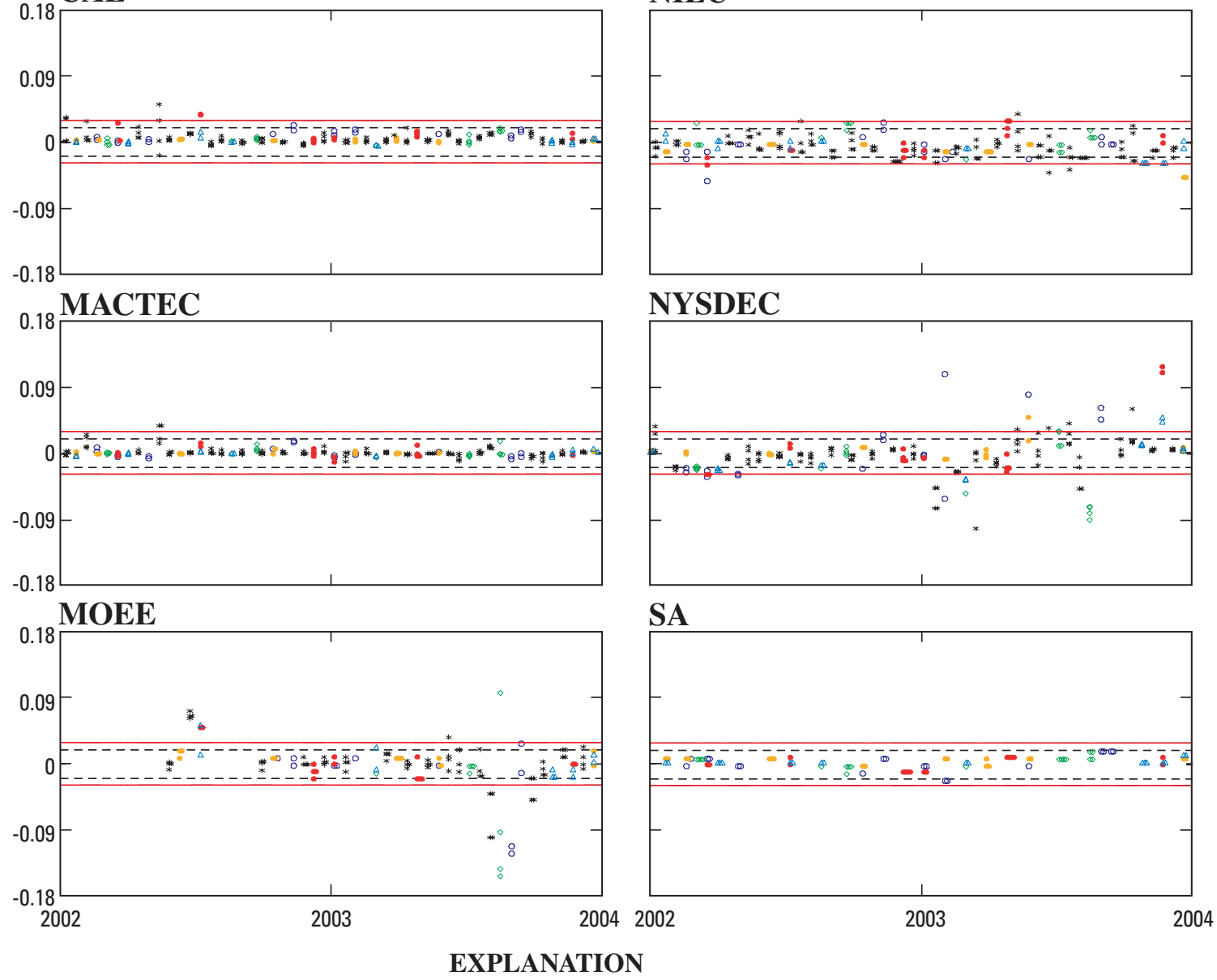

- - - Warning limits (+2 and -2 f-pseudosigmas from zero difference line)

Control limits (+3 and -3 f-pseudosigmas from zero difference line)

Solutions:

- SP1 - SP5 $\triangle$ SP98c

-SP2 -SP97 * Natural precipitation (CALNAT)

Laboratories:

ADORC: Acid Deposition and Oxidant Research Center, Niigata-shi, Japan

CAL: $\quad$ Central Analytical Laboratory, Champaign, Illinois

MACTEC: MACTEC Inc., Gainesville, Florida

MOEE: Ontario Ministry of Environment and Energy, Dorset Research Facility, Dorset, Ontario, Canada

MSC: $\quad$ Meteorological Service of Canada, Downsview, Ontario, Canada

NILU: $\quad$ Norwegian Institute of Air Research, Kjeller, Norway

NYSDEC: New York State Department of Environmental Conservation, Albany, New York

SA: $\quad$ Shepard Analytical, Simi Valley, California

Figure 26. Difference between measured chloride concentration values and median chloride concentration value calculated by solution for all participating laboratories in interlaboratory-comparison program during 2002-03. 


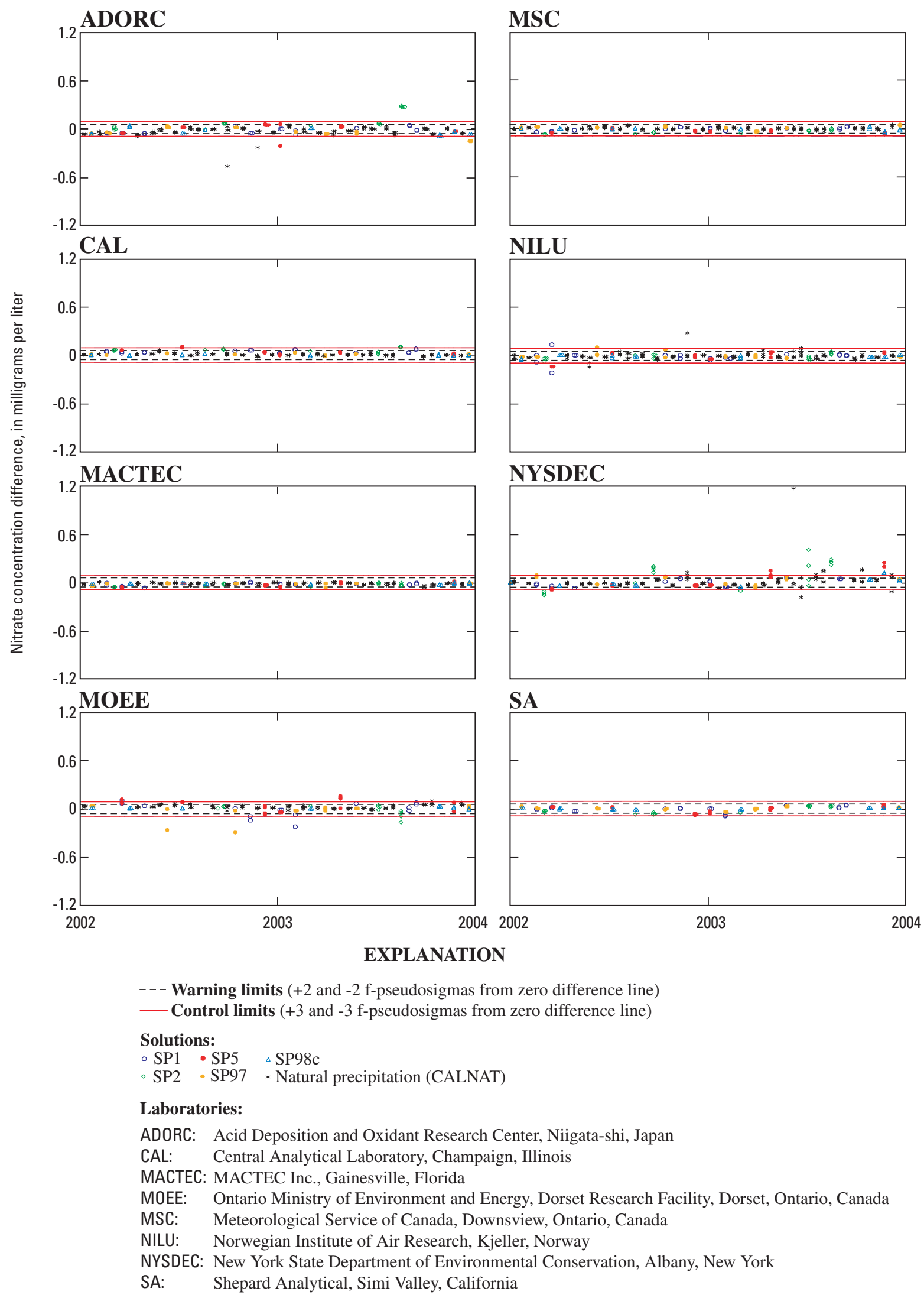

Figure 27. Difference between measured nitrate concentration values and median nitrate concentration value calculated by solution for all participating laboratories in interlaboratory-comparison program during 2002-03. 

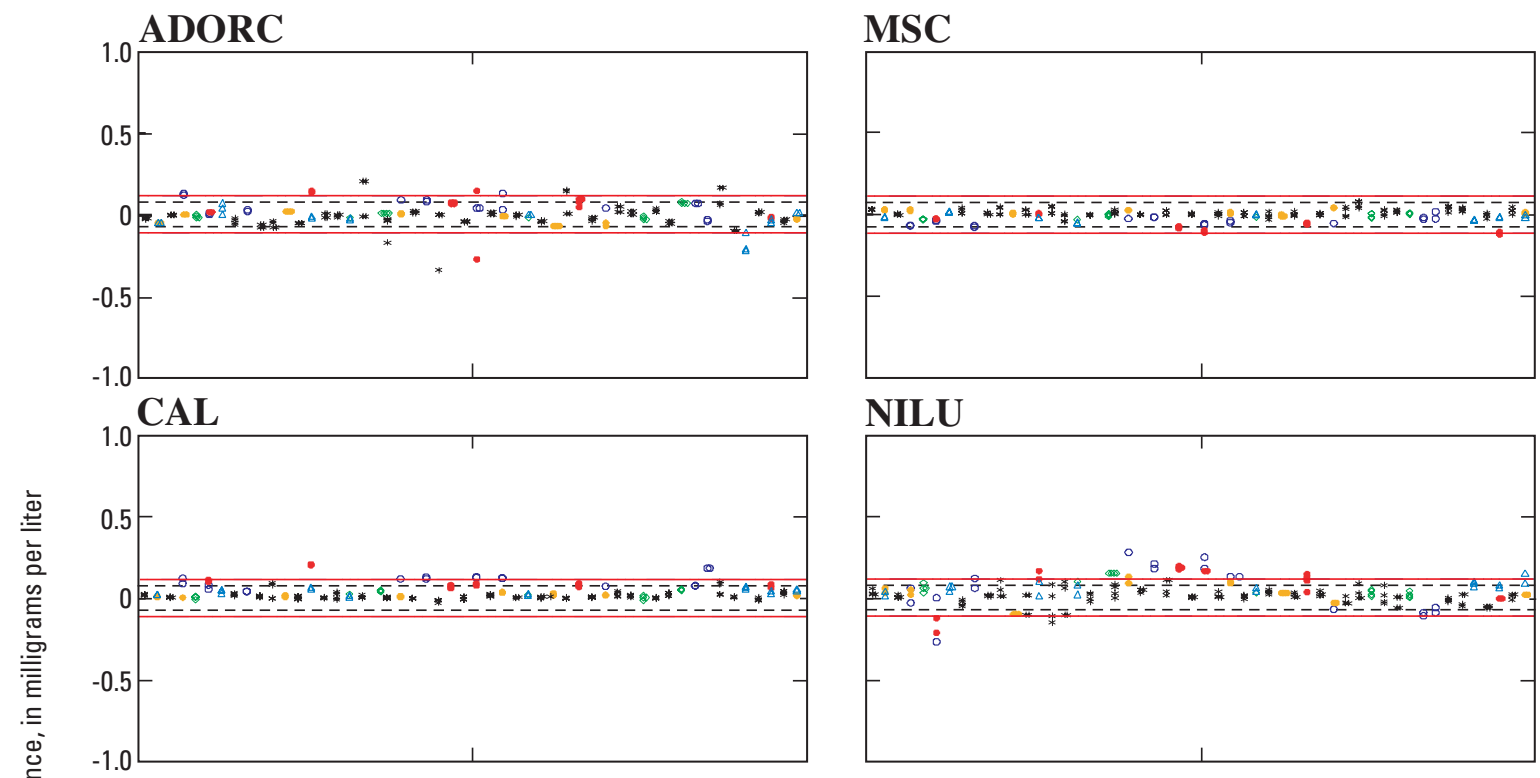

NILU
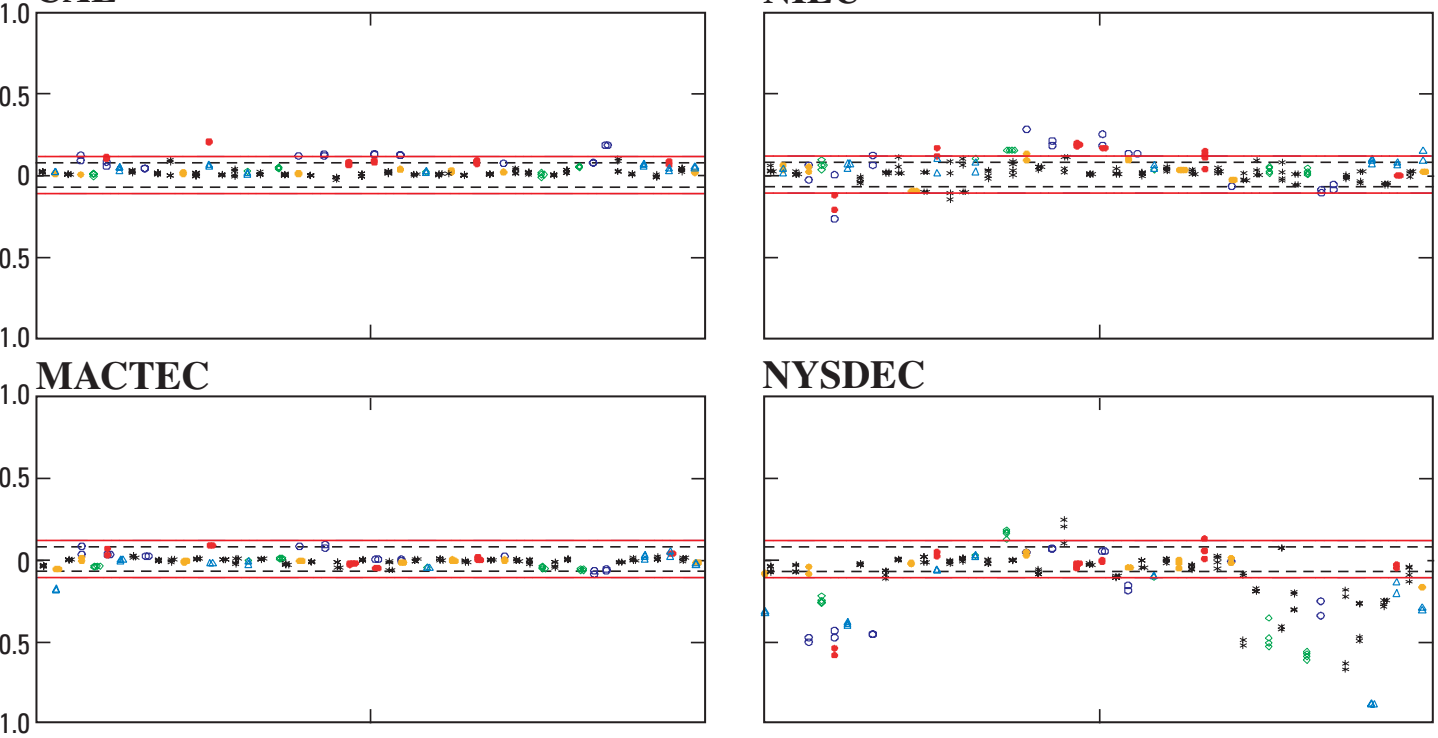

NYSDEC
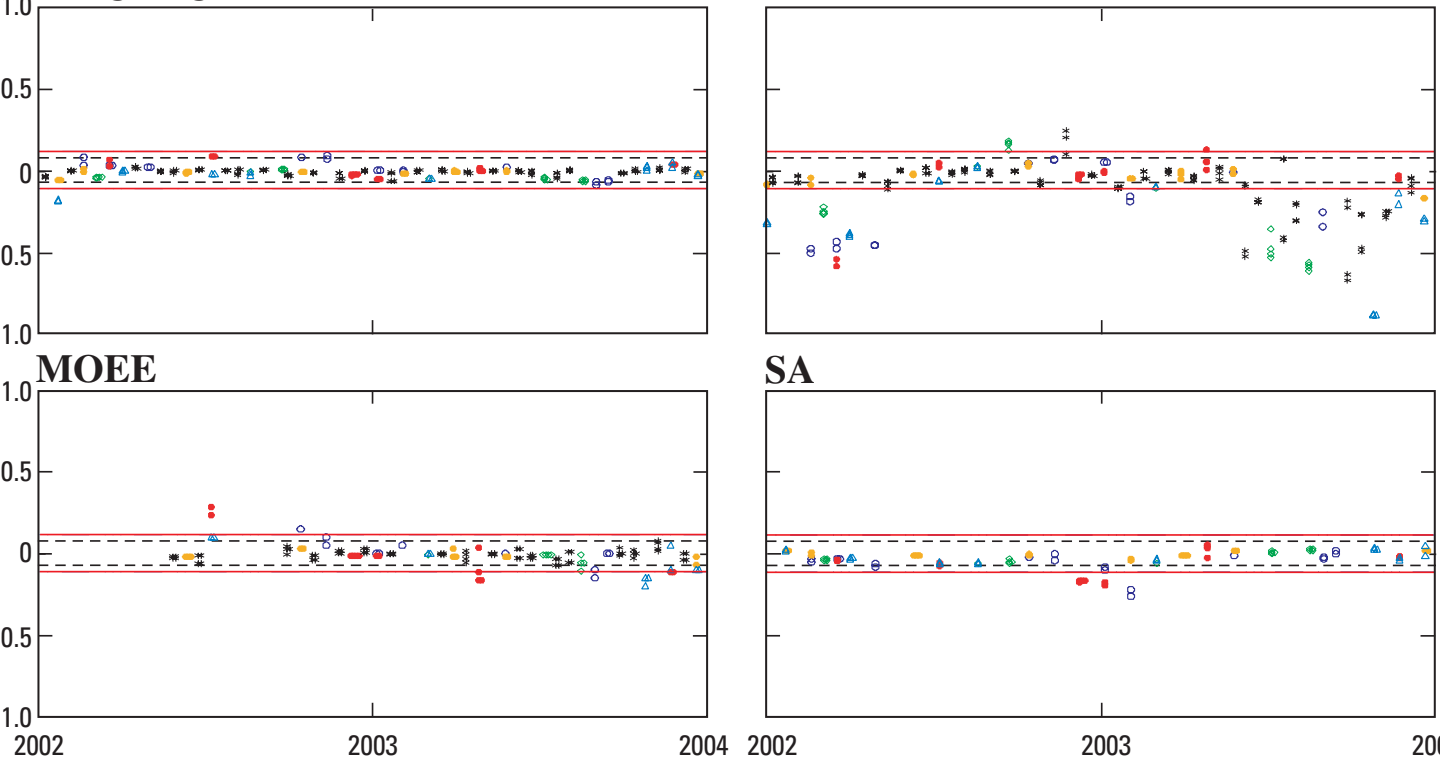

SA

EXPLANATION

- - - Warning limits (+2 and -2 f-pseudosigmas from zero difference line)

Control limits ( +3 and -3 f-pseudosigmas from zero difference line)

Solutions:

- SP1 - SP5 $\triangle$ SP98c

- SP2 -SP97 * Natural precipitation (CALNAT)

Laboratories:

ADORC: Acid Deposition and Oxidant Research Center, Niigata-shi, Japan

CAL: $\quad$ Central Analytical Laboratory, Champaign, Illinois

MACTEC: MACTEC Inc., Gainesville, Florida

MOEE: Ontario Ministry of Environment and Energy, Dorset Research Facility, Dorset, Ontario, Canada

MSC: $\quad$ Meteorological Service of Canada, Downsview, Ontario, Canada

NILU: $\quad$ Norwegian Institute of Air Research, Kjeller, Norway

NYSDEC: New York State Department of Environmental Conservation, Albany, New York

SA: $\quad$ Shepard Analytical, Simi Valley, California

Figure 28. Difference between measured sulfate concentration values and median sulfate concentration value calculated by solution for all participating laboratories in interlaboratory-comparison program during 2002-03. 

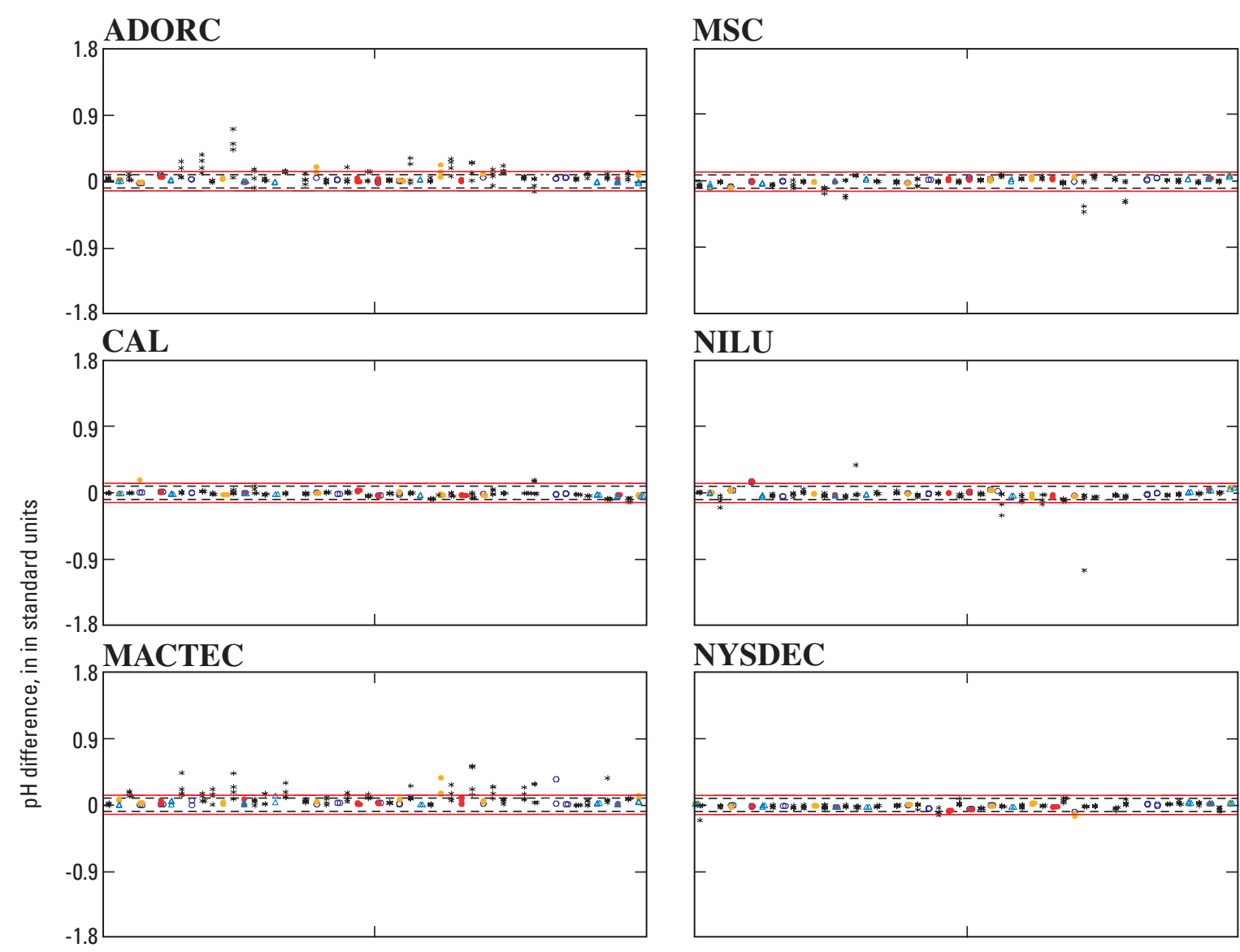

NILU

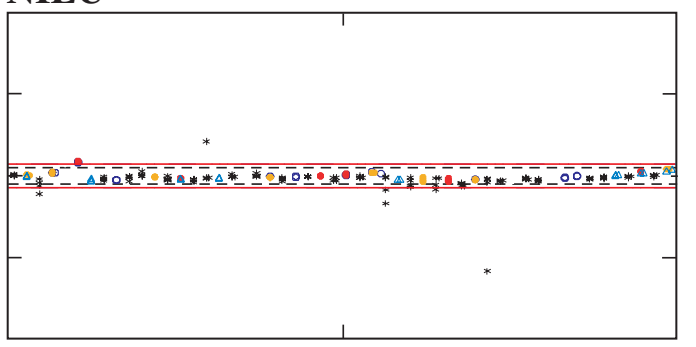

NYSDEC
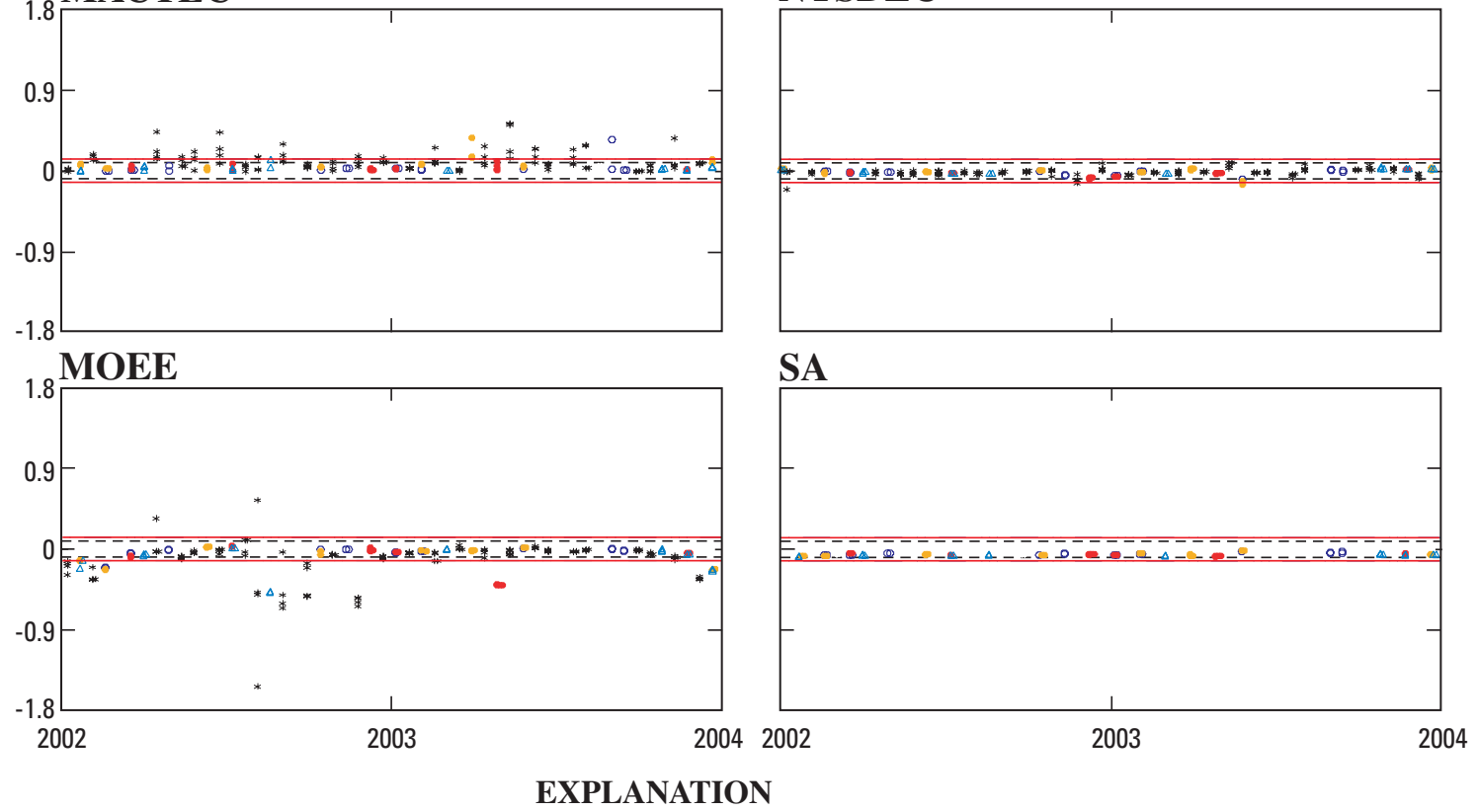

- - - Warning limits (+2 and -2 f-pseudosigmas from zero difference line)

- Control limits ( +3 and -3 f-pseudosigmas from zero difference line)

Solutions:

- SP1 - SP5 $\triangle$ SP98c

-SP2 -SP97 * Natural precipitation (CALNAT)

Laboratories:

ADORC: Acid Deposition and Oxidant Research Center, Niigata-shi, Japan

CAL: $\quad$ Central Analytical Laboratory, Champaign, Illinois

MACTEC: MACTEC Inc., Gainesville, Florida

MOEE: Ontario Ministry of Environment and Energy, Dorset Research Facility, Dorset, Ontario, Canada

MSC: $\quad$ Meteorological Service of Canada, Downsview, Ontario, Canada

NILU: $\quad$ Norwegian Institute of Air Research, Kjeller, Norway

NYSDEC: New York State Department of Environmental Conservation, Albany, New York

SA: $\quad$ Shepard Analytical, Simi Valley, California

Figure 29. Difference between measured $\mathrm{pH}$ values and median $\mathrm{pH}$ value calculated by solution for all participating laboratories in interlaboratory-comparison program during 2002-03. 


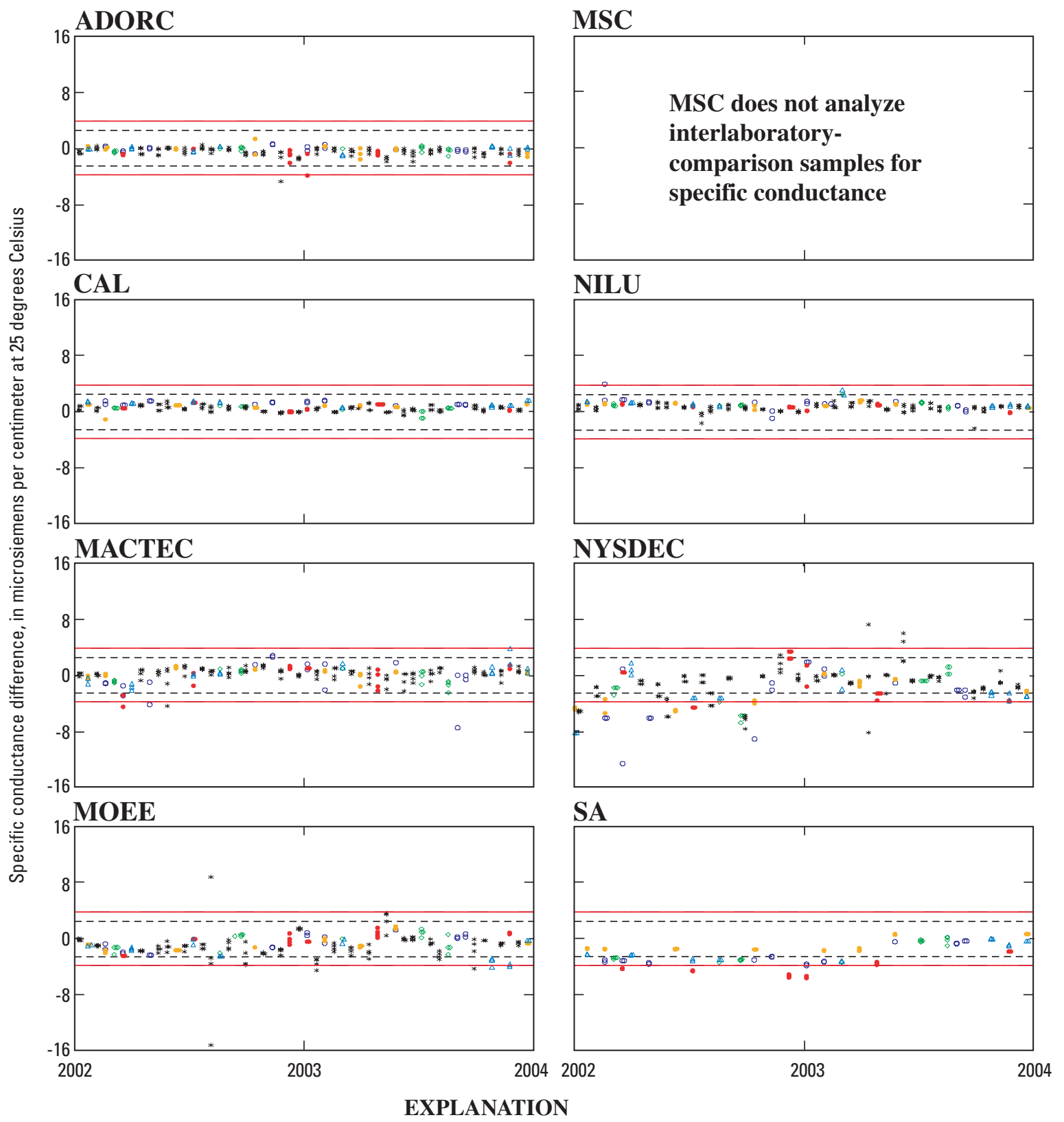

- - Warning limits (+2 and -2 f-pseudosigmas from zero difference line)

- Control limits (+3 and -3 f-pseudosigmas from zero difference line)

Solutions:

- SP1 - SP5 $\triangle$ SP98c

-SP2 -SP97 * Natural precipitation (CALNAT)

Laboratories:

ADORC: Acid Deposition and Oxidant Research Center, Niigata-shi, Japan

CAL: $\quad$ Central Analytical Laboratory, Champaign, Illinois

MACTEC: MACTEC Inc., Gainesville, Florida

MOEE: Ontario Ministry of Environment and Energy, Dorset Research Facility, Dorset, Ontario, Canada

MSC: $\quad$ Meteorological Service of Canada, Downsview, Ontario, Canada

NILU: $\quad$ Norwegian Institute of Air Research, Kjeller, Norway

NYSDEC: New York State Department of Environmental Conservation, Albany, New York

SA: $\quad$ Shepard Analytical, Simi Valley, California

Figure 30. Difference between measured specific conductance values and median specific conductance value calculated by solution for all participating laboratories in interlaboratory-comparison program during 2002-03. 


\section{Collocated-Sampler Program}

The collocated-sampler program was established in October 1988 to provide a method of estimating the overall variability of the precipitation-monitoring system used by NADP/NTN . Included in this estimate of NADP/NTN precision is the variability from the point of sample collection through laboratory analysis and quality control (Gordon, 1999). Nilles and others (1991) provide a detailed description of the collocated-sampler program. Since 1988, collocated sites have been operated on a water-year (October 1-September 30) basis every year except 1994 (Gordon, 1999; Wetherbee and others, 2005).

The two sites selected for the collocated-sampler program in water year 2002 (WY2002)-October 1, 2001, through September 30, 2002-were OR02 (Alsea Guard Ranger Station, Benton County, Oregon) and WI98 (Wildcat Mountain State Park, Vernon County, Wisconsin). In water year 2003

(WY2003)-October 1, 2002, through September 30, 2003-the WI98 site remained in the collocated-sampler program to collect data for 2 consecutive years at the same location. Running a collocated site at WI98 for 2 consecutive years allowed for more long-term evaluation of precipitation variability. The single new site selected for participation in the collocated-sampler program in WY2003 was OK00 (Salt Plains National Wildlife Refuge, Alfalfa County, Oklahoma).

NADP/NTN guidelines for site selection and installation (Dossett and Bowersox, 1999) are used in the establishment of each collocated site. Site selection is made with the goal of distributing sites among diverse ecoregions with different precipitation regimes. In an effort to minimize data loss due to changes in personnel, sites with stable operational histories are given priority consideration. At each collocated site, the original site's equipment-Aerochem Metrics Model 310 collector, Belfort

Model 5-780 rain gage, and the power supply (solar panel, battery, alternating current, and so forth)-are duplicated. The duplicate instruments are installed such that they are no more or less affected by surrounding objects than the original site equipment. Snow platforms, rain-gage shielding, and other accessories also are duplicated. Both the original and collocated sets of equipment are calibrated and tested by USGS before starting sample collection at the collocated sites to ensure that differences between the two sites are not attributable to differences in collection equipment efficiencies.

Over the course of the water year, the site operators process samples from each pair of collectors using standard NADP/NTN procedures (Dossett and Bowersox, 1999). Site operators are given the option of forgoing onsite $\mathrm{pH}$ and specific conductance measurements of samples from the collocated samplers. Regardless of whether the $\mathrm{pH}$ and specific conductance measurements are made, a 20-mL aliquot is removed from samples with volumes greater than $70 \mathrm{~mL}$ to ensure equivalent handling of both samples from the collocated-sampler site. $\mathrm{CAL}$ analyzes the samples from the collocated sites following NADP/NTN SOPs.

\section{Data Analysis}

For the purpose of comparing an original and collocated site, the data from the original and collocated sites were analyzed for differences. Data from the original and collocated site were formally referred to by the four-character site code of the original site followed by the four-character site code of the collocated site. For example, the Wildcat Mountain site was formally referred to as WI98/98WI. For this analysis, the data used were from wet-deposition samples with volumes greater than $35 \mathrm{~mL}$. These samples were identified in the NADP database by a laboratory-type-code "W" to indicate that the samples were of sufficient volume for analysis and did not require dilution. Samples requiring dilution were inherently prone to a greater error component. Samples identified as contaminated with debris, bird droppings, insects, dirt or soot particles, or due to errant sample handling, were eliminated from statistical analysis.

Because annual summaries of NADP/NTN data describe precipitation chemistry in terms of concentration and deposition (National Atmospheric Deposition Program, 2001; 2002), statistical summaries for both the concentration and deposition of constituents are provided in this report. The weekly precipitation depth associated with each Belfort recording rain gage was used to calculate deposition values at the collocated sites. To calculate deposition, concentration in milligrams per liter $(\mathrm{mg} / \mathrm{L})$ was multiplied by $10^{-1}$ times the precipitation depth in centimeters to yield deposition in kilograms per hectare $(\mathrm{kg} / \mathrm{ha})$. The variability in deposition, due to differences in collection efficiencies of rain gages and precipitation collectors at collocated sites, provided an estimate of the variability in deposition amounts at other NADP/NTN sites.

\section{Assessment of Absolute Error}

In the analysis of collocated data, statistical analyses that (1) were useful for describing overall sampling precision and (2) were not overly sensitive to a few extreme values were selected. Precision estimates for each site were calculated from the absolute differences between the pairs of collocated samplers and were expressed as median absolute error (MAE) for a given site and analyte. The equations used to estimate relative and absolute errors from collocated data were:

$$
\text { Absolute difference }=\left|\mathrm{C}_{2}-\mathrm{C}_{1}\right| \text {, }
$$

$$
\begin{gathered}
\text { Absolute error (percent) }=\mid\left[\left(\mathrm{C}_{2}-\mathrm{C}_{1}\right) /\left(\mathrm{C}_{2}+\mathrm{C}_{1} / 2\right] \bullet 100 \mid,\right. \\
\text { and }
\end{gathered}
$$

Median absolute error (percent) $=$ $\mathrm{M}\left|\left[\left(\mathrm{C}_{2}-\mathrm{C}_{1}\right) /\left(\mathrm{C}_{2}+\mathrm{C}_{1}\right) / 2\right]\right| \bullet 100$, 
where

$\mathrm{M}=$ median of all paired differences;

$\mathrm{C}_{1}=$ sample concentration, in milligrams per liter, from the collocated precipitation sampler, or deposition, in kilograms per hectare, from the collocated precipitation sampler and rain gage; and

$\mathrm{C}_{2}=$ sample concentration, in milligrams per liter, from the original precipitation sampler, or deposition, in kilograms per hectare, from the original precipitation sampler and rain gage.

Graphical depictions of all MAEs for collocated sites are shown for concentration, for deposition, and for the physical measurements of specific conductance, sample volume, and precipitation depth in figures 31 and 32 . For clarity, only the four-character codes of the original sites are shown in figures 31 and 32.

MAE was estimated to be approximately 10 percent or less for concentrations of nitrate and sulfate and for specific conductance, sample volume, and precipitation depth at all of the collocated sites during the study period. MAEs for calcium, magnesium, sodium, ammonium, chloride, nitrate, and sulfate were estimated to be less than 10 percent for WI98/98WI during WY2002. Larger MAEs were calculated for nearly every analyte at WI98/98WI during WY2003 as compared to WY2002. Only the precipitation depth MAE was smaller during WY2003 than during WY2002 at WI98/98WI. Many samples collected at WI98/98WI were eliminated from statistical analysis for WI98/98WI during WY2003 due to sample contamination, primarily from bird droppings. The small sample number might have contributed to the increase in MAE observed at WI98/98WI during WY2003. During WY2002, MAEs for OR02/02OR were less than 20 percent for all analytes except potassium and ammonium. During WY2003, MAEs for OK00/00OK were less than 20 percent for all analytes.

Constituent deposition was calculated from the precipitation depth, which made the estimated MAE for deposition rates sensitive to error in precipitation depth measurements. Upon converting concentrations to deposition amounts, MAEs for most constituents increased for all of the collocated sites except for calcium at OR02/02OR and for sodium, potassium, and chloride at WI98/98WI during WY2003 (figs. 31 and 32).

MAEs were approximately 16 to 30 percent for hydrogen ion concentration and less than 10 percent for specific conductance. Contrary to past years, MAEs obtained for sample volume for the collocated sites (measured from the Aerochem Metrics wet-deposition collectors) were slightly larger than MAEs obtained for precipitation depth (measured from the Belfort rain gages), except for WI98/98WI during WY2002. MAEs for sample volume were uniformly small (ranging from 2 to 5 percent). MAEs for precipitation depth ranged from less than 1 percent to approximately 8 percent during the study period. Substantial variability was expected for concentrations approaching MDLs because laboratory percentage error usually increases as analyte concentration decreases. Estimates of network precision covering several years of collocated sampling are given in Nilles and others (1993), and the spatial and temporal variations in collocated-sampler estimated errors are presented by Wetherbee and others (2005).

A comparison of WY2002 and WY2003 MAD values and MAD values determined for 41 collocated-sampler sites during 1989-2001 is shown in tables 16 and 17. The data in tables 16 and 17 indicate that the results for WY2002 and WY2003 generally are consistent with results for the collocated-sampler program for previous water years (Wetherbee and others, 2004). In tables 16 and 17, MAD data for each collocated-sampler site are expressed as percentages of the median values for all NADP/NTN data collected during 2002. MAD values for OR02/02OR expressed as a percentage of the 2002 median NADP/NTN values for magnesium (30 percent), sodium (72 percent), potassium ( 24 percent), and chloride (64 percent) might be environmentally significant to NADP/NTN data users. As in past years, MAEs were generally larger for cations (approximately 8 to 50 percent) than for anions (approximately 3 to 33 percent) (fig. 31). Sample volume MAEs were less than 5 percent. Precipitation depth MAEs were less than 8 percent (fig. 32) during the study period.

\section{Comparison of Sources of Variability}

Two types of QC data are generated by the USGS External QA Project: (1) basic QC data and (2) topical QC data (Jeff Martin, USGS, written commun., 2003). Basic QC data are used to document the quality of NADP/NTN data and identify data-quality problems. Topical QC data are used to make "yes/no" decisions about data quality and to locate the causes of data-quality problems. Basic QC data are obtained from the collocated-sampler program. The goal of the collocatedsampler program is to measure the sum total of as many components of the overall variability (also known as overall error) in NADP/NTN measurements as possible. Topical QC data are obtained from the blind-audit, SHE, field-audit, and interlaboratory-comparison programs. These latter programs are used to measure selected components of the overall variability.

MAE data for each program are shown in table 18 to compare the relative amounts of the overall variability in NADP/NTN measurements attributable to different sources. The variability terms in table 18 compound from right to left across the table. For example, the variability term in column D is a component of the variability term in column $\mathrm{C}$, and both variability terms in columns $\mathrm{C}$ and $\mathrm{D}$ are components of the variability term in column $\mathrm{B}$, which is a component of the overall variability in column A. The laboratory analysis variability, defined earlier as the median absolute error (MAE), is shown in column D.

To determine the proportion of the overall variability attributed to each component, the following computational procedure was used. First, the proportion of variability attributed to laboratory analysis was calculated as column D divided by column A for each constituent and year. Next, the proportion of variability attributed to sample handling was calculated as the 


\section{Calcium}
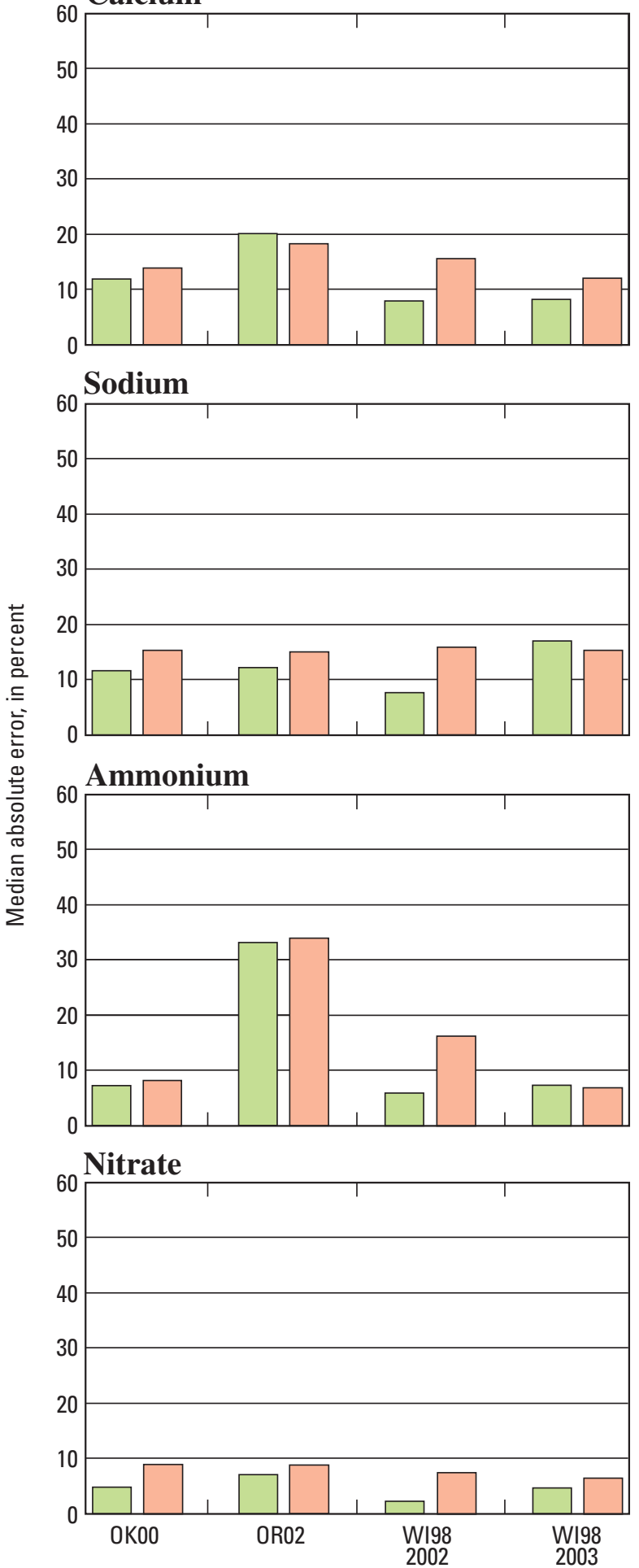

\section{Magnesium}

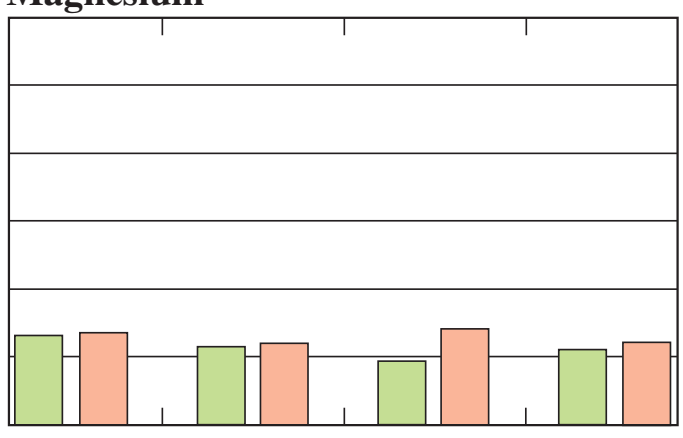

\section{Potassium}

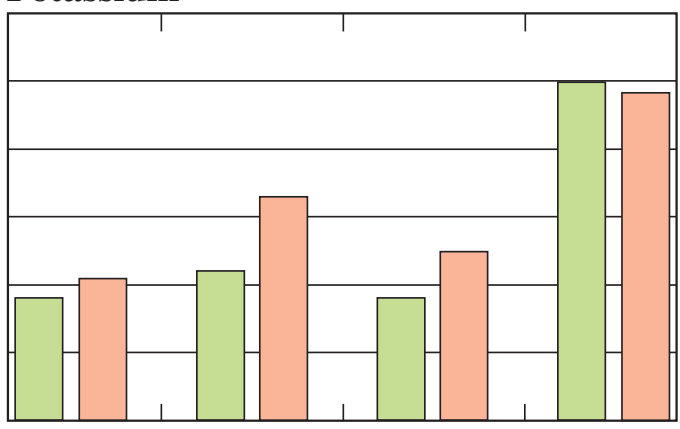

Chloride

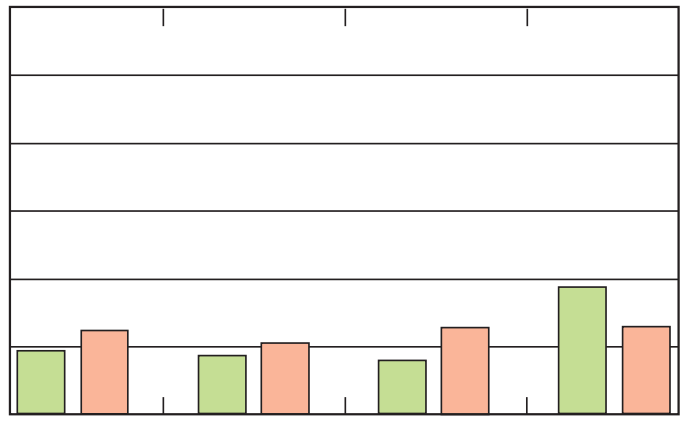

Sulfate

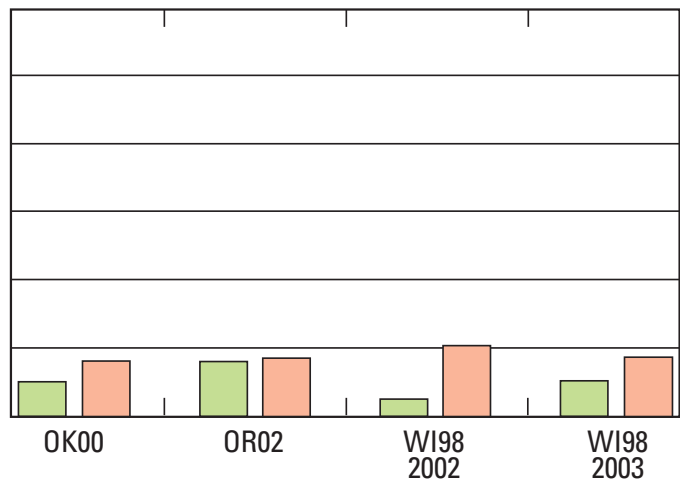

EXPLANATION

$\square$ Error calculated from original and collocated concentration values

Error calculated from original and collocated deposition amounts

Data are from the original and collocated sites. For clarity, only the four-digit codes of the original National Atmospheric Deposition Program/National Trends Network sites are displayed.

Figure 31. Median absolute error for analyte concentration and deposition for weekly samples from collocated precipitation collectors during 2002-03 for selected analytes. 


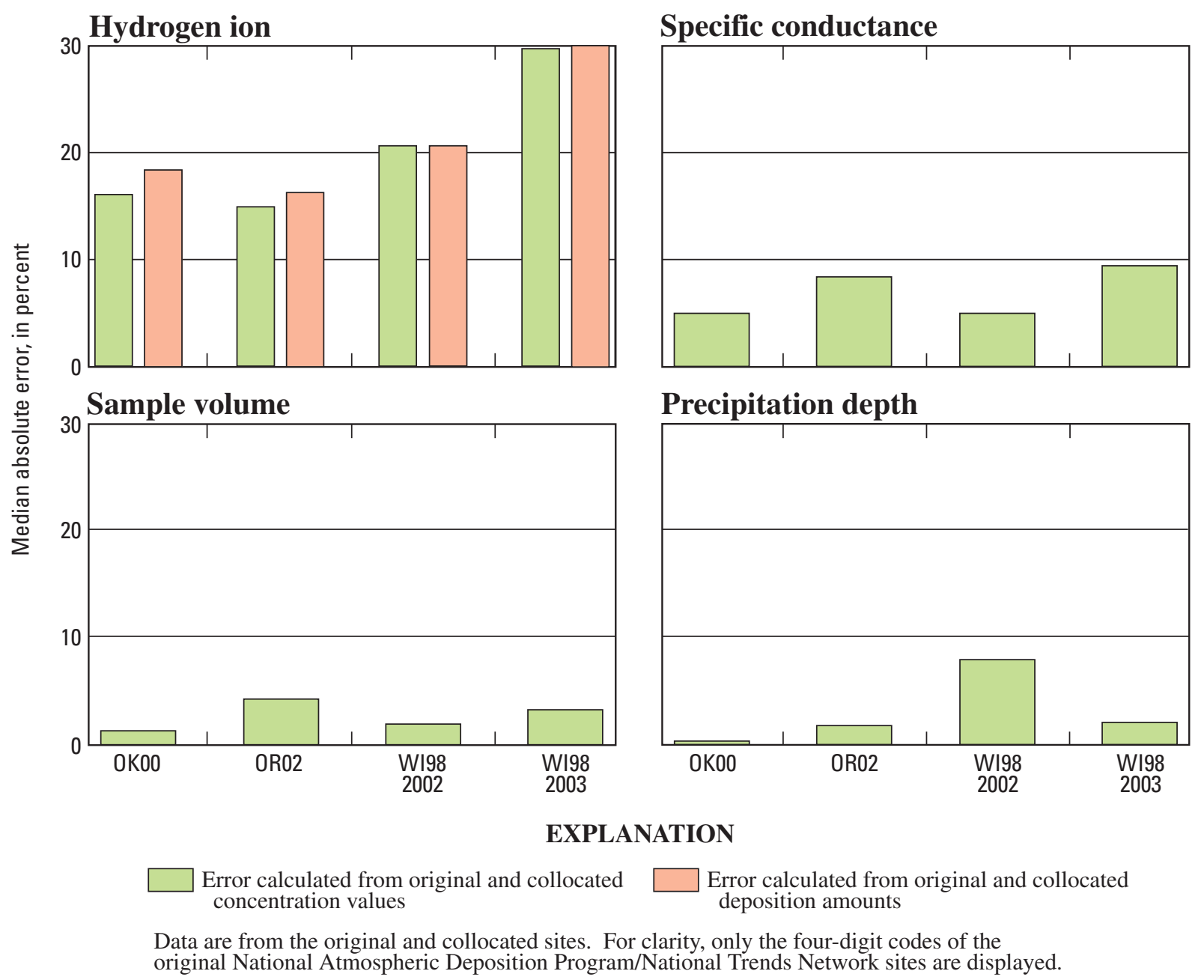

Figure 32. Median absolute error for hydrogen-ion concentration and deposition, specific conductance, and sample volume for weekly samples from collocated precipitation collectors and precipitation depth from collocated rain gages during 2002-03.

difference between column $\mathrm{C}$ and column D divided by column A for each individual analyte and year. Then, the proportion of variability attributed to onsite exposure was calculated as column B minus column $\mathrm{C}$ divided by column A for cases where column $\mathrm{B}$ is more than column $\mathrm{C}$. Where the column $\mathrm{B}$ values are less than column $\mathrm{C}$, the proportion of variability attributed to onsite exposure was set equal to zero. Finally, the proportion of variability attributed to both onsite instrumentation and natural variability was computed for each analyte and year as follows:

$$
\begin{gathered}
\text { Proportion of variability attributed to onsite } \\
\text { instrumentation and natural variability }= \\
1-\{[0 \text { or }(\mathrm{B}-\mathrm{C}) / \mathrm{A}]+[(\mathrm{C}-\mathrm{D}) / \mathrm{A}]+(\mathrm{D} / \mathrm{A})\}
\end{gathered}
$$

For each proportional variability term, the values for each analyte for 2002 and 2003 were averaged. The results of these computations provided an estimate of the proportion of variability attributed to laboratory analysis, onsite exposure, sample handling, and onsite instrumentation and natural variability combined (fig. 33).

Figure 33 shows that laboratory analysis variability, as estimated by the interlaboratory-comparison program, accounted for approximately 2 percent of the overall variability during the study period. Variability attributed to onsite exposure, as measured by the field-audit program, accounted for approximately 8 percent of the overall variability, whereas sample handling, as measured by the blind-audit and SHE programs, accounted for approximately 26 percent of the overall variability. The remaining variability (approximately 64 percent) not accounted for by onsite exposure, sample handling, and laboratory analysis was attributed to onsite instrumentation and natural variability. Overall average variability values for 2002 and 2003 combined are represented in figure 33, whereas the data in table 18 indicate that the estimated variability attributed to each component of the sample-collection and analysis processes varied among analytes. 
Table 16. Comparison of median absolute differences determined for collocated-sampler sites OR02/020R and WI98/98WI during water year 2002 to median values obtained during 2002 for all National Atmospheric Deposition Program/National Trends Network sites and to median absolute differences for 41 collocated-sampler sites during 1989-2001.

[NADP/NTN, National Atmospheric Depsition Program/National Trends Network; mg/L, milligrams per liter; MAD, median absolute difference between collocated-sampler values; $\mu \mathrm{eq} / \mathrm{L}$, microequivalents per liter; $\mu \mathrm{S} / \mathrm{cm}$, microsiemens per centimeter at 25 degrees Celsius; mL, milliliters; $\mathrm{cm}$, centimeters; --, no data]

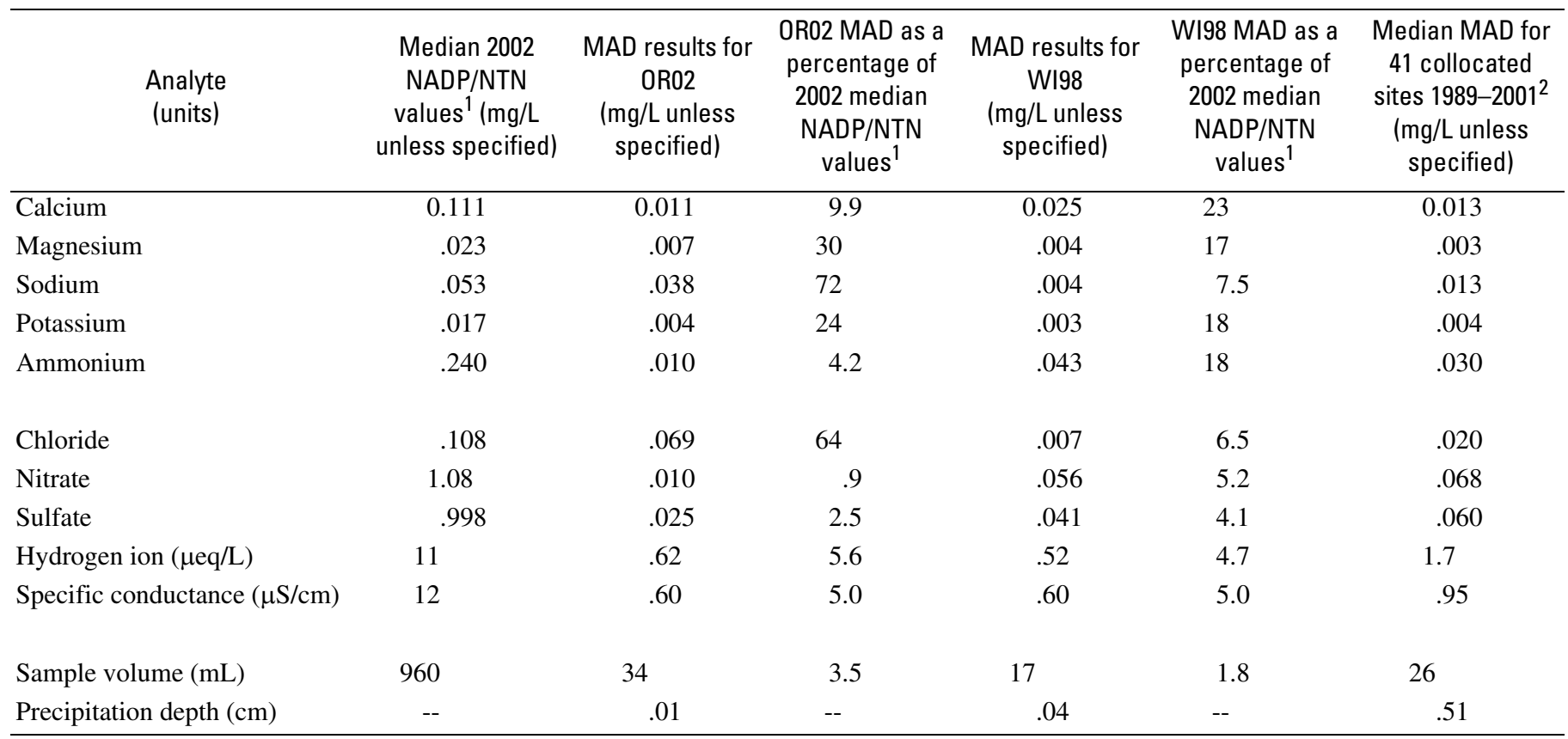

${ }^{1}$ Median values obtained for NADP/NTN during 2002 from Rothert (2004).

${ }^{2}$ Data provided for comparison to MAD results from Wetherbee and others (2005).

\section{Summary}

The U.S. Geological Survey (USGS) used six programs to provide external quality-assurance monitoring for NADP/NTN during 2002-03. An intersite-comparison program was used to estimate the accuracy and precision of onsite $\mathrm{pH}$ and specific conductance determinations. A blind-audit program was used in 2002 and the SHE program was used in 2003 to assess the effects of routine sample handling, processing, and shipping of wet-deposition samples on the variability and bias of NADP/NTN wet-deposition data. A field-audit program assessed the effects of onsite exposure, sample handling, and shipping of sample-collection surfaces on precipitation chemistry. An interlaboratory-comparison program assessed the bias and variability of the chemical analysis data from CAL and seven other laboratories. A collocated-sampler program was used to determine the overall variability applicable to NADP/NTN wet-deposition data.

Four intersite-comparison studies were conducted during the study period. The percentage of site operators responding on time that met the $\mathrm{pH}$ measurement accuracy goals decreased from 92.0 percent in spring 2002 to 86.3 percent in spring 2003. For these intersite-comparison studies, 94.4 to 97.5 percent of the site operators met the accuracy goals for specific conductance. Although performance for specific conductance remained consistent with historical levels, the data indicated a continuing decrease in the quality of onsite $\mathrm{pH}$ measurements compared to previous years.

Variability and bias in NADP/NTN data due to sample handling and shipping were estimated from paired sample concentration and specific conductance differences obtained for the blind-audit and SHE programs. For the 2002 blind audit, the median percentage bias for all analytes was within the range of -6.4 to 4.3 percent. The median percentage bias decreased for the SHE program during 2003 to a range of -5.2 to +2.9 percent, representing an approximate 2-percent decrease from the 2002 blind-audit range.

The blind-audit results indicate that positive bias was introduced by sample handling, processing, and shipping at a level that was less than 10 percent of the median of the measured NADP/NTN constituent concentrations for calcium, ammonium, nitrate, sulfate, and specific conductance and at a level that was slightly more than 10 percent of the median NADP/NTN constituent concentrations for magnesium, sodium, potassium, and chloride concentrations. The blindaudit data also indicated that the absolute variability in hydrogen-ion concentration was 19 percent of the median NTN hydrogen-ion concentration for 2002. Negative bias in hydrogen-ion concentration and specific conductance measurements was attributed to hydrogen-ion buffering due to sample handling and shipping. 
Table 17. Comparison of median absolute differences determined for collocated-sampler sites OK00/000K and WI98/98WI during water year 2003 to median values obtained during 2002 for all National Atmospheric Deposition Program/National Trends Network sites and to median absolute differences for 41 collocated-sampler sites during 1989-2001.

[NADP/NTN, National Atmospheric Depsition Program/National Trends Network; mg/L, milligrams per liter; MAD, median absolute difference between collocated-sampler values; $\mu \mathrm{eq} / \mathrm{L}$, microequivalents per liter; $\mu \mathrm{S} / \mathrm{cm}$, microsiemens per centimeter at 25 degrees Celsius; mL, milliliters; $\mathrm{cm}$, centimeters; --, no data]

\begin{tabular}{|c|c|c|c|c|c|c|}
\hline $\begin{array}{c}\text { Analyte } \\
\text { (units) }\end{array}$ & $\begin{array}{c}\text { Median } 2002 \\
\text { NADP/NTN } \\
\text { values }^{1}(\mathrm{mg} / \mathrm{L} \\
\text { unless specified) }\end{array}$ & $\begin{array}{l}\text { MAD results for } \\
\text { OKO0 } \\
\text { (mg/L unless } \\
\text { specified) }\end{array}$ & $\begin{array}{l}\text { OK00 MAD as a } \\
\text { percentage of } \\
2002 \text { median } \\
\text { NADP/NTN } \\
\text { values }^{1}\end{array}$ & $\begin{array}{l}\text { MAD results for } \\
\text { WI98 } \\
\text { (mg/L unless } \\
\text { specified) }\end{array}$ & $\begin{array}{l}\text { WI98 MAD as a } \\
\text { percentage of } \\
2002 \text { median } \\
\text { NADP/NTN } \\
\text { values }^{1}\end{array}$ & $\begin{array}{l}\text { Median MAD for } \\
41 \text { collocated } \\
\text { sites } 1989-2001^{2} \\
\text { (mg/L unless } \\
\text { specified) }\end{array}$ \\
\hline Calcium & 0.111 & 0.065 & 59 & 0.027 & 24 & 0.013 \\
\hline Magnesium & .023 & .004 & 17 & .004 & 17 & .003 \\
\hline Ammonium & .240 & .037 & 15 & .045 & 19 & .030 \\
\hline Chloride & .108 & .014 & 13 & .011 & 10 & .020 \\
\hline Nitrate & 1.08 & .124 & 11 & .079 & 7.3 & .068 \\
\hline Sample volume $(\mathrm{mL})$ & 960 & 17 & 1.8 & 9.5 & 1.0 & 26 \\
\hline Precipitation depth $(\mathrm{cm})$ & -- & .01 & -- & .01 & -- & .51 \\
\hline
\end{tabular}

${ }^{1}$ Median values obtained for NADP/NTN during 2002 from Rothert (2004).

${ }^{2}$ Data provided for comparison to MAD results from Wetherbee and others (2005).

Less variability attributed to sample handling, processing, and shipping was estimated by the SHE program than by the blind-audit program. The median paired differences for the SHE results were less than 10 percent of the median NADP/NTN values for 2002 except for hydrogen ion (10.5 percent). Error attributed to sample handling and shipping during 2003 was estimated to not be environmentally important to data users as indicated by the SHE results.

During the 2002-03 field-audit program, the median relative percentage bias for all analytes was within a range of -3.7 to +3.1 percent. Overall, positive bias was indicated for most constituents except hydrogen-ion concentration and specific conductance, which displayed negative bias. The negative bias in the paired difference data for hydrogen-ion concentration indicated that buffering of hydrogen ion occurred from onsite exposure of the sample and that the loss of hydrogen ion from solution was accompanied by a decrease in specific conductance. Therefore, NADP/NTN data tend to overestimate $\mathrm{pH}$ and underestimate specific conductance.

Analysis of field-audit ultrapure deionized-water sample results indicated potential low-level contamination of NADP/NTN samples with most of the major ions from onsite exposure and sample handling during the study period. A statistically significant $(\alpha=0.05)$ relation between the paired differences and sample volume was determined from the field- audit data for magnesium, nitrate, and sulfate during 2002 and for calcium, magnesium, sodium, chloride, nitrate, and sulfate concentration and specific conductance during 2003. Slightly less contamination was indicated during 2003 than during 2002 except for ammonium.

Variability and bias in NADP/NTN data from laboratory analysis of wet-deposition samples were evaluated during the study period by the interlaboratory-comparison program. CAL reported results with generally less variability than the other participating laboratories for all constituents except ammonium. The absolute values of the median differences reported by CAL were all less than or equal to MDLs (table 5) except for nitrate, sulfate, and specific conductance. The median differences for data reported by CAL for nitrate and sulfate were approximately three and five times their respective MDLs. The calcium, magnesium, and ammonium data reported by CAL were slightly negatively biased, and the sodium, potassium, chloride, nitrate, sulfate, hydrogen ion, and specific conductance data were slightly positively biased compared to other laboratories participating in the interlaboratorycomparison program. A small number of detections (one in 2002 and two in 2003) in the ultrapure deionized-water samples indicated that contamination was not a problem for CAL, which implies that laboratory contamination did not affect NADP/NTN data during the study period. 
Table 18. Comparison of components of overall variability in National Atmospheric Deposition Program/National Trends Network data as determined by U.S. Geological Survey external quality-assurance programs during 2002-03 for major ion concentrations and specific conductance.

\begin{tabular}{|c|c|c|c|c|}
\hline \multirow[b]{2}{*}{ Analyte } & \multicolumn{4}{|c|}{ Variability as determined by median absolute error } \\
\hline & $\begin{array}{l}\text { Estimated overall } \\
\text { variability }^{1} \\
\text { (percent) } \\
\text { (A) }\end{array}$ & $\begin{array}{l}\text { Variability attributed to onsite } \\
\text { exposure, sample handling, and } \\
\text { laboratory analysis² } \\
\text { (percent) } \\
\text { (B) }\end{array}$ & $\begin{array}{l}\text { Variability attributed to } \\
\text { sample handling and } \\
\text { laboratory analysis }{ }^{3} \\
\text { (percent) } \\
\text { (C) }\end{array}$ & $\begin{array}{l}\text { Variability attributed to } \\
\text { laboratory analysis } \\
\text { (percent) } \\
\text { (D) }\end{array}$ \\
\hline \multicolumn{5}{|c|}{2002} \\
\hline Calcium & 14.0 & 3.1 & 3.7 & 0.2 \\
\hline Magnesium & 11.0 & 3.5 & 4.8 & .3 \\
\hline Sodium & 10.0 & 1.8 & 2.6 & .2 \\
\hline Potassium & 20.0 & 3.8 & 5.8 & .4 \\
\hline Ammonium & 20.0 & 4.5 & 5.4 & 0 \\
\hline Chloride & 8.3 & 2.8 & 2.4 & .2 \\
\hline Nitrate & 4.9 & 1.3 & 1.3 & .1 \\
\hline Sulfate & 5.5 & 1.3 & 1.5 & .1 \\
\hline Hydrogen ion & 18.0 & 4.9 & 6.5 & 0 \\
\hline Specific conductance & 6.7 & 5.4 & 3.3 & 0 \\
\hline \multicolumn{5}{|c|}{2003} \\
\hline Calcium & 10.0 & 5.0 & 2.8 & 6 \\
\hline Magnesium & 12.0 & 2.0 & 3.0 & .2 \\
\hline Sodium & 14.0 & .9 & 1.8 & .3 \\
\hline Potassium & 34.0 & 6.9 & 2.6 & .3 \\
\hline Ammonium & 7.5 & 5.4 & 3.4 & 0 \\
\hline Chloride & 14.0 & 2.9 & 1.2 & .2 \\
\hline Nitrate & 4.9 & 1.0 & .76 & .1 \\
\hline Sulfate & 5.4 & .4 & .70 & .1 \\
\hline Hydrogen ion & 23.0 & 5.2 & 6.0 & .6 \\
\hline Specific conductance & 7.2 & 5.2 & 2.6 & .1 \\
\hline
\end{tabular}

${ }^{1}$ Average median absolute error (MAE) values for sites OR02 and WI98 in 2002 and average MAEs for sites OK00 and WI98 in 2003 obtained from the collocated-sampler program (figs. 31-32).

${ }^{2}$ Combined onsite exposure, sample handling, and laboratory analysis MAEs obtained from the field-audit program (results for 2002 and 2003 combined are reported in table 11).

${ }^{3}$ Combined sample handling and laboratory analysis MAEs obtained from the blind-audit program in 2002 (table 6) and from the sample-handling evaluation program in 2003 (table 8).

${ }^{4}$ Median laboratory analysis variability calculated from analysis of synthetic precipitation sample replicates for the interlaboratory-comparison program.

MAD results obtained for replicate samples analyzed for hydrogen ion concentrations and specific conductance by CAL were less than 10 percent of the median values for 2002 NADP/NTN concentration and specific conductance measurements. On the basis of this comparison, the absolute error introduced by laboratory analysis of hydrogen-ion concentration and specific conductance for NADP/NTN samples is not likely to be environmentally important to NADP/NTN data users. MAD results for all of the participating laboratories for cations generally were less than $0.005 \mathrm{mg} / \mathrm{L}$ during the study period, which is consistent with results for 2000-2001. However, MAD results for all participants for anions were less than $0.030 \mathrm{mg} / \mathrm{L}$ during the study period, compared to $0.020 \mathrm{mg} / \mathrm{L}$ during 2000 2001.

Control charts indicate that most of the constituent concentration data reported by CAL were in statistical control approximately 90 percent of the time. CAL's performance included brief time periods when magnesium, sodium, potassium, ammonium, chloride, nitrate, sulfate, and hydrogen-ion data were outside of the statistical control limits. The control chart 


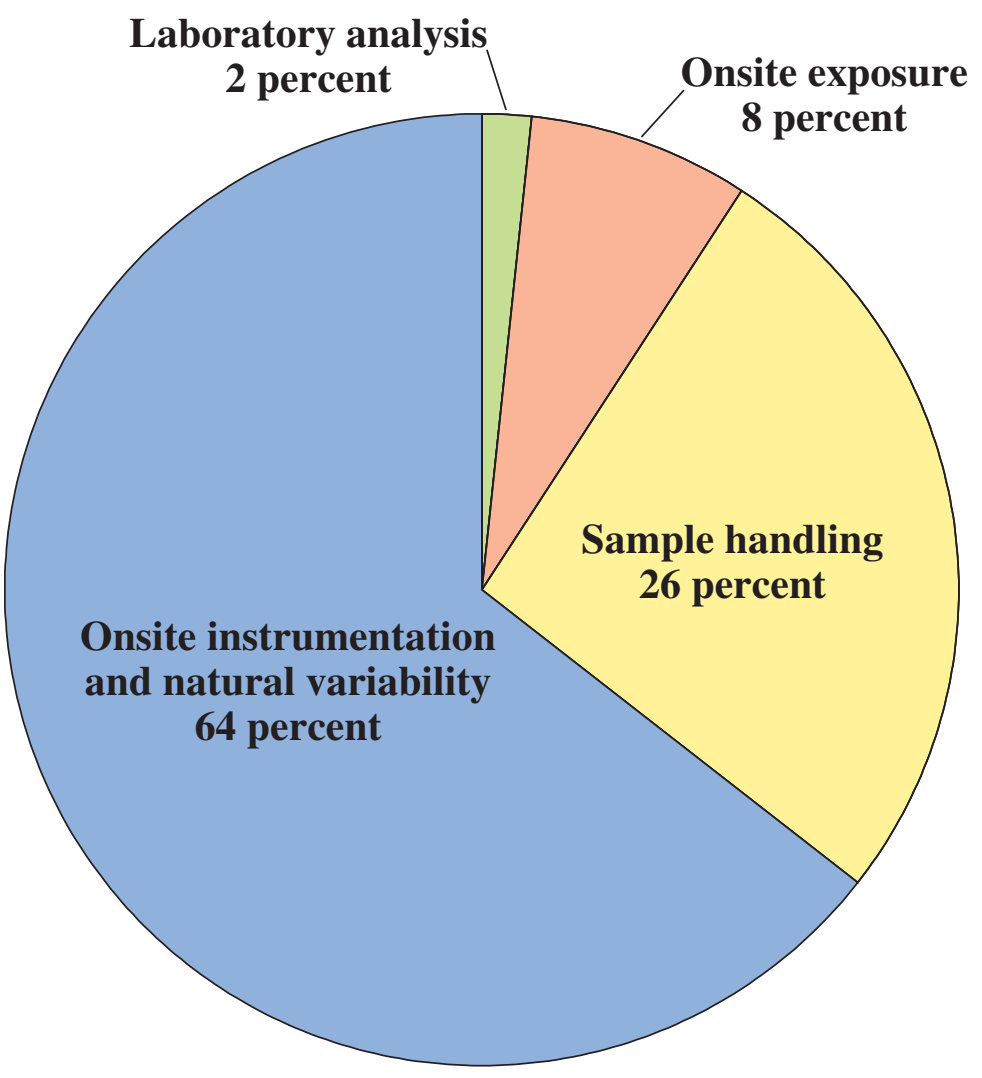

Figure 33. Proportions of selected components of overall variability in National Atmospheric Deposition Program/ National Trends Network measurements as estimated by U.S. Geological Survey external quality-assurance programs during 2002-03. data indicate that CAL's precision was consistent with that of other laboratories performing analysis of low-ionic strength environmental samples.

Overall variability of NADP/NTN measurements was evaluated from data collected in the collocated-sampler program. Weekly wet-deposition sample concentrations and precipitation measurements from three collocated NADP/NTN sites were compared. Estimates of precision were calculated in terms of MAE for concentration and deposition of ionic constituents of wet deposition. As in past years, MAEs were generally larger for cations (approximately 8 to 50 percent) than for anions (approximately 3 to 33 percent). MAEs were approximately 16 to 30 percent for hydrogen-ion concentration, less than 10 percent for specific conductance, less than 5 percent for sample volume, and less than 8 percent for precipitation depth. MAEs for constituent concentrations at collocated sites WI98/98WI generally increased between water years 2002 and 2003.

The variability attributed to each component of the sample-collection and analysis processes, as estimated by USGS QA programs, varied among analytes. Laboratory analysis variability accounted for approximately 2 percent of the overall variability in NADP/NTN measurements. Sample onsite exposure accounted for approximately 8 percent of the overall variability. Sample handling accounted for approximately 26 percent of the estimated overall variability. The remaining variability not accounted for by laboratory analysis, onsite exposure, and sample handling (approximately 64 percent) was attributed to onsite instrumentation and natural variability.

\section{References Cited}

Berthouex, P.M., and Brown, L.C., 1995, Statistics for environmental engineers: Boca Raton, Florida, CRC Press, Inc., $336 \mathrm{p}$.

Bigelow, D.S., Sisterson, D.L., and Schroder, L.J., 1989, An interpretation of differences between field and laboratory $\mathrm{pH}$ values reported by the National Atmospheric Deposition Program/National Trends Network Monitoring Program: Environmental Science and Technology, v. 23, p. 881-887.

Chambers, J.M., Cleveland, W.S., Kleiner, B., and Tukey, P.A., 1983, Graphical methods for data analysis: Boston, Duxbury Press, p. 20-24.

Dean, J.A., ed., 1979, Lange's handbook of chemistry (12th ed.): New York, McGraw-Hill, 644 p.

Dossett, S.R., and Bowersox, V.C., 1999, National Trends Network site operation manual: Champaign, Illinois, National Atmospheric Deposition Program Office at the Illinois State Water Survey, NADP Manual 1999-01, 94 p., information available from World Wide Web at URL http://nadp.sws.uiuc.edu/lib/manuals/opman.pdf

Gordon, J.D., 1999, External quality-assurance results for the National Atmospheric Deposition Program/National Trends Network, 1995-96: U.S. Geological Survey WaterResources Investigations Report 99-4072, 69 p. 
Gordon, J.D., Latysh, N.E., and Lindholm, S.J., 2003, External quality-assurance results for the National Atmospheric Deposition Program/National Trends Network, 1997-99: U.S. Geological Survey Water-Resources Investigations Report 03-4027, 149 p.

Gordon, J.D., Morden-Moore, A.L., Schroder, L.J., and Bowersox, V.C., 1995, The stability of hydrogen ion and specific conductance in filtered wet-deposition samples stored at ambient temperatures: Water, Air, and Soil Pollution, v. 83, p. 299-313.

Gordon, J.D., Nilles, M.A., Polacsek, D.K., and Ratcliff, M.E., 1997, External quality-assurance results for the National Atmospheric Deposition Program/National Trends Network during 1994: U.S. Geological Survey Water-Resources Investigations Report 97-4201, 42 p.

Gordon, J.D., Willoughby, T.C., and Schroder, L.J., 1991, Summary of the National Atmospheric Deposition Program/ National Trends Network intersite-comparison program, November 1978-November 1989: U.S. Geological Survey Water-Resources Investigations Report 91-4061, 26 p.

Helsel, D.R., 1990, Less than obvious-statistical treatment of data below the detection limit: Environmental Science and Technology, v. 24, no. 12, p. 1767-1774.

Helsel, D.R., and Hirsch, R.M., 1992, Statistical methods in water resources: New York, Elsevier Science Publishing Company, Inc., $522 \mathrm{p}$.

Hem, J.D., 1985, Study and interpretation of the chemical characteristics of natural water (3d ed.): U.S. Geological Survey Water-Supply Paper 2252, p. 62-63.

Hoaglin, D.C., Mosteller, F., and Tukey, J.W., 1983, Understanding robust and exploratory data analysis: New York, John Wiley and Sons, p. 38-41.

Hollander, M., and Wolfe, D.A, 1999, Nonparametric statistical methods (2d ed.): New York, John Wiley and Sons, 787 p.

Huntsberger, D.V., and Billingsley, P., 1981, Elements of statistical inference (5th ed.): Boston, Allyn and Bacon, Inc., 503 p.

Iman, R.L., and Conover, W.J., 1983, A modern approach to statistics: New York, John Wiley, 496 p.

Kanji, H.K., 1993, 100 Statistical tests: Newbury Park, California, Sage Publications Inc., 216 p.

Latysh, N.E. and Wetherbee, G.A., 2005, External quality assurance programs and procedures managed by the U.S. Geological Survey in support of the National Atmospheric Deposition Program/National Trends Network, U.S. Geological Survey Open-File Report 2005-1024, 66 p.

National Atmospheric Deposition Program, 2001, National Atmospheric Deposition Program 2000 wet deposition: Champaign, Illinois, Illinois State Water Survey, NADP Data Report 2001-01, 15 p.

National Atmospheric Deposition Program, 2002, National Atmospheric Deposition Program 2001 wet deposition: Champaign, Illinois, Illinois State Water Survey, NADP Data Report 2002-01, 15 p.

Nilles, M.A., 2001, Changes in the chemistry of precipitation in the United States, 1981-1998: Water, Air and Soil Pollution, v. 130 , no. 1, p. 409-414.
Nilles, M.A., Gordon, J.D., and Schroder, L.J., 1993, Precision of wet atmospheric deposition data from National Atmospheric Deposition Program/National Trends Network sites determined with collocated samplers: Atmospheric Environment, v. 28, no. 6, p. 1121-1128.

Nilles, M.A., Gordon, J.D., Schroder, L.J., and Paulin, C.E., 1995, External quality-assurance results for the National Atmospheric Deposition Program/National Trends Network during 1991: U.S. Geological Survey Water-Resources Investigations Report 93-4208, 36 p.

Nilles, M.A., See, R.B., Willoughby, T.C., and Gordon, J.D., 1991, Variability in wet atmospheric deposition data determined with collocated samplers: U.S. Geological Survey Water-Resources Investigations Report 91-4143, 30 p.

Peden, M.E., 1986, Development of standard methods for collection and analysis of precipitation, in Methods for collection and analysis of precipitation: Champaign, Illinois State Water Survey Contract Report 381, p. 19-21.

Peden, M.E., and Skowron, L.M., 1978, Ionic stability of precipitation samples: Atmospheric Environment, v. 12, Pergamon Press Ltd., p. 2343-2349.

Robertson, J.K., and Wilson, J.W., 1985, Design of the National Trends Network for monitoring the chemistry of atmospheric precipitation: U.S. Geological Survey Circular 964, 46 p.

Rothert, J.E., 2004, Quality assurance report, National Atmospheric Deposition Program, 2002: Champaign, Illinois, Illinois State Water Survey, Central Analytical Laboratory, NADP Report 2004-01.

SAS Institute, Inc., 1989, SAS STAT users guide, version 6 (4th ed.), v. 1: Cary, North Carolina, SAS Institute, Inc.

See, R.B., Willoughby, T.C., Brooks, M.H., and Gordon, J.D., 1990, Programs and analytical methods for the U.S. Geological Survey Acid Rain Quality-Assurance Project: U.S. Geological Survey Water-Resources Investigations Report 90-4029, 57 p.

See, R.B., Willoughby, T.C., and Schroder, L.J.,1989, External quality-assurance results for the National Atmospheric Deposition Program/National Trends Network during 1987: U.S. Geological Survey Water-Resources Investigations Report 89-4015, 16 p.

Taylor, J.K., 1987, Quality assurance of chemical measurements ( $2 \mathrm{~d}$ ed.): Chelsea, Michigan, Lewis Publishers, Inc., $328 \mathrm{p}$.

Tchobanoglous, G., and Schroeder, E.D., 1987, Water quality: Reading, Massachusetts, Addison-Wesley Publishing Company, Inc., p. 204-207.

Wetherbee, G.A., Latysh, N.E., and Gordon, J.D., 2004, External quality-assurance results for the National Atmospheric Deposition Program/National Trends Network, 2000-01: U.S. Geological Survey Scientific Investigations Report 2004-5034, 59 p.

Wetherbee, G.A., Latysh, N.E., and Gordon, J.D., 2005, Spatial and temporal variability of the overall error of National Atmospheric Deposition Program measurements determined by the USGS collocated-sampler program, water years 19892001: Environmental Pollution, no. 135, p. 407-418. 
